\title{
Ethnomedicinal Claims on Wound Healing Activity of Certain Leaf Drugs - A Review
}

\author{
Review Article
}

\section{Tarun Sharma $^{1^{*}}$, Bhargav Bhide ${ }^{2}$, Rabinarayan Acharya $^{3}$}

1. PhD Scholar, 3. Professor and HOD,

Department of Dravyaguna Vigyana, I.P.G.T. \& R.A. Jamnagar, Gujarat, India.

2. Assistant Professor, Department of Dravyaguna,

Mahatma Gandhi Ayurved College, Hospital \& Research Centre, Wardha, Maharashtra

\begin{abstract}
Plants are traditionally being used as a source of medicine by indigenous people of different ethnic groups inhabiting various terrains for the control of various ailments effecting both human and animals. Recently, focus on plant research has been increased, all over the world, due to the huge potential of medicinal plants used in various traditional systems. Wounds are the result of injuries to the skin that disrupt the soft tissue. Various plants have been used in treatment of wounds over the years in many tribal areas. Many ethno botanical survey reports and books have been published highlighting the use of plant as a whole or its various parts for the management of wounds. Recent research shows that some of these plants are established either experimental or clinical studies for their wound healing activities. Single hand information regarding these plants with their specific parts used for wound healing activity is lacking.

Hence, the present study is an attempt to compile the leaf drugs reported for their wound healing activity from 85 research articles and 14 books related to ethno medicine and ethno botany. It is observed that ethno medicinal plants belonging to 100 families (Asteraceae-51, Fabaceae-38, Euphorbiaceae-34, Lamiaceae-19, Rubiaceae-17 etc.) are reported for their wound healing activity. Among them 202 plants reported for topical application, 11 for oral administration and 9 for both (oral and topical).
\end{abstract}

Keywords: Ethno medicine, leaf drugs, traditional medicine, wound healing.

\section{Introduction}

In today's conventional medical system, ethno medicinal plants plays a great role for new drug development. Relying on the ethnobotanical information, potential biological activities of the plants have been investigated. Wound is one among common health problem in present era. Wounds are one of the major case of physical disabilities (1). Wounds are physical injuries that result in an opening or break of the skin that causes disturbance in the normal skin anatomy and function. They result in the loss of continuity of epithelium with or without the loss of underlying connective tissue (2). Wounds, that are most difficult to heal, includes delayed acute wounds and chronic wounds. Current estimates indicate that nearly 6 million people suffer from chronic wounds worldwide (3). In traditional medicine all over the world, a wide range of plant preparations are employed as wound healing agents. Through scientific studies, many plants used for wound healing have been investigated intensively, in order to validate them for their reported usage. Therefore, the search for natural

*Corresponding Author:

\section{Tarun Sharma}

PhD Scholar, Department of Dravyaguna,

IPGT \& RA, Gujarat,

India

Email: tarunsharma1286@gmail.com products as new wound healing agents becomes a great target (4).

Wound healing is a complex mechanism for the repairment of tissue integrity, and comprises of four main phases of haemostasis, inflammation, proliferation and tissue remodelling. Any trauma penetrating into the dermis results in bleeding and the blood vessels immediately contract to reduce the blood loss. Due to platelet aggregation, the clotting process starts to continue the coagulation cascade. A scab occurs by the formation of a fibrin mesh to temporarily close the wounded site and wound continues to produce the blood and serous fluid, in order to cleanse the wound surface from the contaminants (5).

Various plants in different dosage forms, are used by tribals and folklore traditions all over world for treatment of cuts, wounds, and burns. Many ethno botanical survey reports and books were published highlighting the use of plant drug for the management of wound healing (6). Single hand information regarding the plant with their specific parts used for wound healing activity is lacking. Leaves are the most easily available parts used as its sustainable collection does not hamper the growth of the plant. Hence, it is considered as one of the best part used for clinical research. Present research work was planned with an aim to compile the leaf drugs reported for their wound healing activity in published ethno botanical and ethno medicinal books and research articles. 


\section{Materials and Methods:}

Various books and research articles related to ethno botany and ethno medicine were scrutinized and reviewed in respect to reported wound healing activity of ethno-medicinal plants. The details of the books including title, publisher, year of publication and page number were noted. The ethno-medicinal plants which have been reported for their use in wounds, cuts, burns etc., where in leaf is the part used, were noted down in a specially designed format in regards to their botanical names, family, local name, dosage form, route of administration and tribal areas. The review was carried out dring January 2017 to November 2017.

Available 14 books on ethnomedicine and 85 research articles on ethnobotany and ethnopharmaocolgy were reviewed. All the books and research articles referred, for easy recording purpose, were assigned with a serial referencing number. The details of the referencing number assigned are: Ethnobotany and medicinal plants of Indian Subcontinent (7), Ethnobotany in South Asia (8), Medicinal plants: Ethnobotany approach (9), A lexicon of medicinal plants in India, vol.-I (10), The medicinal and poisonous plants of India (11), Medicinal plants in India, vol.-I (12), Medicinal plants in India, vol.-II (13), Ethnobotany of Santhal Pargana (14), Medicinal plants of Uttaranchal State (15), An appraisal of tribal-folk medicines (16), Glimpses of medico-botany of Bastar district (M.P.) (17), Medico-botanical exploration of Phulbani and Koraput district of Orissa (18), Medicinal plants of Nagpur and Wardha forest division, Maharashtra (19) and Notable plants in ethnomedicine of India (20). The numbers in bracket in reference column of table 1 are denoting the page numbers of books.

The details of the referencing number for Research articles, presented according to first author, assigned are: Abdul Lateef k et al. 2014 (21), Ayyanar M et al. 2009 (22), Adewale Adetutu et al. 2011 (23), G. D. Wadankar et al. 2011 (24), Chellaiah Muthu et al. 2006 (25), N. Savithramma et al. 2014 (26), Patel DK 2014 (27), Sujata Bhardwaj et al. 2005 (28), Bikram et al. 2012 (29), Prabhat k. Das et al. 2016 (30), Das Amar
Jyoti et al. 2012 (31), Ezekiel Amri et al. 2012 (32), Binu Thomas et al. 2004 (33), Kari Inngjerdingen et al. 2004 (34), Sahu P. K. et al. 2014 (35), Sainkhediya Jeetendra et al. 2015 (36), Sarita Das et al. 2003 (37), Abhijeet Dey et al. 2012 (38), Chopda MZ et al. 2009 (39), Patil SB et al. 2009 (40), Senthil KM et al. 2006 (41), VP Silja et al. 2008 (42), Nallella Sreeramulu et al. 2013 (43), Alok Ranjan Sahu et al. 2011 (44), P.N. Arul Manikandan 2005 (45), Soma Manjula et al. 2013 (46), Subramoniam A et al. 2001 (47), Santhapu H. 1953 (48), Naresh Kumar Ghodela et al. 2017 (49), Srivastava SC et al. 2003 (50) and Revathi P et al. 2010 (51).

The data collected were reflecting the words or terminology used by the tribal people and was being retranslated to equivalent English terms by the concerned ethno botany experts. The above generated data were presented in a tabular form (table 1) under above headings including the references. The shortlisted plants were cross checked from the classical texts of Ayurveda with regards to their pharmacological properties and actions.

Abbreviations were made for local name of plants. Details of abbreviation used are: S-Sanskrit, HHindi, Mr-Marathi, Kn-Kannada, Tm-Tamil, SntSantali, O-Oriya, E-English, Bn-Bengali, MlMalayalam, Asm-Assamaese, Kd-Kadar, Mur-Muria, Tel-Telugu Sik-Sikkimese, Andm-Andamanese, LdkLadakhi, Mnd-Mundari, Pun-Punjabi, Ncb-Nicobarese, Mut-Muthwan, Nag-Nagaland, Mlb-Malabar, GujGujarati, Lut-Local Uttaranchal, Raj-Rajasthani, KmnKumaon, Hp-Himachal and Kur-Kurumban.

In route of administration, " $\mathrm{T}$ " is denoting topical application and " $\mathrm{O}$ " is for oral administration.

\section{Results and Discussion:}

In the present study, 434 plants with leaf as useful part, reported for their wound healing activity in 14 books and 31 published research articles related to ethno botany and ethno medicine were scrutinized and are presented in table 1 .

\section{Table 1: Ethno medicinal leaf drugs highlighted for their Wound healing activity}

\begin{tabular}{|c|c|c|c|c|c|c|}
\hline S.No. & $\begin{array}{l}\text { Botanical Name } \\
\text { (Family) }\end{array}$ & Local name & $\begin{array}{l}\text { Mode of } \\
\text { administration }\end{array}$ & $\begin{array}{l}\text { Route of } \\
\text { administration }\end{array}$ & Tribal Area & References \\
\hline 1 & $\begin{array}{l}\text { Abutilon indicum }(\mathrm{L} .) \\
\text { Sweet } \\
\text { (Malvaceae) }\end{array}$ & $\begin{array}{l}\text { Atibala (S), } \\
\text { Thuthi }\end{array}$ & $\begin{array}{l}\text { Smeared with } \\
\text { castor oil }\end{array}$ & $\mathrm{T}$ & Uttarakhand & $\begin{array}{l}\text { 7(391), 8(292), 11(447), } \\
15(103)\end{array}$ \\
\hline 2 & $\begin{array}{l}\text { Acacia Arabica Willd, } \\
\text { (Mimosaceae) }\end{array}$ & Babbula(S) & Ash + ghee & - & - & $16(304)$ \\
\hline 3 & $\begin{array}{l}\text { Acalypha hispida } \\
\text { Burm.f. } \\
\text { (Euphorbiaceae) }\end{array}$ & $\begin{array}{l}\text { Muktajhuri } \\
\text { (Ben); } \\
\text { Vattattali (Ml) }\end{array}$ & Paste & $\mathrm{T}$ & - & $10(23)$ \\
\hline 4 & $\begin{array}{l}\text { Acalypha fruticosa } \\
\text { Forssk. } \\
\text { (Euphorbiaceae) }\end{array}$ & $\begin{array}{l}\text { Balamunja } \\
\text { Kuppameni }\end{array}$ & Paste & $\mathrm{T}$ & Attappady, Kerala & 21 \\
\hline
\end{tabular}




\begin{tabular}{|c|c|c|c|c|c|c|}
\hline S.No. & $\begin{array}{l}\text { Botanical Name } \\
\text { (Family) }\end{array}$ & Local name & $\begin{array}{l}\text { Mode of } \\
\text { administration }\end{array}$ & $\begin{array}{l}\text { Route of } \\
\text { administration }\end{array}$ & Tribal Area & References \\
\hline \multirow[t]{2}{*}{5} & $\begin{array}{l}\text { Acalypha indica L. } \\
\text { (Euphorbiaceae) }\end{array}$ & Kuppaimeni & Paste & $\mathrm{O}$ & $\begin{array}{l}\text { Tirunelveli hills, } \\
\text { southern India }\end{array}$ & 22 \\
\hline & & $\begin{array}{l}\text { Kuppameni; } \\
\text { Aritamanjari } \\
\text { (S) }\end{array}$ & Powder & $\mathrm{T}$ & $\begin{array}{l}\text { Tirunelveli, Tamil } \\
\text { Nadu; Uttarakhand }\end{array}$ & $\begin{array}{l}\text { 7(363), 8(381), 9(259), } 10 \\
(24), 11(186), 12(18), 15 \\
(400)\end{array}$ \\
\hline 6 & $\begin{array}{l}\text { Acalypha wilkesiana } \\
\text { Müll. Arg. } \\
\text { (Euphorbiaceae) }\end{array}$ & Aworoso & Poultice & $\mathrm{T}$ & South-west Nigeria & 23 \\
\hline \multirow[t]{3}{*}{7} & $\begin{array}{l}\text { Achyranthes aspera L. } \\
\text { (Amaranthaceae) }\end{array}$ & Aghada & - & - & $\begin{array}{l}\text { Washim, } \\
\text { Maharashtra }\end{array}$ & 24 \\
\hline & & Naayuruvi & Paste & $\mathrm{T}$ & $\begin{array}{l}\text { Kancheepuram, } \\
\text { Tamilnadu }\end{array}$ & 25 \\
\hline & & Apamarga (S) & Paste, juice & $\mathrm{T}$ & $\begin{array}{l}\text { Bhadrak, Odisha; } \\
\text { Santhal Pargana, } \\
\text { Bihar; Uttarakhand }\end{array}$ & $\begin{array}{l}7(499), 7(645), 8(37), 8 \\
(192), 9(147), 9(259), 14 \\
(19), 15(386), 16(314)\end{array}$ \\
\hline 8 & $\begin{array}{l}\text { Actinodaphne } \\
\text { maderaspatana Bedd. } \\
\text { (Lauraceae) }\end{array}$ & Panidiripatra & Paste & $\mathrm{T}$ & $\begin{array}{l}\text { Tirumala hills, A. } \\
\text { P. }\end{array}$ & 12(29), 26 \\
\hline \multirow[t]{3}{*}{9} & $\begin{array}{l}\text { Adhatoda vasica Nees. } \\
\text { (Acanthaceae) }\end{array}$ & Vasaka & - & - & $\begin{array}{l}\text { Bilaspur, } \\
\text { Chhattisgarh }\end{array}$ & 27 \\
\hline & & Kawl-dai & Paste & $\mathrm{T}$ & Lunglei, Mizoram & 28 \\
\hline & & $\begin{array}{l}\text { Vasa }(\mathrm{S}) \\
\text { Basanga }(\mathrm{K}, \\
\mathrm{O})\end{array}$ & Powder & $\mathrm{T}$ & $\begin{array}{l}\text { Jajpur, Odisha; } \\
\text { Uttarakhand }\end{array}$ & $10(53), 13(467), 15(356)$ \\
\hline 10 & $\begin{array}{l}\text { Adenanthera pavonia L. } \\
\text { (Fabaceae) }\end{array}$ & $\begin{array}{l}\text { Kucndanah } \\
\text { (S) }\end{array}$ & - & - & & $12(29)$ \\
\hline 11 & $\begin{array}{l}\text { Aegle marmelos L. } \\
\text { Corr. } \\
\text { (Rutaceae) }\end{array}$ & Bilva & Paste & $\mathrm{T}$ & $\begin{array}{l}\text { Bilaspur, } \\
\text { Chhattisgarh } \\
\text { Andhra Pradesh }\end{array}$ & $\begin{array}{l}\text { 7(331), 8(112), 12(29), } \\
27\end{array}$ \\
\hline 12 & $\begin{array}{l}\text { Aerva lanata. Juss-ex } \\
\text { Schult } \\
\text { (Amaranthaceae) }\end{array}$ & Kukrabocha & Paste & $\mathrm{T}$ & $\begin{array}{l}\text { Kalahandi, Odisha; } \\
\text { Santhal Pargana, } \\
\text { Bihar }\end{array}$ & $7(545), 12(33), 14(20), 29$ \\
\hline 13 & $\begin{array}{l}\text { Aerides multiflorum } \\
\text { Roxb. } \\
\text { (Orchidaceae) }\end{array}$ & $\begin{array}{l}\text { Lawh-leng- } \\
\text { per }\end{array}$ & Paste & - & Uttarakhand & $8(439), 15(438)$ \\
\hline 14 & $\begin{array}{l}\text { Agave americana L. } \\
\text { (Agavaceae) }\end{array}$ & Jangli keora & Paste & $\mathrm{T}$ & Uttarakhand & $10(66), 15(448)$ \\
\hline 15 & $\begin{array}{l}\text { Agave angustifolia } \\
\text { Haworth (Agavaceae) }\end{array}$ & Ram bans (H) & Paste & $\mathrm{T}$ & Uttarakhand & $15(448)$ \\
\hline \multirow[t]{2}{*}{16} & $\begin{array}{l}\text { Agave cantala Roxb. } \\
\text { (Agavaceae) }\end{array}$ & - & - & $\mathrm{O}$ & Khargone, M.P. & 30 \\
\hline & & $\begin{array}{l}\text { Bilati anarash } \\
(\mathrm{Bn})\end{array}$ & Paste & - & Uttarakhand & $10(69), 15(449)$ \\
\hline 17 & $\begin{array}{l}\text { Ageratina adenophora } \\
\text { (Sprengel) R.Kings \& } \\
\text { H. Robinson } \\
\text { (Asteraceae) }\end{array}$ & & Juice & - & $\begin{array}{l}\text { Shevaroy hills, } \\
\text { Tamil Nadu }\end{array}$ & $7(391)$ \\
\hline \multirow[t]{3}{*}{18} & $\begin{array}{l}\text { Ageratum conyzoides L. } \\
\text { (Asteraceae) }\end{array}$ & Imin-esu & Paste & $\mathrm{T}$ & South-west Nigeria & 23 \\
\hline & & Ghondva Bon & Paste and juice & $\mathrm{T}$ & Tezpur, Assam & 31 \\
\hline & & Appachedi & Paste & $\mathrm{T}$ & Attappady, Kerala & 21 \\
\hline
\end{tabular}




\begin{tabular}{|c|c|c|c|c|c|c|}
\hline S.No. & $\begin{array}{l}\text { Botanical Name } \\
\text { (Family) }\end{array}$ & Local name & $\begin{array}{l}\text { Mode of } \\
\text { administration }\end{array}$ & $\begin{array}{l}\text { Route of } \\
\text { administration }\end{array}$ & Tribal Area & References \\
\hline \multirow[t]{2}{*}{18} & \multirow[t]{2}{*}{$\begin{array}{l}\text { Ageratum conyzoides L. } \\
\text { (Asteraceae) }\end{array}$} & White weed & - & - & $\begin{array}{l}\text { Bilaspur, } \\
\text { Chhattisgarh }\end{array}$ & 27 \\
\hline & & $\begin{array}{l}\text { Appachi } \\
\text { cheppu }(\mathrm{Kd})\end{array}$ & Juice & - & $\begin{array}{l}\text { Santhal Pargana, } \\
\text { Bihar; Uttarakhand }\end{array}$ & $\begin{array}{l}7(583), 8(175), 8(192), 8 \\
(260), 9(251), 10(70), 13 \\
(312), 14(21), 15(258), 16 \\
(301)\end{array}$ \\
\hline 19 & $\begin{array}{l}\text { Ailanthus excelsa Roxb. } \\
\text { (Simaroubaceae) }\end{array}$ & Maharukh (H) & Paste & $\mathrm{T}$ & Uttarakhand & $\begin{array}{l}8(192), 9(259), 10(75), 12 \\
(35), 15(132)\end{array}$ \\
\hline 20 & $\begin{array}{l}\text { Ajuga bracteosa Wallich } \\
\text { ex Benth (Lamiaceae) }\end{array}$ & - & Juice & - & $\begin{array}{l}\text { Almora, } \\
\text { Uttarakhand }\end{array}$ & $7(247)$ \\
\hline 21 & $\begin{array}{l}\text { Albizia chinensis (Osb.) } \\
\text { Merr. } \\
\text { (Fabaceae) }\end{array}$ & $\begin{array}{l}\text { Kanujera, } \\
\text { Siran }(H)\end{array}$ & Juice & - & $\begin{array}{l}\text { Mahabubnagar, } \\
\text { A.P. }\end{array}$ & $7(341), 8(439), 10(81)$ \\
\hline 22 & $\begin{array}{l}\text { Albizia procera (Roxb.) } \\
\text { Benth. } \\
\text { (Fabaceae) }\end{array}$ & $\begin{array}{l}\text { Safed shiris, } \\
\text { Gurar, Karra, } \\
\text { Karro }(\mathrm{H})\end{array}$ & Poultice & $\mathrm{T}$ & $\begin{array}{l}\text { Amravati, } \\
\text { Maharashtra } \\
\text { Uttarakhand }\end{array}$ & $\begin{array}{l}7(283), 8(439), 10(85), 15 \\
(160), 19(14)\end{array}$ \\
\hline \multirow[t]{6}{*}{23} & $\begin{array}{l}\text { Aloe vera (L.) Burm. f. } \\
\text { (Liliaceae) }\end{array}$ & - & Gel & $\mathrm{T}$ & Khargone, M.P. & 30 \\
\hline & & Mlovera & $\begin{array}{l}\text { Crushed or } \\
\text { Pounded }\end{array}$ & $\mathrm{T}$ & $\begin{array}{l}\text { Kimboza forest, } \\
\text { Tanzania }\end{array}$ & 32 \\
\hline & & Korphad & Juice & - & $\begin{array}{l}\text { Washim, } \\
\text { Maharashtra }\end{array}$ & 24 \\
\hline & & $\begin{array}{l}\text { Chirukatthaall } \\
\text { a }\end{array}$ & Paste & $\mathrm{T}$ & $\begin{array}{l}\text { Kuruma tribes, } \\
\text { Wayanadu, Kerela }\end{array}$ & 33 \\
\hline & & Gawar patha & Juice & - & $\begin{array}{l}\text { Kanyakumari, } \\
\text { Tamil Nadu }\end{array}$ & $\begin{array}{l}7(369), 8(192), 10(100) \\
16(311)\end{array}$ \\
\hline & & Gwarpatha & - & - & $\begin{array}{l}\text { Bilaspur, } \\
\text { Chhattisgarh }\end{array}$ & 27 \\
\hline 24 & $\begin{array}{l}\text { Alterrnanthera tenella } \\
\text { Colla. } \\
\text { (Amaranthaceae) }\end{array}$ & Vishal karani & Crushed & - & Bhadrak, Odisha & $7(499)$ \\
\hline 25 & $\begin{array}{l}\text { Amaranthus spinosus } \\
\text { Linn. } \\
\text { (Amaranthaceae) }\end{array}$ & Marish (S) & Poultice & $\mathrm{T}$ & Uttarakhand & 15(387), 16(318) \\
\hline 26 & $\begin{array}{l}\text { Amaranthus tricolor L. } \\
\text { (Amaranthaceae) }\end{array}$ & $\begin{array}{l}\text { Bishalya } \\
\text { Karani }\end{array}$ & Paste & $\mathrm{T}$ & Tezpur, Assam & 31 \\
\hline 27 & $\begin{array}{l}\text { Ampelocissus grantii } \\
\text { (Baker) Planch. } \\
\text { (Vitaceae) }\end{array}$ & $\begin{array}{l}\text { En`eginnu- } \\
\text { omulu }\end{array}$ & Powder & $\mathrm{T}$ & $\begin{array}{l}\text { Dogonland, Mali, } \\
\text { West Africa }\end{array}$ & 34 \\
\hline 28 & $\begin{array}{l}\text { Ampelocissus latifolia } \\
\text { (Roxb.) Panch } \\
\text { (Vitaceae) }\end{array}$ & Panibel (H) & Juice & $\mathrm{T}$ & - & $10(130), 12(51), 16(320)$ \\
\hline 29 & $\begin{array}{l}\text { Anaphalis adnata } \\
\text { (Asteraceae) }\end{array}$ & Bugla (Lut) & Paste & - & Uttarakhand & $15(279)$ \\
\hline 30 & $\begin{array}{l}\text { Anaphalis brevifoloia } \\
\text { (Asteraceae) }\end{array}$ & - & - & - & - & $8(82)$ \\
\hline 31 & $\begin{array}{l}\text { Anaphalis busua } \\
\text { (Asteraceae) }\end{array}$ & - & Juice & - & Uttarakhand & $15(279)$ \\
\hline 32 & $\begin{array}{l}\text { Anaphalis contorta } \\
\text { (Asteraceae) }\end{array}$ & - & & - & Uttarakhand & $15(279)$ \\
\hline 33 & $\begin{array}{l}\text { Anaphalis cuneifolia } \\
\text { Hk.f. } \\
\text { (Asteraceae) }\end{array}$ & Kat-plaster & Crushed & $\mathrm{T}$ & - & $8(62)$ \\
\hline
\end{tabular}




\begin{tabular}{|c|c|c|c|c|c|c|}
\hline S.No. & $\begin{array}{l}\text { Botanical Name } \\
\text { (Family) }\end{array}$ & Local name & $\begin{array}{l}\text { Mode of } \\
\text { administration }\end{array}$ & $\begin{array}{l}\text { Route of } \\
\text { administration }\end{array}$ & Tribal Area & References \\
\hline 34 & $\begin{array}{l}\text { Anaphalis margaritacea } \\
\text { (Asteraceae) }\end{array}$ & - & & - & Uttarakhand & $15(279)$ \\
\hline 35 & $\begin{array}{l}\text { Anaphalis neelgerriana } \\
\text { DC. } \\
\text { (Asteraceae) }\end{array}$ & $\begin{array}{l}\text { Raktaskandan } \\
\text { a, Vranapatra } \\
\text { (S) }\end{array}$ & $\begin{array}{l}\text { Crushed and } \\
\text { applied as } \\
\text { plaster }\end{array}$ & $\mathrm{T}$ & - & $10(141)$ \\
\hline 36 & $\begin{array}{l}\text { Anaphalis triplinervis } \\
\text { Clarke(Asteraceae) }\end{array}$ & & & - & Uttarakhand & $15(279), 16(324)$ \\
\hline 37 & $\begin{array}{l}\text { Andrographis } \\
\text { paniculata (Burm. f.) } \\
\text { Wall. ex Nees } \\
\text { (Acanthaceae) }\end{array}$ & $\begin{array}{l}\text { Kiriyath } \\
\text { Kaikati (Mur) }\end{array}$ & Paste & $\mathrm{T}$ & $\begin{array}{l}\text { Attappady, Kerala; } \\
\text { Tirunelveli, Tamil } \\
\text { Nadu }\end{array}$ & $7(363), 8(201), 21$ \\
\hline 38 & $\begin{array}{l}\text { Annona muricata Linn. } \\
\text { (Annonaceae) }\end{array}$ & Sour sop (E) & Pounded & - & - & $11(162)$ \\
\hline \multirow[t]{3}{*}{39} & $\begin{array}{l}\text { Annona senegalensis } \\
\text { Pers. } \\
\text { (Annonaceae) }\end{array}$ & - & Paste & $\mathrm{T}$ & $\begin{array}{l}\text { Kimboza forest, } \\
\text { Tanzania }\end{array}$ & 32 \\
\hline & & Abo & Decoction & $\mathrm{T}$ & South-west Nigeria & 23 \\
\hline & & Jankoonno & Decoction & $\mathrm{O}$ & $\begin{array}{l}\text { Dogonland, Mali, } \\
\text { West Africa }\end{array}$ & 34 \\
\hline \multirow[t]{3}{*}{40} & $\begin{array}{l}\text { Annona squamosa Linn. } \\
\text { (Annonaceae) }\end{array}$ & Sitaphal & Juice & $\mathrm{O}$ & $\begin{array}{l}\text { Dantewada, } \\
\text { Chhattisgarh }\end{array}$ & 35 \\
\hline & & Sitaphal & Paste & $\mathrm{T}$ & $\begin{array}{l}\text { Washim, } \\
\text { Maharashtra; } \\
\text { Koraput, Odisha; } \\
\text { Santhal Pargana, } \\
\text { Bihar; } \\
\text { Uttarakhand }\end{array}$ & $\begin{array}{l}\text { 7(473), 9(387), 11(161), } \\
\text { 14(22), 15(71), 16(309), } \\
\text { 18(112), } 24\end{array}$ \\
\hline & & Sitaphal & Poultice & $\mathrm{T}$ & $\begin{array}{l}\text { Nagpur and } \\
\text { Wardha; } \\
\text { Bilaspur, } \\
\text { Chhattisgarh }\end{array}$ & 19(18), 27 \\
\hline 41 & $\begin{array}{l}\text { Anogeissus leiocarpa } \\
\text { Guill. \& Perr. } \\
\text { (Combretaceae) }\end{array}$ & Sigilu & $\begin{array}{l}\text { Dried leaves } \\
\text { powder mixed } \\
\text { with water }\end{array}$ & $\mathrm{T}$ & $\begin{array}{l}\text { Dogonland, Mali, } \\
\text { West Africa }\end{array}$ & 34 \\
\hline 42 & $\begin{array}{l}\text { Anthocephalus chinensis } \\
\text { (Lamk.)A.Rich ex Wall } \\
\text { (Rubiaceae) }\end{array}$ & $\begin{array}{l}\text { Kadamba, } \\
\text { neepa }(\mathrm{S})\end{array}$ & - & - & - & $10(160)$ \\
\hline \multirow[t]{3}{*}{43} & $\begin{array}{l}\text { Argemone maxicana } \\
\text { L. } \\
\text { (Papaveraceae) }\end{array}$ & Pili / Piwala & - & - & $\begin{array}{l}\text { Washim, } \\
\text { Maharashtra }\end{array}$ & 24 \\
\hline & & Dhamoi (Snt) & Juice & - & $\begin{array}{l}\text { Dharmapuri, Tamil } \\
\text { Nadu; } \\
\text { Santhal Pargana, } \\
\text { Bihar }\end{array}$ & $\begin{array}{l}7(395), 8(192), 10(178), \\
11(237), 12(65), 14(22), \\
16(314)\end{array}$ \\
\hline & & Pili kateri & - & - & $\begin{array}{l}\text { Bilaspur, } \\
\text { Chhattisgarh }\end{array}$ & 27 \\
\hline 44 & $\begin{array}{l}\text { Argyreia bella } \\
\text { Raizada } \\
\text { (Convolvulaceae) }\end{array}$ & Tamrabel & - & - & Nimar region, M.P. & 36 \\
\hline
\end{tabular}




\begin{tabular}{|c|c|c|c|c|c|c|}
\hline S.No. & $\begin{array}{l}\text { Botanical Name } \\
\text { (Family) }\end{array}$ & Local name & $\begin{array}{l}\text { Mode of } \\
\text { administration }\end{array}$ & $\begin{array}{l}\text { Route of } \\
\text { administration }\end{array}$ & Tribal Area & References \\
\hline 45 & $\begin{array}{l}\text { Argyreia nervosa } \\
\text { (Burm.f.) Bojer } \\
\text { (Convolvulaceae) }\end{array}$ & $\begin{array}{l}\text { Samudraphala } \\
\text { (S) }\end{array}$ & Poultice & $\mathrm{T}$ & $\begin{array}{l}\text { Amravati dist., } \\
\text { Maharashtra }\end{array}$ & $\begin{array}{l}\text { 7(273), 10(180), 12(67), } \\
\text { 16(306), 16(317) }\end{array}$ \\
\hline 46 & $\begin{array}{l}\text { Aristolochia bracteata } \\
\text { (Aristolochiaceae) }\end{array}$ & $\begin{array}{l}\text { Aduthinapalai } \\
\text {; Kiramar }\end{array}$ & Poultice & $\mathrm{T}$ & $\begin{array}{l}\text { Tirunelveli, Tamil } \\
\text { Nadu } \\
\text { Mahabubnagar, } \\
\text { A.P. } \\
\text { Santhal Pargana, } \\
\text { Bihar }\end{array}$ & $7(341), 7(363), 9(147)$ \\
\hline 47 & $\begin{array}{l}\text { Aristolochia indica L. } \\
\text { (Aristolochiaceae) }\end{array}$ & $\begin{array}{l}\text { Irukodi } \\
\text { Karlakam }\end{array}$ & Paste & $\mathrm{T}$ & Attappady, Kerala & 21 \\
\hline 48 & $\begin{array}{l}\text { Artemisia absinthium } \\
\text { Linn. } \\
\text { (Asteraceae) }\end{array}$ & $\begin{array}{l}\text { Indhana, } \\
\text { Amar (S), } \\
\text { Dammar (S); } \\
\text { Vilayati } \\
\text { afasantin (H) }\end{array}$ & Paste & $\mathrm{T}$ & - & $8(50), 10(189), 11(317)$ \\
\hline 49 & $\begin{array}{l}\text { Artemisia nilagirica } \\
\text { (Clarke) Pamp. } \\
\text { (Asteraceae) }\end{array}$ & $\begin{array}{l}\text { Nagadamani } \\
\text { (S); } \\
\text { Nagduana, } \\
\text { Dona, } \\
\text { Gathivana, } \\
\text { Majtari (H) }\end{array}$ & & & $\begin{array}{l}\text { Assam; } \\
\text { Uttarakhand }\end{array}$ & $\begin{array}{l}\text { 7(599), 8(322), 10(192), } \\
\text { 15(260), }\end{array}$ \\
\hline 50 & $\begin{array}{l}\text { Artocarpus } \\
\text { heterophyllus J. B. } \\
\text { Lamark. } \\
\text { (Moraceae) }\end{array}$ & $\begin{array}{l}\text { Fanas Panasa } \\
\text { (S); Kanthal } \\
\text { (H) }\end{array}$ & - & $\mathrm{O} \& \mathrm{~T}$ & $\begin{array}{l}\text { Dantewada, } \\
\text { Chhattisgarh }\end{array}$ & $\begin{array}{l}35 \\
10(195), 12(75)\end{array}$ \\
\hline 51 & $\begin{array}{l}\text { Asparagus racemosus } \\
\text { Willd. } \\
\text { (Liliaceae) }\end{array}$ & $\begin{array}{l}\text { Tinampori, } \\
\text { Chatavalli }\end{array}$ & Paste & $\mathrm{T}$ & Attappady, Kerala & 21 \\
\hline 52 & $\begin{array}{l}\text { Asystasia gangetica }(\mathrm{L} .) \\
\text { T. Anderson } \\
\text { (Acanthaceae) }\end{array}$ & $\begin{array}{l}\text { Valukkai } \\
\text { keerai }\end{array}$ & $\begin{array}{l}\text { Leaf powder is } \\
\text { mixed with } \\
\text { coconut oil }\end{array}$ & $\mathrm{T}$ & $\begin{array}{l}\text { Kancheepuram, } \\
\text { Tamilnadu }\end{array}$ & 25 \\
\hline 53 & $\begin{array}{l}\text { Atalantica monophylla } \\
\text { (Roxb.) DC. } \\
\text { (Rutaceae) }\end{array}$ & - & - & - & - & $10(212)$ \\
\hline 54 & $\begin{array}{l}\text { Atylosia lineata Wt. \& } \\
\text { Arn. } \\
\text { (Fabaceae) }\end{array}$ & $\begin{array}{l}\text { Rantur, } \\
\text { Janglitur }\end{array}$ & Paste & - & - & $8(169)$ \\
\hline 55 & $\begin{array}{l}\text { Atylosia scarabaeoides } \\
\text { Benth. } \\
\text { (Fabaceae) }\end{array}$ & $\begin{array}{l}\text { Chowkhara ki } \\
\text { kheti }(\mathrm{H})\end{array}$ & Paste & - & - & $16(308)$ \\
\hline \multirow[t]{6}{*}{56} & $\begin{array}{l}\text { Azadirachta indica A. } \\
\text { Juss } \\
\text { (Meliaceae) }\end{array}$ & $\begin{array}{l}\text { Afoforo- } \\
\text { oyimbo }\end{array}$ & Paste & $\mathrm{T}$ & South-west Nigeria & 23 \\
\hline & & Gonji & Decoction & $\mathrm{T}$ & $\begin{array}{l}\text { Dogonland, Mali, } \\
\text { West Africa }\end{array}$ & 34 \\
\hline & & Neempat & Leaf paste & $\mathrm{T}$ & Tezpur, Assam & 31 \\
\hline & & Neem & - & - & $\begin{array}{l}\text { Mayurbhanj, } \\
\text { Odisha }\end{array}$ & 37 \\
\hline & & Neem & Juice & $\mathrm{T}$ & $\begin{array}{l}\text { Nagpur and } \\
\text { Wardha, } \\
\text { Washim, } \\
\text { Maharashtra }\end{array}$ & $\begin{array}{l}19(20) \\
24\end{array}$ \\
\hline & & Neem & - & - & $\begin{array}{l}\text { Bilaspur, } \\
\text { Chhattisgarh }\end{array}$ & 27 \\
\hline
\end{tabular}




\begin{tabular}{|c|c|c|c|c|c|c|}
\hline S.No. & $\begin{array}{l}\text { Botanical Name } \\
\text { (Family) }\end{array}$ & Local name & $\begin{array}{l}\text { Mode of } \\
\text { administration }\end{array}$ & $\begin{array}{l}\text { Route of } \\
\text { administration }\end{array}$ & Tribal Area & References \\
\hline 57 & $\begin{array}{l}\text { Baliospermum } \\
\text { montanum Mull-Arg. } \\
\text { (Euphorbiaceae) }\end{array}$ & Danti (S) & - & - & Uttarakhand & $11(190), 15(400)$ \\
\hline 58 & $\begin{array}{l}\text { Bambusa arundinacea } \\
\text { Roxb. } \\
\text { (Poaceae) }\end{array}$ & Vamsha (S) & Paste & - & Uttarakhand & $10(233), 15(464), 16(309)$ \\
\hline 59 & $\begin{array}{l}\text { Bambusa vulgaris } \\
\text { Schrad. ex Wendl.non } \\
\text { Nees } \\
\text { (Poaceae) }\end{array}$ & $\begin{array}{l}\text { Balkubans } \\
\text { (Snt) }\end{array}$ & - & - & - & $10(236)$ \\
\hline 60 & $\begin{array}{l}\text { Barbarea vulgaris R.Br. } \\
\text { (Brassicaceae) }\end{array}$ & $\begin{array}{l}\text { Bitter winter } \\
\text { cress }\end{array}$ & - & - & - & $10(238)$ \\
\hline 61 & $\begin{array}{l}\text { Barleria cristata Linn. } \\
\text { (Acanthaceae) }\end{array}$ & $\begin{array}{l}\text { Jhinit, Tadrelu } \\
(\mathrm{H})\end{array}$ & - & - & Uttarakhand & $15(354)$ \\
\hline \multirow[t]{2}{*}{62} & $\begin{array}{l}\text { Barleria prionitis Linn. } \\
\text { (Acanthaceae) }\end{array}$ & Itola & Juice & $\mathrm{O}$ & $\begin{array}{l}\text { Dantewada, } \\
\text { Chhattisgarh }\end{array}$ & 35 \\
\hline & & Kantamalati & Leaf paste & $\mathrm{T}$ & $\begin{array}{l}\text { Kalahandi, Odisha; } \\
\text { Uttarakhand }\end{array}$ & $\begin{array}{l}9(147), 10(241), 15(354), \\
16(303), 29\end{array}$ \\
\hline 63 & $\begin{array}{l}\text { Basella alba L. } \\
\text { (Basellaceae) }\end{array}$ & Upodika (S) & Poultice & $\mathrm{T}$ & - & $12(80)$ \\
\hline 64 & $\begin{array}{l}\text { Bauhinia rufescens Lam. } \\
\text { (Fabaceae) }\end{array}$ & 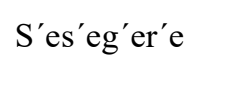 & $\begin{array}{l}\text { Powder of dried } \\
\text { leaves }\end{array}$ & $\mathrm{T}$ & $\begin{array}{l}\text { Dogonland, Mali, } \\
\text { West Africa }\end{array}$ & 34 \\
\hline 65 & $\begin{array}{l}\text { Begonia fallox DC. } \\
\text { (Begoniaceae) }\end{array}$ & Earan-kolli & Paste & $\mathrm{T}$ & $\begin{array}{l}\text { Tirunelveli hills, } \\
\text { southern India }\end{array}$ & 22 \\
\hline 66 & $\begin{array}{l}\text { Begonia picta } \text { Smith } \\
\text { (Begoniaceae) }\end{array}$ & $\begin{array}{l}\text { Longsilawa } \\
\text { (Nag) }\end{array}$ & Juice & $\mathrm{T}$ & Nagaland & $10(256), 20(40)$ \\
\hline 67 & $\begin{array}{l}\text { Bergia odorata Edg. } \\
\text { (Elatinaceae) }\end{array}$ & Gangharun & Poultice & $\mathrm{T}$ & - & $11(444)$ \\
\hline 68 & $\begin{array}{l}\text { Berginia ciliata (Haw.) } \\
\text { Stemb. } \\
\text { (Saxifragaceae) }\end{array}$ & $\begin{array}{l}\text { Pakharabheda } \\
\text { (H); } \\
\text { Pashaabheda } \\
\text { (S) }\end{array}$ & - & - & - & $10(267)$ \\
\hline 69 & $\begin{array}{l}\text { Bidens biternata (Lour.) } \\
\text { Merril \& Sheriff ex } \\
\text { Sheriff } \\
\text { (Asteraceae) }\end{array}$ & Chirchitt (H) & - & - & - & $8(175), 9(259), 10(273)$ \\
\hline 70 & $\begin{array}{l}\text { Bidens fistulosa (Roxb.) } \\
\text { Kurz. } \\
\text { (Asteraceae) }\end{array}$ & $\begin{array}{l}\text { Bir nagula-ba } \\
\text { (Mnd) }\end{array}$ & - & - & - & $10(286)$ \\
\hline 71 & $\begin{array}{l}\text { Bidens lacera (Burm.f.) } \\
\text { DC. } \\
\text { (Asteraceae) }\end{array}$ & $\begin{array}{l}\text { Kukundara } \\
\text { (S) }\end{array}$ & - & - & - & $10(287)$ \\
\hline 72 & $\begin{array}{l}\text { Bidens pilosa L. var. } \\
\text { minor (Blume) Sherff. } \\
\text { (Asteraceae) }\end{array}$ & $\begin{array}{l}\text { Mulkutthi } \\
(\mathrm{Tm})\end{array}$ & Paste & $\mathrm{T}$ & $\begin{array}{l}\text { Dharmapuri dist., } \\
\text { Tamil Nadu }\end{array}$ & $\begin{array}{l}\text { 7(395), 8(272), 11(323), } \\
16(304)\end{array}$ \\
\hline 73 & $\begin{array}{l}\text { Biebersteinia odora } \\
\text { Stepf. ex Fisch. } \\
\text { (Biebersteiniaceae) }\end{array}$ & $\begin{array}{l}\text { Drakspose } \\
\text { (Ldk) }\end{array}$ & Paste & - & - & $8(92), 10(275)$ \\
\hline 74 & $\begin{array}{l}\text { Biophytum nervifolium } \\
\text { Thw. } \\
\text { (Oxalidaceae) }\end{array}$ & Lajjalu (S) & - & - & - & $12(96)$ \\
\hline 75 & $\begin{array}{l}\text { Biophytum sensitivum } \\
\text { (L.) DC. } \\
\text { (Oxalidaceae) }\end{array}$ & $\begin{array}{l}\text { Lajalu, } \\
\text { Lakchana }(\mathrm{H}) \text {; } \\
\text { Jhallapushpa } \\
\text { (S) }\end{array}$ & Paste & - & $\begin{array}{l}\text { Tirunelveli, Tamil } \\
\text { Nadu }\end{array}$ & $\begin{array}{l}7(363), 9(259), 10(276) \\
16(311)\end{array}$ \\
\hline
\end{tabular}




\begin{tabular}{|c|c|c|c|c|c|c|}
\hline S.No. & $\begin{array}{l}\text { Botanical Name } \\
\text { (Family) }\end{array}$ & Local name & $\begin{array}{l}\text { Mode of } \\
\text { administration }\end{array}$ & $\begin{array}{l}\text { Route of } \\
\text { administration }\end{array}$ & Tribal Area & References \\
\hline 76 & $\begin{array}{l}\text { Bischofia javanica } \mathrm{Bl} . \\
\text { (Euphorbiaceae) }\end{array}$ & $\begin{array}{l}\text { Bhillar (H); } \\
\text { Malaichandan } \\
(\mathrm{Tm})\end{array}$ & Juice & - & $\begin{array}{l}\text { Dharmapuri dist., } \\
\text { Tamil Nadu }\end{array}$ & $7(395), 11(190)$ \\
\hline 77 & $\begin{array}{l}\text { Blepharis edulis Pers. } \\
\text { (Acanthaceae) }\end{array}$ & - & - & - & - & $10(283)$ \\
\hline 78 & $\begin{array}{l}\text { Blepharis } \\
\text { maderaspatensis (L.) } \\
\text { B. Heyne ex Roth. } \\
\text { (Acanthaceae) }\end{array}$ & $\begin{array}{l}\text { Pappadak- } \\
\text { kodi }\end{array}$ & $\begin{array}{l}\text { Juice extracted } \\
\text { from the leaf }\end{array}$ & $\mathrm{T}$ & $\begin{array}{l}\text { Tirunelveli hills, } \\
\text { southern India }\end{array}$ & 22 \\
\hline 79 & $\begin{array}{l}\text { Blumea aurita DC. } \\
\text { (Asteraceae) }\end{array}$ & $\begin{array}{l}\text { Morang-puru, } \\
\text { Soan puru } \\
\text { (Mnd) }\end{array}$ & - & - & - & $10(284)$ \\
\hline 80 & $\begin{array}{l}\text { Blumea balsamifera DC. } \\
\text { (Asteraceae) }\end{array}$ & $\begin{array}{l}\text { Kakaronda } \\
(\mathrm{H})\end{array}$ & Decoction & - & - & $11(324)$ \\
\hline 81 & $\begin{array}{l}\text { Blumea lacera DC. } \\
\text { (Asteraceae) }\end{array}$ & $\begin{array}{l}\text { Hul hul } \\
\text { Randoi (Snt.) }\end{array}$ & Juice & $\mathrm{T}$ & $\begin{array}{l}\text { Bilaspur, } \\
\text { Chhattisgarh; } \\
\text { Santhal Pargana, } \\
\text { Bihar }\end{array}$ & $\begin{array}{l}27 \\
14(24)\end{array}$ \\
\hline 82 & $\begin{array}{l}\text { Blumea membranacea } \\
\text { DC. } \\
\text { (Asteraceae) }\end{array}$ & Kukraunda & & - & - & $8(138)$ \\
\hline 83 & $\begin{array}{l}\text { Boeninghausenia } \\
\text { albifora (Hk.) Reichb. } \\
\text { Meissn } \\
\text { (Rutaceae) }\end{array}$ & $\begin{array}{l}\text { Pishumar, } \\
\text { Upniyaghas } \\
\text { (Lut) }\end{array}$ & Paste & - & Uttarakhand & $10(293), 15(128)$ \\
\hline 84 & $\begin{array}{l}\text { Boerhavia diffusa Linn. } \\
\text { (Nyctaginaceae) }\end{array}$ & punarnava & - & - & $\begin{array}{l}\text { Bilaspur, } \\
\text { Chhattisgarh }\end{array}$ & 27 \\
\hline 85 & $\begin{array}{l}\text { Borreria articularis } \\
\text { (L.f.) } \\
\text { (Rubiaceae) }\end{array}$ & $\begin{array}{l}\text { Madanaghanti } \\
(\mathrm{H})\end{array}$ & - & - & - & $10(302)$ \\
\hline 86 & $\begin{array}{l}\text { Borreria hispida } \\
\text { Spruce ex K. Schum. } \\
\text { (Rubiaceae) }\end{array}$ & $\begin{array}{l}\text { Madanghanti } \\
\text {, Satgithia }\end{array}$ & Paste & $\mathrm{T}$ & $\begin{array}{l}\text { Purulia district, } \\
\text { West Bengal }\end{array}$ & 38 \\
\hline 87 & $\begin{array}{l}\text { Brassica nigra (L.)Koch } \\
\text { (Brassicaceae) }\end{array}$ & Kali rai & Paste & $\mathrm{T}$ & - & $8(228), 9(387)$ \\
\hline 88 & $\begin{array}{l}\text { Bridelia ferruginea } \\
\text { Benth. } \\
\text { (Euphorbiaceae) }\end{array}$ & Ira & Poultice & $\mathrm{T}$ & South-west Nigeria & 23 \\
\hline \multirow[t]{2}{*}{89} & \multirow[t]{2}{*}{$\begin{array}{l}\text { Bryophyllum pinnatum } \\
\text { (Lam.) } \\
\text { (Crassulaceae) }\end{array}$} & - & Paste & $\mathrm{T}$ & $\begin{array}{l}\text { Dantewada, } \\
\text { Chhattisgarh; } \\
\text { Uttarakhand }\end{array}$ & $\begin{array}{l}35 \\
13(187), 15(207), 16 \\
(317)\end{array}$ \\
\hline & & Sugulujiinloo & Juice & $\mathrm{T}$ & $\begin{array}{l}\text { Dogonland, Mali, } \\
\text { West Africa }\end{array}$ & 34 \\
\hline \multirow[t]{2}{*}{90} & \multirow[t]{2}{*}{$\begin{array}{l}\text { Bryophyllum calycinum } \\
\text { Salisb. } \\
\text { (Crassulaceae) }\end{array}$} & Panfuti & - & - & $\begin{array}{l}\text { Washim, } \\
\text { Maharashtra }\end{array}$ & 24 \\
\hline & & - & Juice & $\mathrm{T}$ & $\begin{array}{l}\text { Jalgaon, } \\
\text { Maharashtra; } \\
\text { Khargone, M.P. }\end{array}$ & $\begin{array}{l}39 \\
30\end{array}$ \\
\hline 91 & $\begin{array}{l}\text { Buchanania lanzan Spr. } \\
\text { (Anacardiaceae) }\end{array}$ & $\begin{array}{l}\text { Priyala }(\mathrm{S}) \\
\text { Tarop (Snt) }\end{array}$ & Paste & - & $\begin{array}{l}\text { Santhal pargana, } \\
\text { Bihar; } \\
\text { Uttarakhand }\end{array}$ & 10(320), 14(22), 15(151) \\
\hline
\end{tabular}




\begin{tabular}{|c|c|c|c|c|c|c|}
\hline S.No. & $\begin{array}{l}\text { Botanical Name } \\
\text { (Family) }\end{array}$ & Local name & $\begin{array}{l}\text { Mode of } \\
\text { administration }\end{array}$ & $\begin{array}{l}\text { Route of } \\
\text { administration }\end{array}$ & Tribal Area & References \\
\hline 92 & $\begin{array}{l}\text { Cadaba fruticosa }(\mathrm{L} .) \\
\text { Druce } \\
\text { (Capparaceae) }\end{array}$ & Kodhab; Dabi & Poultice & $\mathrm{T}$ & - & $9(147), 10(332)$ \\
\hline 93 & $\begin{array}{l}\text { Cajanas cajan (L.) } \\
\text { Millsp. } \\
\text { (Fabaceae) }\end{array}$ & Adhaki (S.) & Decoction & $\mathrm{T}$ & - & $10(337), 12(108)$ \\
\hline 94 & $\begin{array}{l}\text { Cajanaus indica Spreng. } \\
\text { (Fabaceae) }\end{array}$ & Aadhaki(S) & $\begin{array}{l}\text { Paste fried in } \\
\text { ghee }\end{array}$ & - & - & $16(312)$ \\
\hline 95 & $\begin{array}{l}\text { Callicarpa cana L. } \\
\text { (Verbenaceae) }\end{array}$ & Arusha (Bn) & Poultice & $\mathrm{T}$ & - & $10(341)$ \\
\hline 96 & $\begin{array}{l}\text { Callicarpa longifolia } \\
\text { Lamk. } \\
\text { (Verbenaceae) }\end{array}$ & $\begin{array}{l}\text { Kin-vi-taong } \\
(\mathrm{Ncb})\end{array}$ & $\begin{array}{l}\text { Paste in coconut } \\
\text { oil }\end{array}$ & - & - & $8(375)$ \\
\hline 97 & $\begin{array}{l}\text { Calotropis gigantea } \\
\text { (Linn.) R. Br. ex Ait. } \\
\text { (Asclepiadaceae) }\end{array}$ & $\begin{array}{l}\text { Aak, Rui(M); } \\
\operatorname{Akav}(\mathrm{K})\end{array}$ & - & - & $\begin{array}{l}\text { Bilaspur, } \\
\text { Chhattisgarh; } \\
\text { Amravati, } \\
\text { Maharashtra; } \\
\text { Koraput, Odisha; } \\
\text { Uttarakhand }\end{array}$ & $\begin{array}{l}\text { 7(273), } 7(473), 10(346) \\
15(309), 16(315), 27\end{array}$ \\
\hline \multirow[t]{2}{*}{98} & $\begin{array}{l}\text { Calotropis procera (Ait.) } \\
\text { R. Br. } \\
\text { (Asclepiadaceae) }\end{array}$ & Rui & - & - & $\begin{array}{l}\text { Washim, } \\
\text { Maharashtra }\end{array}$ & 24 \\
\hline & & - & Paste & $\mathrm{T}$ & Khargone, M.P & 30 \\
\hline 99 & $\begin{array}{l}\text { Calycopteris } \\
\text { floribunda (Roxb) } \\
\text { Lam. } \\
\text { (Combretaceae) }\end{array}$ & $\begin{array}{l}\text { Pullanni, } \\
\text { Pullanji, } \\
\text { Varavalli }\end{array}$ & Juice & $\mathrm{T}$ & Attappady, Kerala & $12(113), 21$ \\
\hline 100 & $\begin{array}{l}\text { Canavalia gladiata } \\
\text { (Jacq) DC. } \\
\text { (Fabaceae) }\end{array}$ & $\begin{array}{l}\text { Phatadi; } \\
\text { Asisimbi, } \\
\text { Masimbi (S) }\end{array}$ & $\begin{array}{l}\text { Ointment from } \\
\text { burning in } \\
\text { mustard oil }\end{array}$ & $\mathrm{T}$ & $\begin{array}{l}\text { Amravati, } \\
\text { Maharashtra }\end{array}$ & $7(283), 10(353), 12(115)$ \\
\hline 101 & $\begin{array}{l}\text { Cannabis sativa } \mathrm{L} . \\
\text { (Cannabaceae) }\end{array}$ & Bhanga (S) & - & - & Uttarakhand & $8(112), 10(356), 15(418)$ \\
\hline 102 & $\begin{array}{l}\text { Capparis zeylanica L. } \\
\text { (Capparaceae) }\end{array}$ & Asaria (S) & Paste & - & $\begin{array}{l}\text { Santhal pargana, } \\
\text { Bihar; } \\
\text { Uttarakhand; } \\
\text { Nagpur \& Wardha }\end{array}$ & $14(25), 15(86), 19(28)$ \\
\hline 103 & $\begin{array}{l}\text { Capsicum frutescence } \\
\text { L. } \\
\text { (Solanaceae) }\end{array}$ & Atarodo & $\begin{array}{l}\text { Leaves are } \\
\text { mixed with palm } \\
\text { oil }\end{array}$ & $\mathrm{T}$ & South-west Nigeria & 23 \\
\hline \multirow[t]{2}{*}{104} & $\begin{array}{l}\text { Carica papaya L. } \\
\text { (Caricaceae) }\end{array}$ & Ibepe & $\begin{array}{l}\text { Roasted leaf } \\
\text { pulp is applied }\end{array}$ & $\mathrm{T}$ & South-west Nigeria & 23 \\
\hline & & Papita & - & - & $\begin{array}{l}\text { Bilaspur, } \\
\text { Chhattisgarh }\end{array}$ & 27 \\
\hline 105 & $\begin{array}{l}\text { Carissa carandas L. } \\
\text { (Apocynaceae) }\end{array}$ & Karandakoli & - & - & $\begin{array}{l}\text { Mayurbhanj, } \\
\text { Odisha }\end{array}$ & 37 \\
\hline 106 & $\begin{array}{l}\text { Cassia absus L. } \\
\text { (Fabaceae) }\end{array}$ & Chaksu (H) & - & - & - & $10(26)$ \\
\hline 107 & $\begin{array}{l}\text { Cassia alata L. } \\
\text { (Fabaceae) }\end{array}$ & - & - & - & $\begin{array}{l}\text { Bilaspur, } \\
\text { Chhattisgarh }\end{array}$ & 27 \\
\hline 108 & $\begin{array}{l}\text { Cassia angustifolia } \\
\text { Linn. } \\
\text { (Fabaceae) }\end{array}$ & $\begin{array}{l}\text { Swarnapatri } \\
\text { (S) }\end{array}$ & Paste & - & - & $16(320)$ \\
\hline
\end{tabular}




\begin{tabular}{|c|c|c|c|c|c|c|}
\hline S.No. & $\begin{array}{l}\text { Botanical Name } \\
\text { (Family) }\end{array}$ & Local name & $\begin{array}{l}\text { Mode of } \\
\text { administration }\end{array}$ & $\begin{array}{l}\text { Route of } \\
\text { administration }\end{array}$ & Tribal Area & References \\
\hline 109 & $\begin{array}{l}\text { Cassia auriculata L. } \\
\text { (Caesalpiniacea) }\end{array}$ & - & Paste & $\mathrm{T}$ & $\begin{array}{l}\text { Sangli, } \\
\text { Maharashtra; } \\
\text { Khargone, M.P. }\end{array}$ & $\begin{array}{l}40 \\
30 \\
12(132)\end{array}$ \\
\hline 110 & $\begin{array}{l}\text { Cassia fistula Linn. } \\
\text { (Fabaceae) }\end{array}$ & Amaltas & Juice & $O \& T$ & $\begin{array}{l}\text { Dantewada, } \\
\text { Chhattisgarh }\end{array}$ & $10(388), 35,41$ \\
\hline 111 & $\begin{array}{l}\text { Cassia italica (Mill.) } \\
\text { Lam. Ex F.W. Andrews } \\
\text { (Fabaceae) }\end{array}$ & $\begin{array}{l}\text { Anrangun } \\
\text { gangalu }\end{array}$ & $\begin{array}{l}\text { Powder of dried } \\
\text { stem with leaves }\end{array}$ & $\mathrm{T}$ & $\begin{array}{l}\text { Dogonland, Mali, } \\
\text { West Africa }\end{array}$ & 34 \\
\hline 112 & $\begin{array}{l}\text { Cassia obtusifolia L. } \\
\text { (Fabaceae) }\end{array}$ & $\begin{array}{l}\text { Chakragaja } \\
(\mathrm{S}) ; \text { Banarh, } \\
\text { Chakwar }(\mathrm{H})\end{array}$ & $\begin{array}{l}\text { Fried in castor } \\
\text { oil }\end{array}$ & - & - & $12(135)$ \\
\hline 113 & $\begin{array}{l}\text { Cassia podocarpa Guill. } \\
\text { \& Perr. (Fabaceae) }\end{array}$ & Anranwee & Powder & $\mathrm{T}$ & $\begin{array}{l}\text { Dogonland, Mali, } \\
\text { West Africa }\end{array}$ & 34 \\
\hline \multirow[t]{2}{*}{114} & $\begin{array}{l}\text { Cassia tora } \mathrm{L} . \\
\text { (Fabaceae) }\end{array}$ & Chakunda & - & - & $\begin{array}{l}\text { Mayurbhanj, } \\
\text { Odisha }\end{array}$ & 37 \\
\hline & & Charota & Paste & - & $\begin{array}{l}\text { Bilaspur, } \\
\text { Chhattisgarh; } \\
\text { Uttarakhand }\end{array}$ & $\begin{array}{l}27 \\
10(394), 15(176)\end{array}$ \\
\hline 115 & $\begin{array}{l}\text { Cayratia pedata (Lamk.) } \\
\text { Juss.ex Gagnep. } \\
\text { (Vitaceae) }\end{array}$ & $\begin{array}{l}\text { Pannikodi; } \\
\text { Godhapadi, } \\
\text { Suraha }(\mathrm{S})\end{array}$ & Paste & - & - & $8(284), 10(401)$ \\
\hline 116 & $\begin{array}{l}\text { Cayratia trifolia }(\mathrm{L} .) \\
\text { Domin. } \\
\text { (Vitaceae) }\end{array}$ & Gandira (S) & Poultice & $\mathrm{T}$ & - & $12(146)$ \\
\hline 117 & $\begin{array}{l}\text { Ceiba pentandra Gaerth } \\
\text { (Malvaceae) }\end{array}$ & Genhu & $\begin{array}{l}\text { Decoction is } \\
\text { used as eye } \\
\text { drops }\end{array}$ & $\mathrm{T}$ & $\begin{array}{l}\text { Dogonland, Mali, } \\
\text { West Africa }\end{array}$ & 34 \\
\hline 118 & $\begin{array}{l}\text { Celastrus paniculatus } \\
\text { Willd. } \\
\text { (Celastraceae) }\end{array}$ & $\begin{array}{l}\text { Kangoge } \\
\text { chedi }\end{array}$ & Juice & $\mathrm{T}$ & Attappady, Kerala & 21 \\
\hline \multirow[t]{2}{*}{119} & $\begin{array}{l}\text { Centella asiatica (Linn.) } \\
\text { Urban } \\
\text { (Apiaceae) }\end{array}$ & Bor manimuni & Paste & $\mathrm{T}$ & Tezpur, Assam & 31 \\
\hline & & Mandukparni & - & - & $\begin{array}{l}\text { Bilaspur, } \\
\text { Chhattisgarh }\end{array}$ & $\begin{array}{l}27 \\
10(413), 9(259), 16(307)\end{array}$ \\
\hline 120 & $\begin{array}{l}\text { Chasalia chartacea } \\
\text { Craib. } \\
\text { (Rubiaceae) }\end{array}$ & $\begin{array}{l}\text { Vellakurinji } \\
\text { (Tm) }\end{array}$ & - & $\mathrm{T}$ & - & $10(422)$ \\
\hline \multirow[t]{2}{*}{121} & $\begin{array}{l}\text { Chenopodium album L. } \\
\text { (Chenopodiaceae) }\end{array}$ & - & Crushed & $\mathrm{T}$ & Khargone, M.P. & 30 \\
\hline & & Bathua & - & - & $\begin{array}{l}\text { Bilaspur, } \\
\text { Chhattisgarh }\end{array}$ & 27 \\
\hline 122 & $\begin{array}{l}\text { Chenopodium } \\
\text { ambrosioides L. } \\
\text { (Chenopodiaceae) }\end{array}$ & Medicated tea & Juice & - & North East India & $7(583)$ \\
\hline 123 & $\begin{array}{l}\text { Chloroxylon swietenia } \\
\text { DC. } \\
\text { (Rutaceae) }\end{array}$ & Bhirra $(\mathrm{H})$ & Paste & $\mathrm{T}$ & Bastar, M.P. & $\begin{array}{l}10(428), \\
17(102)\end{array}$ \\
\hline 124 & $\begin{array}{l}\text { Chromolaena odorata } \\
\text { (L.) } \\
\text { R. M. King \& H. } \\
\text { Robins. } \\
\text { (Asteraceae) }\end{array}$ & $\begin{array}{l}\text { Awolowo } \\
\text { Akintola Taku }\end{array}$ & $\begin{array}{l}\text { An infusion is } \\
\text { used for wash }\end{array}$ & $\mathrm{T}$ & Attappady, Kerala & 21 \\
\hline
\end{tabular}




\begin{tabular}{|c|c|c|c|c|c|c|}
\hline S.No. & $\begin{array}{l}\text { Botanical Name } \\
\text { (Family) }\end{array}$ & Local name & $\begin{array}{l}\text { Mode of } \\
\text { administration }\end{array}$ & $\begin{array}{l}\text { Route of } \\
\text { administration }\end{array}$ & Tribal Area & References \\
\hline \multirow[t]{2}{*}{124} & \multirow{2}{*}{$\begin{array}{l}\text { Chromolaena odorata } \\
\text { (L.) } \\
\text { R. M. King \& H. } \\
\text { Robins. } \\
\text { (Asteraceae) }\end{array}$} & $\begin{array}{l}\text { Communist } \\
\text { paccha }\end{array}$ & Juice & $\mathrm{T}$ & $\begin{array}{l}\text { Mulla Kuruma } \\
\text { tribes, Wayanadu, } \\
\text { kerela }\end{array}$ & 42 \\
\hline & & Kuppa pacha & Juice and paste & $\mathrm{T}$ & $\begin{array}{l}\text { Kuruma tribes, } \\
\text { Wayanadu, kerela; } \\
\text { Phulbani, Odisha; } \\
\text { Andaman \& } \\
\text { Nicobar; } \\
\text { North East India; } \\
\text { Santhal Pargana. }\end{array}$ & $\begin{array}{l}7(569), 7(515), 7(583), 8 \\
(439), 8(350), 8(253), 8 \\
(381), 9(219), 12(154), 14 \\
(25), 33\end{array}$ \\
\hline 125 & $\begin{array}{l}\text { Chrozophora prostrata } \\
\text { Dalz. } \\
\text { (Euphorbiaceae) }\end{array}$ & $\begin{array}{l}\text { Pujbantago } \\
\text { (Phr) }\end{array}$ & Paste & - & $\begin{array}{l}\text { Santhal Pargana, } \\
\text { Bihar }\end{array}$ & $14(27)$ \\
\hline 126 & $\begin{array}{l}\text { Cirsium arvense (L.) } \\
\text { Scop. } \\
\text { (Asteraceae) }\end{array}$ & $\begin{array}{l}\text { Vangstar/ } \\
\text { Canada thistle }\end{array}$ & Juice & - & - & $8(92)$ \\
\hline \multirow[t]{3}{*}{127} & \multirow[t]{3}{*}{$\begin{array}{l}\text { Cissampelos pareira } \\
\text { L. } \\
\text { (Menispermaceae) }\end{array}$} & Malaithangi & Juice & $\mathrm{O}$ & $\begin{array}{l}\text { Tirunelveli hills, } \\
\text { southern India }\end{array}$ & 22 \\
\hline & & $\begin{array}{l}\text { Akaabindu } \\
\text { (O) }\end{array}$ & Crushed and tied & $\mathrm{T}$ & Koraput, Odisha & $18(119)$ \\
\hline & & $\begin{array}{l}\text { Patha }(\mathrm{S}) \\
\text { Tubuki lot } \\
\text { (Asm) }\end{array}$ & Juice, Paste & - & Uttarakhand & $\begin{array}{l}8(284), 8(338), 9(259), 10 \\
(441), 15(67), 16(324)\end{array}$ \\
\hline 128 & $\begin{array}{l}\text { Citrullus lanatus } \\
\text { (Thunb.) Matsum. \& } \\
\text { Nakai } \\
\text { (Cucurbitaceae) }\end{array}$ & Osan & $\begin{array}{l}\text { Softened warm } \\
\text { leaf is applied }\end{array}$ & $\mathrm{T}$ & South-west Nigeria & 23 \\
\hline 129 & $\begin{array}{l}\text { Claoxylon indicum } \\
\text { Hassk (Euphorbiaceae) }\end{array}$ & $\begin{array}{l}\text { Sing-ke-ra } \\
(\mathrm{Ncb})\end{array}$ & Paste & - & - & $8(375)$ \\
\hline 130 & $\begin{array}{l}\text { Cleistanthus collinus } \\
\text { (Euphorbiaceae) }\end{array}$ & Nalla kodisha & - & - & $\begin{array}{l}\text { Nalgonda \& } \\
\text { Warangal, A. P. }\end{array}$ & 43 \\
\hline 131 & $\begin{array}{l}\text { Clematis buchananiana } \\
\text { DC. var. vitifolia } \\
\text { (Ranunculaceae) }\end{array}$ & $\begin{array}{l}\text { Kehinha } \\
\text { Veraphul }\end{array}$ & Paste & $\mathrm{T}$ & Nagaland & $20(71)$ \\
\hline 132 & $\begin{array}{l}\text { Clematis gouriana } \\
\text { Roxb. } \\
\text { (Ranunculaceae) }\end{array}$ & Elivallu & $\begin{array}{l}\text { leaves are } \\
\text { crushed }\end{array}$ & $\mathrm{T}$ & $\begin{array}{l}\text { Paniya tribes, } \\
\text { Nilgiri, Tamil } \\
\text { Nadu }\end{array}$ & $\begin{array}{l}45 \\
8(228)\end{array}$ \\
\hline 133 & $\begin{array}{l}\text { Cleome gynandra Linn. } \\
\text { (Cleomaceae) }\end{array}$ & Tilaparna (S) & Crushed leaves & $\mathrm{T}$ & $\begin{array}{l}\text { Uttarakhand; } \\
\text { Nagpur and } \\
\text { Wardha }\end{array}$ & $\begin{array}{l}15(88) \\
19(32)\end{array}$ \\
\hline \multirow[t]{5}{*}{134} & \multirow[t]{5}{*}{$\begin{array}{l}\text { Cleome viscosa } \mathrm{L} . \\
\text { (Cleomaceae) }\end{array}$} & $\begin{array}{l}\text { Kukka } \\
\text { vaminta }\end{array}$ & - & - & $\begin{array}{l}\text { Nalgonda \& } \\
\text { Warangal, A. P. }\end{array}$ & 43 \\
\hline & & Naai kadugu & Leaf paste & $\mathrm{T}$ & $\begin{array}{l}\text { Tirunelveli hills, } \\
\text { southern India }\end{array}$ & 22 \\
\hline & & $\begin{array}{l}\text { Ellukkusakkal } \\
\text { athi }\end{array}$ & Paste & $\mathrm{T}$ & $\begin{array}{l}\text { Kuruma tribes, } \\
\text { Wayanadu, kerela }\end{array}$ & 33 \\
\hline & & Naikadugu & Paste & $\mathrm{T}$ & $\begin{array}{l}\text { Kancheepuram, } \\
\text { Tamil Nadu }\end{array}$ & 25 \\
\hline & & Tilwan & - & $\mathrm{T}$ & $\begin{array}{l}\text { Nagpur and } \\
\text { Wardha }\end{array}$ & $19(33)$ \\
\hline
\end{tabular}




\begin{tabular}{|c|c|c|c|c|c|c|}
\hline S.No. & $\begin{array}{l}\text { Botanical Name } \\
\text { (Family) }\end{array}$ & Local name & $\begin{array}{l}\text { Mode of } \\
\text { administration }\end{array}$ & $\begin{array}{l}\text { Route of } \\
\text { administration }\end{array}$ & Tribal Area & References \\
\hline 135 & $\begin{array}{l}\text { Clerodendrum } \\
\text { infortunatum L. } \\
\text { (Verbenaceae) }\end{array}$ & $\begin{array}{l}\text { Peruku } \\
\text { perukila }\end{array}$ & $\begin{array}{l}\text { Tender Leaves } \\
\text { crushed with } \\
\text { Lime }\left(\mathrm{Ca}(\mathrm{OH})_{2}\right)\end{array}$ & $\mathrm{T}$ & Attappady, Kerala & 21 \\
\hline 136 & $\begin{array}{l}\text { Clerodendrum } \\
\text { paniculatum } \mathrm{L} . \\
\text { (Verbenaceae) }\end{array}$ & $\begin{array}{l}\text { Tang-vong } \\
(\mathrm{Ncb})\end{array}$ & Paste & - & - & $8(375)$ \\
\hline 137 & $\begin{array}{l}\text { Clerodendrum serratum } \\
\text { (L.) Moon. } \\
\text { (Verbenaceae) }\end{array}$ & $\begin{array}{l}\text { Sarom-lutur, } \\
\text { Bhetkona } \\
\text { (Snt); Nekti } \\
\text { (Paniyan) }\end{array}$ & Paste & - & $\begin{array}{l}\text { Santhal Pargana, } \\
\text { Bihar }\end{array}$ & $8(272), 14(28)$ \\
\hline 138 & $\begin{array}{l}\text { Clerodendrum viscosum } \\
\text { Vent. } \\
\text { (Verbenaceae) }\end{array}$ & $\begin{array}{l}\text { Bhandirah } \\
\text { (S); } \\
\text { Tinabharmi, } \\
\text { Bhutes (H), } \\
\text { Barni (Snt) }\end{array}$ & Paste & - & $\begin{array}{l}\text { Santhal Pargana, } \\
\text { Bihar }\end{array}$ & $10(457), 14(29)$ \\
\hline 139 & $\begin{array}{l}\text { Clitoria ternatea Linn. } \\
\text { (Fabaceae) }\end{array}$ & $\begin{array}{l}\text { Butterfly } \\
\text { flower }\end{array}$ & - & - & $\begin{array}{l}\text { Bilaspur, } \\
\text { Chhattisgarh }\end{array}$ & 27 \\
\hline 140 & $\begin{array}{l}\text { Cocculus hirsutus } \\
\text { (Menispermaceae) }\end{array}$ & Hulhul & Paste & - & - & $9(387), 16(315)$ \\
\hline 141 & $\begin{array}{l}\text { Colebrookea } \\
\text { oppositaefolia } \mathrm{Sm} . \\
\text { (Lamiaceae) }\end{array}$ & $\begin{array}{l}\text { Tile, Pulhadi } \\
\text { mandardoo } \\
(\mathrm{Phr}) ; \text { Binda, } \\
\text { pansra }(\mathrm{H})\end{array}$ & Paste & - & $\begin{array}{l}\text { Santhal Pargana, } \\
\text { Bihar } \\
\text { Uttarakhand }\end{array}$ & $\begin{array}{l}\text { 8(423), 11(388), 12(178), } \\
14(29), 15(380)\end{array}$ \\
\hline 142 & $\begin{array}{l}\text { Colocasia esculenta (L.) } \\
\text { Schott (Araceae) }\end{array}$ & Alu & - & - & $\begin{array}{l}\text { Washim, } \\
\text { Maharashtra }\end{array}$ & 24 \\
\hline 143 & $\begin{array}{l}\text { Combretum } \\
\text { flagrocarpum C.B. } \\
\text { Clark (Combretaceae) }\end{array}$ & Leihrui-sen & Juice & $\mathrm{T}$ & Lunglei, Mizoram & $\begin{array}{l}28 \\
8(439)\end{array}$ \\
\hline 144 & $\begin{array}{l}\text { Combretum ghasalense } \\
\text { Engl. \& Diels } \\
\text { (Combretaceae) }\end{array}$ & Gujapilu & Powder & $\mathrm{T}$ & $\begin{array}{l}\text { Dogonland, Mali, } \\
\text { West Africa }\end{array}$ & 34 \\
\hline 145 & $\begin{array}{l}\text { Combretum glutinosum } \\
\text { Perr. ex DC. } \\
\text { (Combretaceae) }\end{array}$ & Bannakile & Powder & $\mathrm{T}$ & $\begin{array}{l}\text { Dogonland, Mali, } \\
\text { West Africa }\end{array}$ & 34 \\
\hline 146 & $\begin{array}{l}\text { Combretummolle R.Br. } \\
\text { ex G. Don. } \\
\text { (Combretaceae) }\end{array}$ & Mlamweusi & Decoction & $\mathrm{O}$ & $\begin{array}{l}\text { Kimboza forest, } \\
\text { Tanzania }\end{array}$ & 32 \\
\hline 147 & $\begin{array}{l}\text { Combretum roxburghii } \\
\text { Spreng. } \\
\text { (Combretaceae) }\end{array}$ & $\begin{array}{l}\text { Aten, Atin } \\
\text { (Snt) }\end{array}$ & Paste & - & $\begin{array}{l}\text { Santhal Pargana, } \\
\text { Bihar }\end{array}$ & $14(29)$ \\
\hline 148 & $\begin{array}{l}\text { Commelina nudiflora } \\
\text { Linn. } \\
\text { (Commelinaceae) }\end{array}$ & $\begin{array}{l}\text { Kanshura (H), } \\
\text { Katsapriya (S) }\end{array}$ & Poultice & $\mathrm{T}$ & - & $11(126)$ \\
\hline 149 & $\begin{array}{l}\text { Commiphora caudata } \\
\text { (Wight \& Arn.) Engl. } \\
\text { (Burseraceae) }\end{array}$ & Kiluvai & Juice & $\mathrm{T}$ & $\begin{array}{l}\text { Kuruma tribes, } \\
\text { Wayanadu, Kerela }\end{array}$ & 33 \\
\hline 150 & $\begin{array}{l}\text { Corchorus depressus } \\
\text { Stocks } \\
\text { (Tiliaceae) }\end{array}$ & - & - & - & - & $11(475)$ \\
\hline 151 & $\begin{array}{l}\text { Cordia dichotoma } \\
\text { Forst.f. } \\
\text { (Boraginaceae) }\end{array}$ & $\begin{array}{l}\text { Shleshmataka } \\
\text { (S), Lasora }\end{array}$ & - & - & Uttarakhand & $9(147), 15(324)$ \\
\hline 152 & $\begin{array}{l}\text { Cordia macleodii Hook. } \\
\text { (Boraginaceae) }\end{array}$ & Pinaki & - & - & $\begin{array}{l}\text { Sohela block, } \\
\text { Western Odisha }\end{array}$ & $17,18,44$ \\
\hline
\end{tabular}




\begin{tabular}{|c|c|c|c|c|c|c|}
\hline S.No. & $\begin{array}{l}\text { Botanical Name } \\
\text { (Family) }\end{array}$ & Local name & $\begin{array}{l}\text { Mode of } \\
\text { administration }\end{array}$ & $\begin{array}{l}\text { Route of } \\
\text { administration }\end{array}$ & Tribal Area & References \\
\hline 153 & $\begin{array}{l}\text { Coscinium fenestratum } \\
\text { (Gaertn.) Colebr. } \\
\text { (Menispermaceae) }\end{array}$ & $\begin{array}{l}\text { Jhar-i-haldi } \\
(\mathrm{H}) \text {; } \\
\text { Daruharidra } \\
\text { (S) }\end{array}$ & Decoction & $\mathrm{T}$ & - & 10(478), 11(171), 12(184) \\
\hline \multirow[t]{2}{*}{154} & $\begin{array}{l}\text { Costus speciosus } \\
\text { (Koen.) Sm. } \\
\text { (Costaceae) }\end{array}$ & Keu kand & - & - & $\begin{array}{l}\text { Bilaspur, } \\
\text { Chhattisgarh }\end{array}$ & 27 \\
\hline & & $\begin{array}{l}\text { Kostak- } \\
\text { kilangu }\end{array}$ & Juice & $\mathrm{T}$ & $\begin{array}{l}\text { Tirunelveli hills, } \\
\text { southern India }\end{array}$ & 22 \\
\hline 155 & $\begin{array}{l}\text { Cousinia thomsonii } \\
\text { C.B.Clarke (Asteraceae) }\end{array}$ & Megthan & - & - & - & $8(92)$ \\
\hline 156 & $\begin{array}{l}\text { Crassocephalum } \\
\text { crepidioides (Benth.) } \\
\text { S. Moore } \\
\text { (Asteraceae) }\end{array}$ & Ebolo & $\begin{array}{l}\text { Chopped leaves } \\
\text { are applied }\end{array}$ & $\mathrm{T}$ & South-west Nigeria & $\begin{array}{l}23 \\
8(260)\end{array}$ \\
\hline 157 & $\begin{array}{l}\text { Cremanthodium ellisii } \\
\text { (Hook) Kitam } \\
\text { (Asteraceae) }\end{array}$ & Phunchuk & - & - & - & $8(92)$ \\
\hline 158 & $\begin{array}{l}\text { Crotalaria spectabilis } \\
\text { Roth. } \\
\text { (Fabaceae) }\end{array}$ & Nirmisi & Juice & $\mathrm{T}$ & Bhadrak, Odisha & $\begin{array}{l}37 \\
7(499)\end{array}$ \\
\hline 159 & $\begin{array}{l}\text { Crotalaria verrucosa } \\
\text { Linn. } \\
\text { (Fabaceae) }\end{array}$ & $\begin{array}{l}\text { Shanapushpi } \\
\text { (S) }\end{array}$ & Paste & - & - & $16(319)$ \\
\hline 160 & $\begin{array}{l}\text { Croton roxburghii } \\
\text { Balak. } \\
\text { Euphorbiaceae }\end{array}$ & $\begin{array}{l}\text { Kuti } \\
\text { (Mundari) }\end{array}$ & - & - & - & $10(495)$ \\
\hline 161 & $\begin{array}{l}\text { Cyathea albo-setacea } \\
\text { (Bedd.) Copel } \\
\text { (Cyatheaceae) }\end{array}$ & - & Pounded & - & - & $8(375)$ \\
\hline 162 & $\begin{array}{l}\text { Cyathea spinulosa Wall. } \\
\text { ex Hook. } \\
\text { (Cyatheaceae) }\end{array}$ & - & Pounded & - & - & $8(375)$ \\
\hline 163 & $\begin{array}{l}\text { Cyathula prostrata }(\mathrm{L} .) \\
\text { B1. } \\
\text { (Amaranthaceae) }\end{array}$ & $\begin{array}{l}\text { Raktapamarga } \\
\text { (S); Devil's } \\
\text { grass }\end{array}$ & Juice & - & North East India & $7(583), 12(200)$ \\
\hline \multirow[t]{2}{*}{164} & $\begin{array}{l}\text { Cynodon dactylon Pers. } \\
\text { (Poaceae) }\end{array}$ & Phaitualhlo & Juice & $\mathrm{T}$ & Lunglei, Mizoram & 28 \\
\hline & & Arugampillu & Paste & $\mathrm{T}$ & $\begin{array}{l}\text { Paniya tribes, } \\
\text { Nilgiri, Tamil } \\
\text { Nadu }\end{array}$ & 45 \\
\hline 165 & $\begin{array}{l}\text { Cyperus rotandus L. } \\
\text { (Cyperaceae) }\end{array}$ & Garika & - & $\mathrm{T}$ & $\begin{array}{l}\text { Thadvai Mandal, } \\
\text { Warangal, A.P. }\end{array}$ & 46 \\
\hline 166 & $\begin{array}{l}\text { Daemia extensa } \mathrm{R} . \mathrm{Br} . \\
\text { (Asclepiadaceae) }\end{array}$ & $\begin{array}{l}\text { Velliparuthi } \\
\text { (Ml) }\end{array}$ & Juice with honey & - & - & $16(321)$ \\
\hline 167 & $\begin{array}{l}\text { Datura metel Linn. } \\
\text { (Solanaceae) }\end{array}$ & Dhattura (S) & - & - & $\begin{array}{l}\text { Uttarakhand; } \\
\text { Nagpur and } \\
\text { Wardha }\end{array}$ & $\begin{array}{l}15(331) \\
19(38)\end{array}$ \\
\hline \multirow[t]{2}{*}{168} & $\begin{array}{l}\text { Datura stramonium L. } \\
\text { (Solanaceae) }\end{array}$ & - & latex & $\mathrm{T}$ & $\begin{array}{l}\text { Khargone, M.P.; } \\
\text { Dharmapuri, Tamil } \\
\text { Nadu; Uttarakhand }\end{array}$ & $\begin{array}{l}7(395), 15(331), 16(314), \\
30\end{array}$ \\
\hline & & Apikan & Crushed leaves & $\mathrm{T}$ & South-west Nigeria & 23 \\
\hline
\end{tabular}




\begin{tabular}{|c|c|c|c|c|c|c|}
\hline S.No. & $\begin{array}{l}\text { Botanical Name } \\
\text { (Family) }\end{array}$ & Local name & $\begin{array}{l}\text { Mode of } \\
\text { administration }\end{array}$ & $\begin{array}{l}\text { Route of } \\
\text { administration }\end{array}$ & Tribal Area & References \\
\hline 169 & $\begin{array}{l}\text { Delonix regia Raf. } \\
\text { (Fabaceae) }\end{array}$ & Krishnochura & $\begin{array}{l}\text { Leaves are } \\
\text { crushed }\end{array}$ & $\mathrm{T}$ & Tezpur, Assam & 31 \\
\hline 170 & $\begin{array}{l}\text { Dendrophthoe falcata } \\
\text { (L.f) Etting. } \\
\text { (Loranthaceae) }\end{array}$ & $\begin{array}{l}\text { Ottunichedi / } \\
\text { Pulluruvi }\end{array}$ & Paste & $\mathrm{T}$ & $\begin{array}{l}\text { Tirunelveli hills, } \\
\text { southern India }\end{array}$ & 22 \\
\hline 171 & $\begin{array}{l}\text { Desmodium gangeticum } \\
\text { DC. } \\
\text { (Fabaceae) }\end{array}$ & Shalaparni(S) & Paste & - & - & $16(307)$ \\
\hline 172 & $\begin{array}{l}\text { Desmodium pulchellum } \\
\text { (L.) Benth. } \\
\text { (Fabaceae) }\end{array}$ & $\begin{array}{l}\text { Salange chedy } \\
\text { (Mlb) }\end{array}$ & Paste & $\mathrm{T}$ & Koraput, Odisha & $7(473), 8(260), 9(259)$ \\
\hline 173 & $\begin{array}{l}\text { Desmodium triflorum } \\
\text { (L.)DC. } \\
\text { (Fabaceae) }\end{array}$ & $\begin{array}{l}\text { Tripadi (S); } \\
\text { Kudaliya (H); } \\
\text { Janngli methi }\end{array}$ & Juice, Paste & - & Kullu dist. & $7(185), 9(259), 12(216)$ \\
\hline 174 & $\begin{array}{l}\text { Dichrostachys } \\
\text { glomerata Chiov. } \\
\text { (Fabaceae) }\end{array}$ & Kara & $\begin{array}{l}\text { An infusion of } \\
\text { the leaves }\end{array}$ & $\mathrm{T}$ & South-west Nigeria & 23 \\
\hline 175 & $\begin{array}{l}\text { Dimorphocalyx } \\
\text { lawianus (Muell.- } \\
\text { Arg.) Hook. f. } \\
\text { (Euphorbiaceae) }\end{array}$ & $\begin{array}{l}\text { Sirukottai } \\
\text { maram }\end{array}$ & Paste & $\mathrm{T}$ & $\begin{array}{l}\text { Tirunelveli hills, } \\
\text { southern India }\end{array}$ & 22 \\
\hline 176 & $\begin{array}{l}\text { Dioscorea hirtiflora } \\
\text { Benth.and Hook. } \\
\text { (Dioscoreaceae) }\end{array}$ & Isanyinahun & Paste & $\mathrm{T}$ & South-west Nigeria & 23 \\
\hline 177 & $\begin{array}{l}\text { Diospyros canaliculata } \\
\text { De Wild } \\
\text { (Ebenaceae) }\end{array}$ & Orile ijebu & Paste & $\mathrm{T}$ & South-west Nigeria & 23 \\
\hline 178 & $\begin{array}{l}\text { Diospyros malabarica } \\
\text { (Desr.) Kostel } \\
\text { (Ebenaceae) }\end{array}$ & Tinduka (S) & Juice & - & Uttarakhand & $8(423), 15(282), 12(223)$ \\
\hline 179 & $\begin{array}{l}\text { Diotacanthus } \\
\text { albiflorus (Bedd.) } \\
\text { Benth. } \\
\text { (Acanthaceae) }\end{array}$ & Kodi urinji & Paste & $\mathrm{T}$ & $\begin{array}{l}\text { Tirunelveli hills, } \\
\text { southern India }\end{array}$ & 22 \\
\hline 180 & $\begin{array}{l}\text { Dissotis rotundifolia } \\
\text { (Sm.) Triana. } \\
\text { (Melastomataceae) }\end{array}$ & Kinzasu & $\begin{array}{l}\text { Crushed or } \\
\text { pounded }\end{array}$ & $\mathrm{T}$ & $\begin{array}{l}\text { Kimboza forest, } \\
\text { Tanzania }\end{array}$ & 32 \\
\hline 181 & $\begin{array}{l}\text { Drymaria cordata L. } \\
\text { (Caryophyllaceae) }\end{array}$ & Lai Jabor & $\begin{array}{l}\text { Leaves are } \\
\text { crushed with } \\
\text { spit }\end{array}$ & $\mathrm{T}$ & $\begin{array}{l}\text { Tezpur, Assam; } \\
\text { Rajbanshis, Assam }\end{array}$ & $7(609), 8(260), 31$ \\
\hline 182 & $\begin{array}{l}\text { Echinops cornigerus } \\
\text { DC. } \\
\text { (Asteraceae) }\end{array}$ & Akjema & Paste & - & - & $8(92)$ \\
\hline 183 & $\begin{array}{l}\text { Eclipta alba Hassk. } \\
\text { (Asteraceae) }\end{array}$ & Bhringraj & Juice & - & $\begin{array}{l}\text { Bilaspur, } \\
\text { Chhattisgarh; } \\
\text { Bhadrak and } \\
\text { Phulbani, Odisha }\end{array}$ & $\begin{array}{l}7(515), 7(499), 9(259), 11 \\
(339), 15(265), 16(301), \\
27\end{array}$ \\
\hline 184 & $\begin{array}{l}\text { Eclipta prostrata L. } \\
\text { (Asteraceae) }\end{array}$ & Bhingraaj & $\begin{array}{l}\text { Pounded and } \\
\text { paste }\end{array}$ & $\mathrm{T}$ & Bastar, M.P. & $17(108)$ \\
\hline 185 & $\begin{array}{l}\text { Elytraria acaulis (L.f.) } \\
\text { Lindau } \\
\text { (Acanthaceae) }\end{array}$ & $\begin{array}{l}\text { Sahastra } \\
\text { musari }\end{array}$ & Paste & $\mathrm{T}$ & Banda dist., U.P. & $20(104)$ \\
\hline
\end{tabular}




\begin{tabular}{|c|c|c|c|c|c|c|}
\hline S.No. & $\begin{array}{l}\text { Botanical Name } \\
\text { (Family) }\end{array}$ & Local name & $\begin{array}{l}\text { Mode of } \\
\text { administration }\end{array}$ & $\begin{array}{l}\text { Route of } \\
\text { administration }\end{array}$ & Tribal Area & References \\
\hline 186 & $\begin{array}{l}\text { Emilia sonchifolia (L.) } \\
\text { DC. } \\
\text { (Asteraceae) }\end{array}$ & $\begin{array}{l}\text { Elichevianver } \\
\mathrm{u}\end{array}$ & Paste & $\mathrm{T}$ & Attappady, Kerala & $\begin{array}{l}8(260), 12(233), 16(320), \\
21\end{array}$ \\
\hline 187 & $\begin{array}{l}\text { Ermania lanuginosa } \\
\text { (Hk.f. \& T.) O. E. } \\
\text { Schulz } \\
\text { (Brassicaceae) }\end{array}$ & - & Infusion & - & - & 7 \\
\hline 188 & $\begin{array}{l}\text { Erythrina indica Lam. } \\
\text { (Fabaceae) }\end{array}$ & $\begin{array}{l}\text { Poa ban; } \\
\text { Gadela }\end{array}$ & Paste & - & - & $9(243), 9(259)$ \\
\hline 189 & $\begin{array}{l}\text { Erythrina varaegata } \mathrm{L} . \\
\text { (Fabaceae) }\end{array}$ & Pangara & - & - & $\begin{array}{l}\text { Washim, } \\
\text { Maharashtra }\end{array}$ & 24 \\
\hline 190 & $\begin{array}{l}\text { Eupatorium } \\
\text { adenophorum Spreng. } \\
\text { (Asteraceae) }\end{array}$ & $\begin{array}{l}\text { Banamara, } \\
\text { Kalojhar, } \\
\text { Muk; } \\
\text { Shamathoru } \\
\text { (Trib) }\end{array}$ & Juice & - & - & $8(332), 8(268)$ \\
\hline 191 & $\begin{array}{l}\text { Eupatorium cannabinum } \\
\text { Linn. } \\
\text { (Asteraceae) }\end{array}$ & $\begin{array}{l}\text { Hemp } \\
\text { agrimony, } \\
\text { Holy rope (E) }\end{array}$ & Crushed & - & Assam & 7(599), 11(344) \\
\hline \multirow[t]{4}{*}{192} & $\begin{array}{l}\text { Eupatorium odoratum } \\
\text { Linn. } \\
\text { (Asteraceae) }\end{array}$ & Aana vanthan & Paste & $\mathrm{T}$ & $\begin{array}{l}\text { Tirunelveli hills, } \\
\text { southern India }\end{array}$ & $\begin{array}{l}22 \\
16(309)\end{array}$ \\
\hline & & Gondri & Juice & $\mathrm{T}$ & Koraput, Odisha & $18(125)$ \\
\hline & & Jarmani bon & Paste & $\mathrm{T}$ & Tezpur, Assam & 31 \\
\hline & & Tlangsam & Crushed & $\mathrm{T}$ & Lungsen, Mizoram & 28 \\
\hline 193 & $\begin{array}{l}\text { Eupatorium triplinerve } \\
\text { Vahl. } \\
\text { (Asteraceae) }\end{array}$ & $\begin{array}{l}\text { Ayaparnah } \\
\text { (S); Ayapana } \\
(\mathrm{H})\end{array}$ & Juice & - & - & $12(241)$ \\
\hline 194 & $\begin{array}{l}\text { Euphorbia atoto Forst.f. } \\
\text { (Euphorbiaceae) }\end{array}$ & Mupet (Ncb) & Paste & - & - & $8(375)$ \\
\hline 195 & $\begin{array}{l}\text { Euphorbia } \\
\text { heterophylla L. } \\
\text { (Euphorbiaceae) }\end{array}$ & Oro & $\begin{array}{l}\text { Leaf ash in a } \\
\text { cloth is dipped } \\
\text { in the oil }\end{array}$ & $\mathrm{T}$ & South-west Nigeria & 23 \\
\hline \multirow[t]{2}{*}{196} & $\begin{array}{l}\text { Euphorbia hirta L. } \\
\text { (Euphorbiaceae) }\end{array}$ & $\begin{array}{l}\text { Amampatchai } \\
\text { arisi }\end{array}$ & Paste & $\mathrm{T}$ & $\begin{array}{l}\text { Kuruma tribes, } \\
\text { Wayanadu, kerela } \\
\text { Bhadrak, Odisha }\end{array}$ & $7(499), 11(202), 33$ \\
\hline & & Dudhi & - & - & $\begin{array}{l}\text { Bilaspur, } \\
\text { Chhattisgarh }\end{array}$ & 27 \\
\hline 197 & $\begin{array}{l}\text { Euphorbia nyikae Pax } \\
\text { ex Engl. } \\
\text { (Euphorbiaceae) }\end{array}$ & Mngwede & $\begin{array}{l}\text { Crushed and } \\
\text { pounded }\end{array}$ & $\mathrm{T}$ & $\begin{array}{l}\text { Kimboza forest, } \\
\text { Tanzania }\end{array}$ & 32 \\
\hline 198 & $\begin{array}{l}\text { Euphorbia poissonii } \\
\text { L. } \\
\text { (Euphorbiaceae) }\end{array}$ & Oro-adete & $\begin{array}{l}\text { Fresh leaves are } \\
\text { applied }\end{array}$ & $\mathrm{T}$ & South-west Nigeria & 23 \\
\hline
\end{tabular}




\begin{tabular}{|c|c|c|c|c|c|c|}
\hline S.No. & $\begin{array}{l}\text { Botanical Name } \\
\text { (Family) }\end{array}$ & Local name & $\begin{array}{l}\text { Mode of } \\
\text { administration }\end{array}$ & $\begin{array}{l}\text { Route of } \\
\text { administration }\end{array}$ & Tribal Area & References \\
\hline 199 & $\begin{array}{l}\text { Euphorbia thymifolia } \\
\text { Linn. } \\
\text { (Euphorbiaceae) }\end{array}$ & $\begin{array}{l}\text { Choti dudhi, } \\
\text { dudhi }(\mathrm{H})\end{array}$ & Paste & - & - & $9(259), 11(206)$ \\
\hline 200 & $\begin{array}{l}\text { Evolvulus alsinoides L. } \\
\text { (Convulvulaceae) }\end{array}$ & Khurnighas & Juice & $\mathrm{T}$ & North Gujarat & $20(111)$ \\
\hline 201 & $\begin{array}{l}\text { Excoecaria agallocha } \\
\text { Linn. } \\
\text { (Euphorbiaceae) }\end{array}$ & Agaru & Decoction & - & - & $11(208)$ \\
\hline \multirow[t]{2}{*}{202} & $\begin{array}{l}\text { Ficus asperifolia Hook. } \\
\text { ex Steud. } \\
\text { (Moraceae) }\end{array}$ & Mkoya & $\begin{array}{l}\text { Crushed or } \\
\text { pounded }\end{array}$ & $\mathrm{T}$ & $\begin{array}{l}\text { Kimboza forest, } \\
\text { Tanzania }\end{array}$ & 32 \\
\hline & & Eripin & Paste & $\mathrm{T}$ & South-west Nigeria & 23 \\
\hline 203 & $\begin{array}{l}\text { Ficus benjamina L. } \\
\text { (Moraceae) }\end{array}$ & $\begin{array}{l}\text { Konda goluga } \\
\text { (Tel) }\end{array}$ & - & - & - & $12(253)$ \\
\hline \multirow[t]{4}{*}{204} & $\begin{array}{l}\text { Ficus benghalensis L. } \\
\text { (Moraceae) }\end{array}$ & Aalamaram & $\begin{array}{l}\text { Leaf powder is } \\
\text { mixed with } \\
\text { coconut oil }\end{array}$ & $\mathrm{T}$ & $\begin{array}{l}\text { Tirunelveli hills, } \\
\text { southern India }\end{array}$ & 22 \\
\hline & & bargad & - & - & $\begin{array}{l}\text { Bilaspur, } \\
\text { Chhattisgarh }\end{array}$ & 27 \\
\hline & & $\begin{array}{l}\text { Madar/ } \\
\text { Marmada }\end{array}$ & - & $\mathrm{T}$ & $\begin{array}{l}\text { Dantewada, } \\
\text { Chhattisgarh }\end{array}$ & 35 \\
\hline & & - & Powder & $\mathrm{T}$ & Khargone, M.P. & 30 \\
\hline 205 & $\begin{array}{l}\text { Ficus racemosa Linn. } \\
\text { (Moraceae) }\end{array}$ & Udumbara(S) & Paste & - & - & $16(317)$ \\
\hline 206 & $\begin{array}{l}\text { Ficus retusa auct. non } \\
\text { (Moraceae) }\end{array}$ & $\begin{array}{l}\text { Plaksah(S); } \\
\text { Chilkan(H) }\end{array}$ & Decoction & $\mathrm{T}$ & - & $12(256)$ \\
\hline 207 & $\begin{array}{l}\text { Flabellaria paniculata } \\
\text { Cav. } \\
\text { (Malpighiaceae) }\end{array}$ & Lagbolagbo & $\begin{array}{l}\text { Decoction of the } \\
\text { leaf }\end{array}$ & $\mathrm{T}$ & South-west Nigeria & 23 \\
\hline 208 & $\begin{array}{l}\text { Flacourtia indica } \\
\text { (Burm.f.) Merill. } \\
\text { (Flacourtiaceae) }\end{array}$ & $\begin{array}{l}\text { Swadukantaka } \\
\text {, Vikankata } \\
\text { (S), Bilangara } \\
\text { (H) }\end{array}$ & Paste & - & Uttarakhand & $15(94), 16(318)$ \\
\hline 209 & $\begin{array}{l}\text { Flueggea leucopyrus } \\
\text { Willd (Phyllanthaceae) }\end{array}$ & $\begin{array}{l}\text { Svetakamboja } \\
\text {, Bhuriphala } \\
\text { (S) }\end{array}$ & Juice & - & - & $11(209)$ \\
\hline \multirow[t]{2}{*}{210} & $\begin{array}{l}\text { Fluggea virosa Willd. } \\
\text { (Euphorbiaceae) }\end{array}$ & Mkalananga & Infusion & $\mathrm{O}$ & $\begin{array}{l}\text { Kimboza forest, } \\
\text { Tanzania }\end{array}$ & 32 \\
\hline & & Patali (S) & $\begin{array}{l}\text { Leaves juice/ } \\
\text { paste }\end{array}$ & - & - & $11(210)$ \\
\hline 211 & $\begin{array}{l}\text { Garcinia gummigatta } \\
\text { (L.) N. Robson. } \\
\text { (Clusiaceae) }\end{array}$ & $\begin{array}{l}\text { Vrksamla(S); } \\
\text { Bilatti amli } \\
(\mathrm{H})\end{array}$ & - & - & - & $12(263)$ \\
\hline
\end{tabular}




\begin{tabular}{|c|c|c|c|c|c|c|}
\hline S.No. & $\begin{array}{l}\text { Botanical Name } \\
\text { (Family) }\end{array}$ & Local name & $\begin{array}{l}\text { Mode of } \\
\text { administration }\end{array}$ & $\begin{array}{l}\text { Route of } \\
\text { administration }\end{array}$ & Tribal Area & References \\
\hline 212 & $\begin{array}{l}\text { Gardenia latifolia } \\
\text { (Rubiaceae) }\end{array}$ & Pedda karinga & - & - & $\begin{array}{l}\text { Nalgonda } \\
\text { \&Warangal, A. P. }\end{array}$ & 43 \\
\hline 213 & $\begin{array}{l}\text { Gelsemium elegeans } \\
\text { Benth. } \\
\text { (Loganiaceae) }\end{array}$ & Hnam-tur & - & $\mathrm{T}$ & $\begin{array}{l}\text { Haululong, } \\
\text { Mizoram }\end{array}$ & 28 \\
\hline 214 & $\begin{array}{l}\text { Gentianella } \\
\text { moorcroftiana Wallich } \\
\text { ex Don } \\
\text { (Gentianaceae) }\end{array}$ & Chhukmu & Paste & - & - & $8(92)$ \\
\hline 215 & $\begin{array}{l}\text { Gloroisa superba L. } \\
\text { (Liliaceae) }\end{array}$ & Kal-lawi & - & - & $\begin{array}{l}\text { Washim, } \\
\text { Maharashtra }\end{array}$ & 24 \\
\hline 216 & $\begin{array}{l}\text { Glycosmis arborea } \\
\text { (Roxb.) DC. } \\
\text { (Rutaceae) }\end{array}$ & $\begin{array}{l}\text { Girgiti, Potali } \\
\text { (H); Kupiluh, } \\
\text { Asvasakhtah } \\
\text { (S) }\end{array}$ & Pounded & - & - & $8(423), 12(270)$ \\
\hline 217 & $\begin{array}{l}\text { Gmelina arborea Roxb. } \\
\text { (Verbenaceae) }\end{array}$ & $\begin{array}{l}\text { Gambhari (S), } \\
\text { Kumhar }\end{array}$ & - & - & Uttarakhand & $9(147), 15(362)$ \\
\hline 218 & $\begin{array}{l}\text { Grangea maderaspatana } \\
\text { (Linn.)Poir. (Asteraceae) }\end{array}$ & $\begin{array}{l}\text { Mukhataru, } \\
\text { Mustaru (H); } \\
\text { Badagudari }\end{array}$ & Crushed & $\mathrm{T}$ & Phulbani, Odisha & $7(515), 11(347)$ \\
\hline 219 & $\begin{array}{l}\text { Grewia obtusa Wall. ex } \\
\text { Gamble (Tiliaceae) }\end{array}$ & $\begin{array}{l}\text { Kule taro } \\
\text { (Snt) }\end{array}$ & Paste & - & $\begin{array}{l}\text { Santhal Pargana, } \\
\text { Bihar }\end{array}$ & $14(34)$ \\
\hline 220 & $\begin{array}{l}\text { Grewia umbellata Roxb. } \\
\text { (Tiliaceae) }\end{array}$ & $\begin{array}{l}\text { Akar } \\
\text { chenderai } \\
(\mathrm{Ml})\end{array}$ & - & - & - & $11(481)$ \\
\hline 221 & $\begin{array}{l}\text { Gymnema sylvestre } \\
\text { (Retz.) R. Br. ex } \\
\text { Schult } \\
\text { (Asclepiadaceae) }\end{array}$ & $\begin{array}{l}\text { Chakkarakkol } \\
\mathrm{i}\end{array}$ & Paste & $\mathrm{T}$ & $\begin{array}{l}\text { Mulla Kuruma } \\
\text { tribes, Wayanadu, } \\
\text { kerela }\end{array}$ & 42 \\
\hline 222 & $\begin{array}{l}\text { Gynandropsis gynandra } \\
\text { Merrill. } \\
\text { (Capparidaceae) }\end{array}$ & Ajagandha (S) & Crushed & - & - & $11(275)$ \\
\hline 223 & $\begin{array}{l}\text { Haldina cordifolia } \\
\text { (Roxb.) Ridsdale } \\
\text { (Rubiaceae) }\end{array}$ & $\begin{array}{l}\text { Haldu, } \\
\text { Halsava, } \\
\text { Hardu (H); } \\
\text { Nondong, } \\
\text { Haridru (S) }\end{array}$ & $\begin{array}{l}\text { Paste of leaves } \\
\text { with Sida } \\
\text { cordata leaves } \\
\text { and Sida acuta } \\
\text { leaves }\end{array}$ & - & $\begin{array}{l}\text { Koraput and } \\
\text { Phulbani, Odisha; } \\
\text { Uttarakhand }\end{array}$ & $\begin{array}{l}7(515), 7(473), 13(279) \\
15(253)\end{array}$ \\
\hline 224 & $\begin{array}{l}\text { Hedyotis herbacea L. } \\
\text { (Rubiaceae) }\end{array}$ & $\begin{array}{l}\text { Chayaparpatik } \\
\text { a(S); Paper } \\
\text { bhed(H) }\end{array}$ & Paste & - & - & $13(281)$ \\
\hline 225 & $\begin{array}{l}\text { Hedyotis scandens Roxb. } \\
\text { (Rubiaceae) }\end{array}$ & Baina Haniktu & Paste & $\mathrm{T}$ & Assam & $20(124)$ \\
\hline 226 & $\begin{array}{l}\text { Helianthus annus Linn. } \\
\text { (Asteraceae) }\end{array}$ & $\begin{array}{l}\text { Adityabhakta } \\
\text { (S); } \\
\text { Sunflower }\end{array}$ & - & - & $\begin{array}{l}\text { Nilgiri dist., Tamil } \\
\text { Nadu; Lucknow }\end{array}$ & $7(381), 7(223), 13(282)$ \\
\hline \multirow[t]{2}{*}{227} & $\begin{array}{l}\text { Heliotropium indicum L. } \\
\text { (Boraginaceae) }\end{array}$ & $\begin{array}{l}\text { Indian } \\
\text { Turnsole }\end{array}$ & - & - & $\begin{array}{l}\text { Bilaspur, } \\
\text { Chhattisgarh }\end{array}$ & 27 \\
\hline & & $\begin{array}{l}\text { Hatisar, } \\
\text { Bhurundi (S) }\end{array}$ & - & - & $\begin{array}{l}\text { Mayurbhanj, } \\
\text { Odisha; Thane, } \\
\text { Maharashtra }\end{array}$ & $\begin{array}{l}7(265), 13(283), 16(305), \\
37\end{array}$ \\
\hline 228 & $\begin{array}{l}\text { Heliotropium strigosum } \\
\text { Willd. } \\
\text { (Boraginaceae) }\end{array}$ & $\begin{array}{l}\text { Hasthishundi } \\
\text { (S) }\end{array}$ & Juice & - & Uttarakhannd & $15(321)$ \\
\hline
\end{tabular}




\begin{tabular}{|c|c|c|c|c|c|c|}
\hline S.No. & $\begin{array}{l}\text { Botanical Name } \\
\text { (Family) }\end{array}$ & Local name & $\begin{array}{l}\text { Mode of } \\
\text { administration }\end{array}$ & $\begin{array}{l}\text { Route of } \\
\text { administration }\end{array}$ & Tribal Area & References \\
\hline 229 & $\begin{array}{l}\text { Hemidesmus } \\
\text { indicus (L.) R. Brown } \\
\text { (Asclepiadaceae) }\end{array}$ & Suganti Jad & - & $\mathrm{T}$ & $\begin{array}{l}\text { Dantewada, } \\
\text { Chhattisgarh }\end{array}$ & 35 \\
\hline \multirow[t]{2}{*}{230} & Hemigraphis colorata & Murikootti & Paste & $\mathrm{T}$ & Attappady, Kerala & 21 \\
\hline & & Murikoodi & Juice & $\mathrm{T}$ & $\begin{array}{l}\text { Mulla Kuruma } \\
\text { tribes, Wayanadu, } \\
\text { kerela }\end{array}$ & 42,47 \\
\hline 231 & $\begin{array}{l}\text { Hernandia peltata } \\
\text { Meissn. } \\
\text { (Hernandiaceae) }\end{array}$ & $\begin{array}{l}\text { Talo (Andm) } \\
\text { Minhont } \\
(\mathrm{Ncb})\end{array}$ & Paste & - & - & $8(375)$ \\
\hline 232 & $\begin{array}{l}\text { Hibiscus ficulneus L. } \\
\text { (Malvaceae) }\end{array}$ & Lal ambary & - & $\mathrm{O}$ & - & $9(147)$ \\
\hline 233 & $\begin{array}{l}\text { Hibiscus pandulaeformis } \\
\text { Burm. } \\
\text { (Malvaceae) }\end{array}$ & Kochli & Paste & $\mathrm{T}$ & $\begin{array}{l}\text { Nagpur and } \\
\text { Wardha }\end{array}$ & $19(52)$ \\
\hline 234 & $\begin{array}{l}\text { Hibiscus sabdariffa } \\
\text { Linn. } \\
\text { (Malvaceae) }\end{array}$ & - & Lotion & $\mathrm{T}$ & - & $11(458)$ \\
\hline 235 & $\begin{array}{l}\text { Hibiscus surattensis L. } \\
\text { (Malvaceae) }\end{array}$ & Lumotomoto & $\begin{array}{l}\text { Crushed or } \\
\text { pounded }\end{array}$ & $\mathrm{T}$ & $\begin{array}{l}\text { Kimboza forest, } \\
\text { Tanzania }\end{array}$ & 32 \\
\hline 236 & $\begin{array}{l}\text { Hibiscus tiliaceous L. } \\
\text { (Malvaceae) }\end{array}$ & $\begin{array}{l}\text { Bola, Chelwa } \\
\text { (H) }\end{array}$ & Infusion & - & - & $13(289)$ \\
\hline 237 & $\begin{array}{l}\text { Hippophae salicifolia D. } \\
\text { Don. } \\
\text { (Elaeagnaceae) }\end{array}$ & Amil & Paste & - & - & $16(304)$ \\
\hline 238 & $\begin{array}{l}\text { Hiptage benghalensis } \\
\text { (L.) Kurz. } \\
\text { (Malpighiaceae) }\end{array}$ & Madhavi (S) & - & - & $\begin{array}{l}\text { Dharmapuri, Tamil } \\
\text { Nadu }\end{array}$ & 7(395), 13(290) \\
\hline 239 & $\begin{array}{l}\text { Holarrhena } \\
\text { antidysenterica (Linn.) } \\
\text { Wall. } \\
\text { (Apocynaceae) }\end{array}$ & Kutaja (S) & - & - & Uttarakhand & 14(304), 16(301) \\
\hline 240 & $\begin{array}{l}\text { Hoya parasitica Wall. } \\
\text { (Asclepiadaceae) }\end{array}$ & Lanvush & Paste & - & - & $8(381)$ \\
\hline 241 & $\begin{array}{l}\text { Hydrocotyle } \\
\text { sibthorpioides Lamk. } \\
\text { (Apiaceae) }\end{array}$ & $\begin{array}{l}\text { Khoru } \\
\text { manimuni }\end{array}$ & Leaves paste & $\mathrm{T}$ & Tezpur, Assam & 31 \\
\hline 242 & $\begin{array}{l}\text { Hygrophila salicifolia } \\
\text { (Vahl.) Nees. } \\
\text { (Flacourtiaceae) }\end{array}$ & Jianti (Snt) & Juice & - & $\begin{array}{l}\text { Santhal Pargana, } \\
\text { Bihar }\end{array}$ & $14(34)$ \\
\hline 243 & $\begin{array}{l}\text { Hygrophilla auriculata } \\
\text { (Schumach) Hein } \\
\text { (Acanthaceae) }\end{array}$ & $\begin{array}{l}\text { Kuila khada } \\
\text { (S) }\end{array}$ & - & - & $\begin{array}{l}\text { Bankura, West } \\
\text { Bengal }\end{array}$ & $7(545)$ \\
\hline 244 & $\begin{array}{l}\text { Hyoscymus niger Linn. } \\
\text { (Solanaceae) }\end{array}$ & $\begin{array}{l}\text { Khurasani } \\
\text { yamani (S) }\end{array}$ & - & - & Uttarakhand & $15(332)$ \\
\hline \multirow[t]{2}{*}{245} & $\begin{array}{l}\text { Hyptis suaveolens (L.) } \\
\text { Poit. } \\
\text { (Lamiaceae) }\end{array}$ & Van tulsi & - & - & $\begin{array}{l}\text { Bilaspur, } \\
\text { Chhattisgarh }\end{array}$ & $8(423), 13(303), 27$ \\
\hline & $\begin{array}{l}\text { Hyptis suaveolens (L.) } \\
\text { Poit. } \\
\text { (Lamiaceae) }\end{array}$ & - & Juice & $\mathrm{T}$ & $\begin{array}{l}\text { Dogonland, Mali, } \\
\text { West Africa }\end{array}$ & 34 \\
\hline
\end{tabular}




\begin{tabular}{|c|c|c|c|c|c|c|}
\hline S.No. & $\begin{array}{l}\text { Botanical Name } \\
\text { (Family) }\end{array}$ & Local name & $\begin{array}{l}\text { Mode of } \\
\text { administration }\end{array}$ & $\begin{array}{l}\text { Route of } \\
\text { administration }\end{array}$ & Tribal Area & References \\
\hline 246 & $\begin{array}{l}\text { Ichnocarpus frutescens } \\
\text { (L.) R. Br. } \\
\text { (Lamiaceae) }\end{array}$ & Paravalli & Paste & $\mathrm{T}$ & $\begin{array}{l}\text { Kuruma tribes, } \\
\text { Wayanadu, kerela }\end{array}$ & 33 \\
\hline 247 & $\begin{array}{l}\text { Imperata cylindrical } \\
\text { (Linn.) P. Beauv. } \\
\text { (Poaceae) }\end{array}$ & Darbha gaddi & As bandage & $\mathrm{T}$ & Koraput, Odisha & $18(129)$ \\
\hline 248 & $\begin{array}{l}\text { Indigofera oblongifolia } \\
\text { Forsk. } \\
\text { (Fabaceae) }\end{array}$ & Jheel (Guj) & Ash + ghee & - & - & $16(304)$ \\
\hline 249 & $\begin{array}{l}\text { Indigofera obscura L. } \\
\text { (Fabaceae) }\end{array}$ & Utran & - & - & $\begin{array}{l}\text { Nagpur and } \\
\text { Wardha }\end{array}$ & $19(54)$ \\
\hline 250 & $\begin{array}{l}\text { Inula obtusifolia Kerner } \\
\text { (Asteraceae) }\end{array}$ & Rupmak & Decoction & $\mathrm{O}$ & - & $8(92)$ \\
\hline 251 & $\begin{array}{l}\text { Ipomoea carnea Jacq. } \\
\text { (Convolvulaceae) }\end{array}$ & $\begin{array}{l}\text { Amari; } \\
\text { Behaya }\end{array}$ & - & - & Bhadrak, Odisha & 7(499), 8(112) \\
\hline 252 & $\begin{array}{l}\text { Ipomoea hederifolia L. } \\
\text { (Convolvulaceae) }\end{array}$ & - & Paste & $\mathrm{T}$ & - & $8(118)$ \\
\hline 253 & $\begin{array}{l}\text { Ipomoea reptans Poir. } \\
\text { (Convolvulaceae) }\end{array}$ & Kalambi (S) & Paste & - & - & $16(306)$ \\
\hline 254 & $\begin{array}{l}\text { Jasminum auriculatum } \\
\text { (Oleaceae) }\end{array}$ & Adavi malli & - & - & $\begin{array}{l}\text { Nalgonda \& } \\
\text { Warangal, A. P. }\end{array}$ & 43 \\
\hline 255 & $\begin{array}{l}\text { Jasminum dispermum } \\
\text { Wall. } \\
\text { (Oleaceae) }\end{array}$ & Basilla (Lut) & & - & Uttarakhand & $15(290)$ \\
\hline 256 & $\begin{array}{l}\text { Jasminum multiflorum } \\
\text { (Burm.f.) Andrews } \\
\text { (Oleaceae) }\end{array}$ & Kundah (S) & Dried leaves & - & - & $13(314)$ \\
\hline 257 & $\begin{array}{l}\text { Jasminum pubescens } \\
\text { Willd. } \\
\text { (Oleaceae) }\end{array}$ & Kundphul & Poultice & $\mathrm{T}$ & - & $8(56)$ \\
\hline 258 & $\begin{array}{l}\text { Jasminum sambac (L.) } \\
\text { Ait. } \\
\text { (Oleaceae) }\end{array}$ & Mallika (S) & Poultice & $\mathrm{T}$ & - & $13(314)$ \\
\hline \multirow[t]{6}{*}{259} & $\begin{array}{l}\text { Jatropha curcas L. } \\
\text { (Euphorbiaceae) }\end{array}$ & $\begin{array}{l}\text { Botuje, } \\
\text { Lapalapa }\end{array}$ & Leaf juice & $\mathrm{T}$ & South-west Nigeria & 23 \\
\hline & & $\begin{array}{l}\text { Dhodajji; } \\
\text { Dravanti (S) }\end{array}$ & Juice & $\mathrm{T}$ & Bhadrak, Odisha & $\begin{array}{l}\text { 7(499), 8(253), 11(212), } \\
13(315)\end{array}$ \\
\hline & & Mbono & $\begin{array}{l}\text { Crushed } \\
\text { and pounded }\end{array}$ & $\mathrm{T}$ & $\begin{array}{l}\text { Kimboza forest, } \\
\text { Tanzania }\end{array}$ & 32 \\
\hline & & $\begin{array}{l}\text { Botuje, } \\
\text { Lapalapa }\end{array}$ & Leaf juice & $\mathrm{T}$ & South-west Nigeria & 23 \\
\hline & & $\begin{array}{l}\text { Dhodajji; } \\
\text { Dravanti (S) }\end{array}$ & Juice & $\mathrm{T}$ & Bhadrak, Odisha & $\begin{array}{l}\text { 7(499), 8(253), 11(212), } \\
13(315)\end{array}$ \\
\hline & & Mbono & $\begin{array}{l}\text { Crushed } \\
\text { and pounded }\end{array}$ & $\mathrm{T}$ & $\begin{array}{l}\text { Kimboza forest, } \\
\text { Tanzania }\end{array}$ & 32 \\
\hline \multirow[t]{2}{*}{260} & $\begin{array}{l}\text { Jatropha gossypifolia L. } \\
\text { (Euphorbiaceae) }\end{array}$ & Ramjada & $\begin{array}{l}\text { Dried leaf } \\
\text { powder }\end{array}$ & $\mathrm{T}$ & Kalahandi, Odisha & 29 \\
\hline & & Jatanjot & - & - & Nimar region, M.P. & 36 \\
\hline 261 & $\begin{array}{l}\text { Justicia adhatoda L. } \\
\text { (Acanthaceae) }\end{array}$ & Basang & $\begin{array}{l}\text { Dried leaf } \\
\text { powder }\end{array}$ & $\mathrm{T}$ & Kalahandi, Odisha & 29 \\
\hline
\end{tabular}




\begin{tabular}{lllllll}
\hline S.No. & $\begin{array}{l}\text { Botanical Name } \\
\text { (Family) }\end{array}$ & Local name & $\begin{array}{l}\text { Mode of } \\
\text { administration }\end{array}$ & $\begin{array}{l}\text { Route of } \\
\text { administration }\end{array}$ & Tribal Area & References \\
\hline 262 & $\begin{array}{l}\text { Justicia gendarussa } \\
\text { Burm. }\end{array}$ & $\begin{array}{l}\text { Karunachi } \\
\text { (Trib.) }\end{array}$ & Paste & - & - & $8(268)$ \\
& $\begin{array}{l}\text { Nilinargandi } \\
\text { (H) }\end{array}$ & & & & \\
\end{tabular}

263 Kalanchoe pinnata (Lam.) Pers.

(Crassulaceae)

264 Kalanchoe spathulata

DC.

(Crassulaceae)

265 Kirganelia reticulate Baill (Euphorbiaceae)

266 Lagescea mollis Cav. (Asteraceae)

267 Lantana camara Linn (Verbenaceae)
Runakalli

(Tm),

Asthibhaksha

(S); Chigari

Haiza, Tataru, -

Rugru; Hathi

kane $(\mathrm{N})$

Kambal (Raj.) Juice, Paste, T

Smeldam Powder

(Snt)

Kosia patta Juice

(Snt)

Ghaneri

Leaf juice

Lantana indica Roxb.

(Verbenaceae)

Lawsonia inermis L. (Lythraceae)

Gul sitara

Paste

Mehandi

$$
\text { Lali }
$$

Maruthani

An infusion of

$\mathrm{T}$

the leaves is

used as wash

Leaf powder is

mixed with

coconut oil

Mehndi

270 Leea crispa L.

(Vitaceae)

27

Leea indica (Burm. f.)

Merr.

(Vitaceae)

272 Leptadenia reticulata

(Retz.) Wt. \& Arn

(Asclepiadaceae)

273 Leucas indica Linn.

(Lamiaceae)

274 Limnophila heterophylla Nerugida

(Roxb.) Benth.

(Scrophulariaceae)
Kum-tin-tuai Juice

Kurkurjiwah Paste

(Ncb)

Dudhkadi

Guma (Lut)

Poultice

The plant

leaves are crushed with

coconut oil

Paste
Dharmapuri, Tamil Nadu

7(395), 8(244), 13(322), 16(308)

Madhubani and

7(651), 9(147), 16(311)

Sitamarhi, Bihar

Nagpur and

Wardha; Santhal

Pargana, Bihar

Santhal Pargana, Bihar

Washim,

Maharashtra;

Uttarakhand;

Bhadrak, Odisha;

Dharmapuri, Tamil

Nadu

Bilaspur,

Chhattisgarh

14(37),

$16(310)$

14(34)

7(395), 7(499), 8(439), 8 (260), 8(272), 15(363), 16 (321), 24

South-west Nigeria (307), 27

23

Kancheepuram,

25

Tamil Nadu

Nagpur and

19(56)

Wardha

Washim,

Maharashtra

$8(439)$

$8(375)$

Nagpur and

19(57)

Wardha

Uttarakhand

15(371)

Paniya tribes,

Nilgiri, Tamil

Nadu

Kancheepuram,

25

Tamil Nadu 
Tarun Sharma et.al., Ethnomedicinal Claims on Wound Healing Activity of Certain Leaf Drugs - A Review

\begin{tabular}{|c|c|c|c|c|c|c|}
\hline S.No. & $\begin{array}{l}\text { Botanical Name } \\
\text { (Family) }\end{array}$ & Local name & $\begin{array}{l}\text { Mode of } \\
\text { administration }\end{array}$ & $\begin{array}{l}\text { Route of } \\
\text { administration }\end{array}$ & Tribal Area & References \\
\hline 276 & $\begin{array}{l}\text { Litsea monopetala } \\
\text { (Roxb.) Pers. } \\
\text { (Lauraceae) }\end{array}$ & Poja (S) & $\begin{array}{l}\text { Pounded and } \\
\text { paste }\end{array}$ & - & $\begin{array}{l}\text { Santhal Pargana, } \\
\text { Bihar }\end{array}$ & $8(350), 14(34)$ \\
\hline 277 & $\begin{array}{l}\text { Lycopersicon } \\
\text { esculentum L. } \\
\text { (Solanaceae) }\end{array}$ & Igi Tomato & $\begin{array}{l}\text { Fresh leaves are } \\
\text { used }\end{array}$ & $\mathrm{T}$ & South-west Nigeria & 23 \\
\hline 278 & $\begin{array}{l}\text { Lycopus europaeus } \\
\text { Linn. } \\
\text { (Lamiaceae) }\end{array}$ & $\begin{array}{l}\text { Jalnim (Pun), } \\
\text { Gipsywort (E) }\end{array}$ & Poultice & $\mathrm{T}$ & - & 11(399), 13(340) \\
\hline 279 & $\begin{array}{l}\text { Macaranga peltata } \\
\text { (Roxb.) Muller. } \\
\text { (Euphorbiaceae) }\end{array}$ & $\begin{array}{l}\text { Malavetta } \\
\text { Puthatamara }\end{array}$ & Paste & $\mathrm{T}$ & Attappady, Kerala & 21 \\
\hline 280 & $\begin{array}{l}\text { Mallotus philippensis } \\
\text { (Lamk.) Muell. Arg. } \\
\text { (Euphorbiaceae) }\end{array}$ & $\begin{array}{l}\text { Rora (Snt); } \\
\text { Kampillka(S) }\end{array}$ & Powder & $\mathrm{T}$ & $\begin{array}{l}\text { Santhal Pargana, } \\
\text { Bihar; } \\
\text { Uttarakhand }\end{array}$ & $\begin{array}{l}9(147), 9(259), 11(217) \\
14(40), 15(412), 16(307)\end{array}$ \\
\hline 281 & $\begin{array}{l}\text { Malva parviflora Linn. } \\
\text { (Malvaceae) }\end{array}$ & $\begin{array}{l}\text { Panrik }(\mathrm{H}) \\
\text { Bakoul } \\
\text { (Arabic) }\end{array}$ & Hot poultice & $\mathrm{T}$ & Uttarakhand & $11(462), 15(103)$ \\
\hline 282 & $\begin{array}{l}\text { Malvastrum } \\
\text { coromandelianum (L.) } \\
\text { Garcke } \\
\text { (Malvaceae) }\end{array}$ & $\begin{array}{l}\text { Bala bheda } \\
\text { (H), Ouade- } \\
\text { Ouade } \\
\text { (French } \\
\text { Guiana) }\end{array}$ & - & - & Uttarakhand & 13(345), 11(464), 15(106) \\
\hline 283 & $\begin{array}{l}\text { Mangifera indica } \mathrm{L} \text {. } \\
\text { (Anacardiaceae) }\end{array}$ & $\begin{array}{l}\text { Amra }(\mathrm{S}) \\
\text { Amba }\end{array}$ & Juice & - & $\begin{array}{l}\text { Thane, } \\
\text { Maharashtra }\end{array}$ & $7(265), 13(346)$ \\
\hline 284 & $\begin{array}{l}\text { Manihot esculenta } \\
\text { Crantz. } \\
\text { (Euphorbiaceae) }\end{array}$ & Mhogo & Infusion & $\mathrm{O}$ & $\begin{array}{l}\text { Kimboza forest, } \\
\text { Tanzania }\end{array}$ & 32 \\
\hline \multirow[t]{2}{*}{285} & $\begin{array}{l}\text { Maytenus emarginata } \\
\text { (Willd.) Ding Hou } \\
\text { (Celastraceae) }\end{array}$ & Danthi(Tel.) & $\begin{array}{l}\text { Crushed with } \\
\text { Betel Leaves }\end{array}$ & - & - & $16(301), 16(311)$ \\
\hline & & $\begin{array}{l}\text { Dantapa } \\
\text { chettu }\end{array}$ & Powder & $\mathrm{T}$ & Bastar, M.P. & $17(112)$ \\
\hline 286 & $\begin{array}{l}\text { Melastoma } \\
\text { malabathricum L. } \\
\text { (Melastomataceae) }\end{array}$ & $\begin{array}{l}\text { Palore (M); } \\
\text { Tinrok (Ncb) }\end{array}$ & Paste & - & - & $8(375), 13(350)$ \\
\hline 287 & $\begin{array}{l}\text { Melia azedarach Linn. } \\
\text { (Meliaceae) }\end{array}$ & $\begin{array}{l}\text { Mahanimba } \\
\text { (S) }\end{array}$ & Decoction & $\mathrm{T}$ & - & $16(314)$ \\
\hline 288 & $\begin{array}{l}\text { Melochia umbellata } \\
\text { (Houtt.) Stapf. } \\
\text { (Sterculiaceae) }\end{array}$ & To $\mathrm{Hu} \mathrm{O} \mathrm{Ka}$ & $\begin{array}{l}\text { Pounded with } \\
\text { sugar }\end{array}$ & - & - & $8(381)$ \\
\hline 289 & $\begin{array}{l}\text { Merremia umbellata (L.) } \\
\text { Hallf. ssp. orientalis Hk. } \\
\text { f. } \\
\text { (Convolvulaceae) }\end{array}$ & Vawktesen-til & Poultice & $\mathrm{T}$ & Assam & $7(591), 8(439)$ \\
\hline 290 & $\begin{array}{l}\text { Mentha viridis } \\
\text { (Lamiaceae) }\end{array}$ & Podina & - & - & $\begin{array}{l}\text { Bilaspur, } \\
\text { Chhattisgarh }\end{array}$ & 27 \\
\hline 291 & $\begin{array}{l}\text { Microsorium punctatum } \\
\text { (L.) Copel } \\
\text { (Polypodiaceae) }\end{array}$ & - & - & - & - & $8(24)$ \\
\hline 292 & $\begin{array}{l}\text { Mikania micrantha } \\
\text { H.B.K. } \\
\text { (Asteraceae) }\end{array}$ & Japan-hlo & Juice & $\mathrm{T}$ & $\begin{array}{l}\text { Lunglei, Mizoram } \\
\text { Sonitpur, Assam }\end{array}$ & $\begin{array}{l}28 \\
7(604)\end{array}$ \\
\hline
\end{tabular}




\begin{tabular}{|c|c|c|c|c|c|c|}
\hline S.No. & $\begin{array}{l}\text { Botanical Name } \\
\text { (Family) }\end{array}$ & Local name & $\begin{array}{l}\text { Mode of } \\
\text { administration }\end{array}$ & $\begin{array}{l}\text { Route of } \\
\text { administration }\end{array}$ & Tribal Area & References \\
\hline \multirow[t]{6}{*}{293} & $\begin{array}{l}\text { Mimosa pudica Linn. } \\
\text { (Fabaceae) }\end{array}$ & Uskadpoda & - & $\mathrm{T}$ & $\begin{array}{l}\text { Dantewada, } \\
\text { Chhattisgarh }\end{array}$ & 35 \\
\hline & & $\begin{array}{l}\text { Lajalu } \\
\text { Lajwanti }\end{array}$ & Juice & $\mathrm{T}$ & $\begin{array}{l}\text { Nagpur and } \\
\text { Wardha; } \\
\text { Washim, } \\
\text { Maharashtra }\end{array}$ & $\begin{array}{l}\text { 8(166), 8(253), 9(387), } 9 \\
\text { (147), 13(358), 19(61), } 24\end{array}$ \\
\hline & & Thotta vaadi & Juice & $\mathrm{T}$ & $\begin{array}{l}\text { Kuruma tribes, } \\
\text { Wayanadu, kerela }\end{array}$ & 33 \\
\hline & & Nilaj bon & Crushed leaves & $\mathrm{T}$ & Tezpur, Assam & 31 \\
\hline & & Thottasurungi & $\begin{array}{l}\text { Pinch of leaf } \\
\text { paste }\end{array}$ & $\mathrm{T}$ & $\begin{array}{l}\text { Kancheepuram, } \\
\text { Tamil Nadu }\end{array}$ & 25 \\
\hline & & Chui-mui & - & - & $\begin{array}{l}\text { Bilaspur, } \\
\text { Chhattisgarh }\end{array}$ & 27 \\
\hline 294 & $\begin{array}{l}\text { Mirabilis jalapa L. } \\
\text { (Nyctaginaceae) }\end{array}$ & Badhrakshi & Crushed & $\mathrm{T}$ & $\begin{array}{l}\text { Tirumala hills, A. } \\
\text { P. }\end{array}$ & $13(361), 38$ \\
\hline 295 & $\begin{array}{l}\text { Mitracarpus villosa } \\
\text { (Sw.) DC. (Rubiaceae) }\end{array}$ & - & Paste & - & - & $8(260)$ \\
\hline 296 & $\begin{array}{l}\text { Mitragyna inermis } \\
\text { Kuntze } \\
\text { (Rubiaceae) }\end{array}$ & Sadeene & $\begin{array}{l}\text { The vapour of a } \\
\text { decoction is } \\
\text { inhaled }\end{array}$ & $\mathrm{O}$ & $\begin{array}{l}\text { Dogonland, Mali, } \\
\text { West Africa }\end{array}$ & 34 \\
\hline 297 & $\begin{array}{l}\text { Mitragyna parviflora } \\
\text { (Roxb) Korth. } \\
\text { (Rubiaceae) }\end{array}$ & $\begin{array}{l}\text { Vitanah }(\mathrm{S}) \\
\text { Kalmi(H) }\end{array}$ & - & - & - & $13(361)$ \\
\hline 298 & $\begin{array}{l}\text { Momordia charantia L. } \\
\text { (Cucurbitaceae) }\end{array}$ & Karvellam & Juice & - & Assam & $7(591), 13(363)$ \\
\hline 299 & $\begin{array}{l}\text { Morinda citrifolia L. } \\
\text { (Rubiaceae) }\end{array}$ & $\begin{array}{l}\text { Nibase }(\mathrm{Ncb}) \\
\text { Asyaka }(\mathrm{S})\end{array}$ & Paste & - & $\begin{array}{l}\text { Nagpur And } \\
\text { Wardha }\end{array}$ & $8(375), 13(366), 19(63)$ \\
\hline 300 & $\begin{array}{l}\text { Morinda lucida Benth } \\
\text { (Rubiaceae) }\end{array}$ & Oruwo & Paste & $\mathrm{T}$ & South-west Nigeria & 23 \\
\hline 301 & $\begin{array}{l}\text { Morinda pubescens J.E. } \\
\text { Smith. } \\
\text { (Rubiaceae) }\end{array}$ & $\begin{array}{l}\text { Manjanatthi / } \\
\text { Nuna }\end{array}$ & Paste & $\mathrm{T}$ & $\begin{array}{l}\text { Tirunelveli hills, } \\
\text { southern India }\end{array}$ & 22 \\
\hline 302 & $\begin{array}{l}\text { Morinda tinctoria Roxb. } \\
\text { (Rubiaceae) }\end{array}$ & Aal (Guj) & Paste & - & - & $16(312)$ \\
\hline \multirow[t]{3}{*}{303} & $\begin{array}{l}\text { Moringa oleifera Lam. } \\
\text { (Moringaceae) }\end{array}$ & - & Paste & $\mathrm{T}$ & Khargone, M.P. & 30 \\
\hline & & Munga & - & - & $\begin{array}{l}\text { Bilaspur, } \\
\text { Chhattisgarh }\end{array}$ & 27 \\
\hline & & Shewaga & - & $\mathrm{T}$ & $\begin{array}{l}\text { Nagpur and } \\
\text { Wardha; } \\
\text { Washim, } \\
\text { Maharashtra }\end{array}$ & $19(63), 24$ \\
\hline \multirow[t]{2}{*}{304} & $\begin{array}{l}\text { Morus alba L. } \\
\text { (Moraceae) }\end{array}$ & - & Paste & $\mathrm{T}$ & $\begin{array}{l}\text { Tirunelveli hills, } \\
\text { southern India }\end{array}$ & 22 \\
\hline & & - & Paste & $\mathrm{T}$ & Khargone, M.P. & 30 \\
\hline 305 & $\begin{array}{l}\text { Morus australis Poiret } \\
\text { (Moraceae) }\end{array}$ & Nooni & Infusion & - & Assam & $7(591)$ \\
\hline 306 & $\begin{array}{l}\text { Mucuna pruriens (L.) } \\
\text { DC. } \\
\text { (Fabaceae) }\end{array}$ & $\begin{array}{l}\text { Etka (Snt); } \\
\text { Khajkuri, } \\
\text { Kapikachchhu } \\
\text { (S) }\end{array}$ & Paste & - & $\begin{array}{l}\text { Amravati, } \\
\text { Maharashtra; } \\
\text { Santhal Pargana; } \\
\text { Uttarakhand }\end{array}$ & $7(283), 14(41), 15(188)$ \\
\hline
\end{tabular}




\begin{tabular}{|c|c|c|c|c|c|c|}
\hline S.No. & $\begin{array}{l}\text { Botanical Name } \\
\text { (Family) }\end{array}$ & Local name & $\begin{array}{l}\text { Mode of } \\
\text { administration }\end{array}$ & $\begin{array}{l}\text { Route of } \\
\text { administration }\end{array}$ & Tribal Area & References \\
\hline 307 & $\begin{array}{l}\text { Murraya paniculata (L.) } \\
\text { Jack } \\
\text { (Rutaceae) }\end{array}$ & Meetha neem & Powder & - & $\begin{array}{l}\text { Bilaspur, } \\
\text { Chhattisgarh }\end{array}$ & $9(147), 27$ \\
\hline \multirow[t]{3}{*}{308} & $\begin{array}{l}\text { Nerium indicum Mill. } \\
\text { (Apocynaceae) }\end{array}$ & Kaneri & - & - & $\begin{array}{l}\text { Washim, } \\
\text { Maharashtra }\end{array}$ & 24 \\
\hline & & Kaner & - & - & $\begin{array}{l}\text { Bilaspur, } \\
\text { Chhattisgarh }\end{array}$ & 27 \\
\hline & & - & Juice & $\mathrm{T}$ & $\begin{array}{l}\text { Sangli, } \\
\text { Maharashtra; } \\
\text { Khargone, M.P. }\end{array}$ & 30,40 \\
\hline 309 & $\begin{array}{l}\text { Nicotiana rustica Linn. } \\
\text { (Solanaceae) }\end{array}$ & $\begin{array}{l}\text { Calcuttia } \\
\text { tambaku }(\mathrm{H})\end{array}$ & - & - & Uttarakhand & $15(332)$ \\
\hline \multirow[t]{2}{*}{310} & $\begin{array}{l}\text { Nicotiana tobacum L. } \\
\text { (Solanaceae) }\end{array}$ & Pukayila & Paste & $\mathrm{T}$ & $\begin{array}{l}\text { Attappady, Kerala } \\
\text { Uttarakhand }\end{array}$ & 13(380), 15(334), 21 \\
\hline & & Vaihlo & Juice & $\mathrm{T}$ & $\begin{array}{l}\text { Thlabung, } \\
\text { Mizoram }\end{array}$ & 28 \\
\hline 311 & $\begin{array}{l}\text { Nipa fruiticans Wurmb. } \\
\text { (Arecaceae) }\end{array}$ & Nipa palm & Lotion & $\mathrm{T}$ & - & $11(20)$ \\
\hline 312 & $\begin{array}{l}\text { Nymphaea lotus L. } \\
\text { (Nymphaeaceae) }\end{array}$ & Ira & poultice & $\mathrm{T}$ & South-west Nigeria & 23 \\
\hline 313 & $\begin{array}{l}\text { Ochradenus baccatus } \\
\text { Del. } \\
\text { (Resedaceae) }\end{array}$ & $\begin{array}{l}\text { Kalirram } \\
\text { (Baluchistan) }\end{array}$ & - & - & - & $11(277)$ \\
\hline 314 & $\begin{array}{l}\text { Ocimum gratissimum L. } \\
\text { (Lamiaceae) }\end{array}$ & Effirin & $\begin{array}{l}\text { An infusion of } \\
\text { the leaves is } \\
\text { used as a wash }\end{array}$ & $\mathrm{T}$ & South-west Nigeria & 23 \\
\hline 315 & $\begin{array}{l}\text { Ocimum } \\
\text { kilimandscharicum } \\
\text { Guerke. } \quad \text { (Lamiaceae) }\end{array}$ & $\begin{array}{l}\text { Karpuratulasi } \\
\text { (S) }\end{array}$ & - & - & - & 13(386) \\
\hline 316 & $\begin{array}{l}\text { Ocimum sanctum } \mathrm{L} . \\
\text { (Lamiaceae) }\end{array}$ & Tulsi & - & - & $\begin{array}{l}\text { Washim, } \\
\text { Maharashtra } \\
\text { Uttarakhand }\end{array}$ & 13(387), 15(374), 24 \\
\hline 317 & $\begin{array}{l}\text { Olax subscorpioides } \\
\text { Oliv. } \\
\text { (Olacaceae) }\end{array}$ & Ifon & Fresh leaves & $\mathrm{T}$ & South-west Nigeria & 23 \\
\hline 318 & $\begin{array}{l}\text { Orthosiphon thymiflorus } \\
\text { (Roth.) Sleasen } \\
\text { (Lamiaceae) }\end{array}$ & Pratanika (S) & Pounded & - & - & $13(391)$ \\
\hline \multirow[t]{2}{*}{319} & $\begin{array}{l}\text { Oxalis corniculata Linn. } \\
\text { (Oxalidaceae) }\end{array}$ & Tinpatiya & Decoction & $\mathrm{O}$ & $\begin{array}{l}\text { Dantewada, } \\
\text { Chhattisgarh }\end{array}$ & 35 \\
\hline & & Puliyaarila & Paste & $\mathrm{T}$ & $\begin{array}{l}\text { Kuruma tribes, } \\
\text { Wayanadu, kerela }\end{array}$ & 33 \\
\hline 320 & $\begin{array}{l}\text { Oxytropis lapponica } \\
\text { (Wahlenb.)Gay } \\
\text { (Fabaceae) }\end{array}$ & Chilsut & - & - & - & $8(92)$ \\
\hline 321 & $\begin{array}{l}\text { Passiflora edulis Sims. } \\
\text { (Passifloraceae) }\end{array}$ & Krinshakamal & - & $\mathrm{T}$ & $\begin{array}{l}\text { Nagpur and } \\
\text { Wardha }\end{array}$ & $19(66)$ \\
\hline 322 & $\begin{array}{l}\text { Pedalium murex L. } \\
\text { (Pedaliaceae) }\end{array}$ & $\begin{array}{l}\text { Gokshura }(\mathrm{S}) \\
\text { Vilayati } \\
\text { gokharu }\end{array}$ & - & - & - & $9(147), 13(398)$ \\
\hline 323 & $\begin{array}{l}\text { Pedicularis } \\
\text { cheilanthifolia } \text { Screnk } \\
\text { (Scrophulariaceae) }\end{array}$ & Chukchuk & Extract & - & - & $8(92)$ \\
\hline
\end{tabular}




\begin{tabular}{|c|c|c|c|c|c|c|}
\hline S.No. & $\begin{array}{l}\text { Botanical Name } \\
\text { (Family) }\end{array}$ & Local name & $\begin{array}{l}\text { Mode of } \\
\text { administration }\end{array}$ & $\begin{array}{l}\text { Route of } \\
\text { administration }\end{array}$ & Tribal Area & References \\
\hline 324 & $\begin{array}{l}\text { Pedilanthus } \\
\text { tithymaloides Poit. } \\
\text { (Euphorbiaceae) }\end{array}$ & Hemsagar & Warmed & - & Bhadrak, Odisha & $7(499), 116(317)$ \\
\hline 325 & $\begin{array}{l}\text { Pentanema indicum (L.) } \\
\text { King. } \\
\text { (Asteraceae) }\end{array}$ & $\begin{array}{l}\text { Banjhouri, } \\
\text { Seema (Snt) }\end{array}$ & Paste & - & $\begin{array}{l}\text { Santhal Pargana, } \\
\text { Bihar }\end{array}$ & $8(253), 14(41)$ \\
\hline \multirow[t]{2}{*}{326} & Pergularia daemia & Juttupu & - & - & Nalgonda \& & 43 \\
\hline & & $\begin{array}{l}\text { Dushtupu } \\
\text { aaku }\end{array}$ & Crushed and tied & $\mathrm{T}$ & Bastar, M.P. & $17(114)$ \\
\hline 327 & $\begin{array}{l}\text { Peristrophe bicalyculata } \\
\text { (Retz.) Nees } \\
\text { (Acanthaceae) }\end{array}$ & $\begin{array}{l}\text { Kakajangha } \\
\text { (S) }\end{array}$ & - & - & Uttarakhand & $15(357)$ \\
\hline 328 & $\begin{array}{l}\text { Peristrophe paniculata } \\
\text { (Forsk.) Brummitt } \\
\text { (Acanthaceae) }\end{array}$ & Kakajangha & - & $\mathrm{T}$ & Nagpur and wardha & $19(67)$ \\
\hline 329 & $\begin{array}{l}\text { Phyla nodiflora (L.) } \\
\text { Greene (Verbenaceae) }\end{array}$ & Jalapippali (S) & Poultice & $\mathrm{T}$ & - & $9(147), 13(402)$ \\
\hline 330 & $\begin{array}{l}\text { Phyllanthhus emblica } \\
\text { (Euphorbiaceae) }\end{array}$ & Avala & Paste & $\mathrm{T}$ & Bastar, M.P. & $17(115)$ \\
\hline 331 & $\begin{array}{l}\text { Phyllanthhus virgatus } \\
\text { Forst.f. } \\
\text { (Euphorbiaceae) }\end{array}$ & - & - & - & - & $9(147)$ \\
\hline 332 & $\begin{array}{l}\text { Phyllanthus reticulatas } \\
\text { Poir. } \\
\text { (Euphorbiaceae) }\end{array}$ & $\begin{array}{l}\text { Buinowla, } \\
\text { Makhi, } \\
\text { Panjoli (H); } \\
\text { Krsnakamboji } \\
\text { (S) }\end{array}$ & $\begin{array}{l}\text { Powder; } \\
\text { Pounded and } \\
\text { tied }\end{array}$ & $\mathrm{T}$ & Bastar, M.P. & $\begin{array}{l}11(223), 13(406) \\
17(115)\end{array}$ \\
\hline 333 & $\begin{array}{l}\text { Phyllanthus urinaria L. } \\
\text { (Euphorbiaceae) }\end{array}$ & $\begin{array}{l}\text { Tandimeral, } \\
\text { Kanthad } \\
\text { (Snth.) }\end{array}$ & Paste & - & $\begin{array}{l}\text { Santhal Pargana, } \\
\text { Bihar }\end{array}$ & $14(41)$ \\
\hline 334 & $\begin{array}{l}\text { Phyllanthus virgatus G. } \\
\text { Foster (Euphorbiaceae) }\end{array}$ & $\begin{array}{l}\text { Bhiuavate } \\
\text { (Lut) }\end{array}$ & & - & $\begin{array}{l}\text { Uttarakhand } \\
\text { Nagpur and } \\
\text { Wardha }\end{array}$ & $\begin{array}{l}15(413) \\
19(68)\end{array}$ \\
\hline 335 & $\begin{array}{l}\text { Phyllochlamys spinosa } \\
\text { Bur. } \\
\text { (Moraceae) }\end{array}$ & $\begin{array}{l}\text { Jee }(\mathrm{M}) \\
\text { Jhumpuri }(\mathrm{O})\end{array}$ & $\begin{array}{l}\text { Powder } \\
\text { sprinkled }\end{array}$ & $\mathrm{T}$ & Jajpur, Odisha & $7(467)$ \\
\hline 336 & $\begin{array}{l}\text { Pieris ovalifolia D.Don. } \\
\text { (Ericaceae) }\end{array}$ & $\begin{array}{l}\text { Anyar, Ayar } \\
(\mathrm{Hp})\end{array}$ & Decoction & $\mathrm{T}$ & - & $16(304)$ \\
\hline 337 & $\begin{array}{l}\text { Pinus roxbirghii Sarg. } \\
\text { (Pinaceae) }\end{array}$ & $\begin{array}{l}\text { Sarala (S); } \\
\text { Chir, Sal }\end{array}$ & Decoction & $\mathrm{T}$ & $\begin{array}{l}\text { Kumaun Himalaya } \\
\text { Uttarakhand }\end{array}$ & $7(253), 9(251), 15(50)$ \\
\hline 338 & $\begin{array}{l}\text { Piliostigma thonningii } \\
\text { (Schumach.) Milne- } \\
\text { Redh. } \\
\text { (Fabaceae) }\end{array}$ & Abafe & $\begin{array}{l}\text { Young leaves } \\
\text { are macerated in } \\
\text { water }\end{array}$ & $\mathrm{T}$ & South-west Nigeria & 23 \\
\hline 339 & $\begin{array}{l}\text { Piper betle L. } \\
\text { (Piperaceae) }\end{array}$ & Vettilakodi & Paste & $\mathrm{T}$ & Attappady, Kerala & 21 \\
\hline 340 & $\begin{array}{l}\text { Plantago brachyphylla } \\
\text { Edgew. } \\
\text { (Plantaginaceae) }\end{array}$ & $\begin{array}{l}\text { Parsharpangi; } \\
\text { Pushtu }\end{array}$ & - & - & - & $8(70)$ \\
\hline 341 & $\begin{array}{l}\text { Plantago depressa } \\
\text { Willd. } \\
\text { (Plantaginaceae) }\end{array}$ & Isabgol $(\mathrm{H})$ & Paste & - & Uttarakhand & $15(384)$ \\
\hline
\end{tabular}




\begin{tabular}{|c|c|c|c|c|c|c|}
\hline S.No. & $\begin{array}{l}\text { Botanical Name } \\
\text { (Family) }\end{array}$ & Local name & $\begin{array}{l}\text { Mode of } \\
\text { administration }\end{array}$ & $\begin{array}{l}\text { Route of } \\
\text { administration }\end{array}$ & Tribal Area & References \\
\hline 342 & $\begin{array}{l}\text { Plantago erosa Wall. } \\
\text { (Plantaginaceae) }\end{array}$ & $\begin{array}{l}\text { Nila chakka, } \\
\text { Njaramboori }\end{array}$ & Paste & - & Kerela & $7(451)$ \\
\hline 343 & $\begin{array}{l}\text { Plantago lanceolata L. } \\
\text { (Plantaginaceae) }\end{array}$ & Battanga & - & - & - & $8(75)$ \\
\hline 344 & $\begin{array}{l}\text { Plantago major Linn. } \\
\text { (Plantaginaceae) }\end{array}$ & Isabgol (H) & Pounded & - & Uttarakhand & $15(384), 16(301)$ \\
\hline 345 & $\begin{array}{l}\text { Pogostemon } \\
\text { benghalensis (Burm. f.) } \\
\text { O. Kunze. } \\
\text { (Lamiaceae) }\end{array}$ & $\begin{array}{l}\text { Kal-basingu } \\
(\mathrm{H}), \text { Phangla }\end{array}$ & - & - & Uttarakhand & $9(147), 15(376)$ \\
\hline 346 & $\begin{array}{l}\text { Pogostemon parviflorus } \\
\text { Benth. } \\
\text { (Lamiaceae) }\end{array}$ & $\begin{array}{l}\text { Phangla, } \\
\text { Phang }(\mathrm{H})\end{array}$ & Fresh leaves & $\mathrm{T}$ & - & $11(414)$ \\
\hline 347 & $\begin{array}{l}\text { Pogostemon pubescens } \\
\text { Benth. } \\
\text { (Lamiaceae) }\end{array}$ & Vanjira (Lut) & Paste & - & Uttarakhand & $15(376)$ \\
\hline 348 & $\begin{array}{l}\text { Polygonum orientalis L. } \\
\text { (Liliaceae) }\end{array}$ & $\begin{array}{l}\text { Bishkatali } \\
\text { (M) }\end{array}$ & Pounded & - & - & $9(219)$ \\
\hline 349 & $\begin{array}{l}\text { Polygonum rumicifolium } \\
\text { Royle ex Bab. } \\
\text { (Liliaceae) }\end{array}$ & $\begin{array}{l}\text { Divya kand } \\
\text { (Hp) }\end{array}$ & Paste & - & - & $16(317)$ \\
\hline 350 & $\begin{array}{l}\text { Pothos scandens L. } \\
\text { (Araceae) }\end{array}$ & Money plant & - & - & $\begin{array}{l}\text { Bilaspur, } \\
\text { Chhattisgarh }\end{array}$ & 27 \\
\hline 351 & $\begin{array}{l}\text { Portulaca oleracea } \\
\text { Linn. } \\
\text { (Portulacaceae) }\end{array}$ & $\begin{array}{l}\text { Brihalloni, } \\
\text { Lonika (S); } \\
\text { Kulfa }\end{array}$ & Paste poultice & $\mathrm{T}$ & - & $9(259)$ \\
\hline 352 & $\begin{array}{l}\text { Potentilla sericea L. } \\
\text { (Rosaceae) }\end{array}$ & Tasmo & & - & - & $8(92)$ \\
\hline 353 & $\begin{array}{l}\text { Pouzolzia zeylanica (L.) } \\
\text { Benn. } \\
\text { (Urticaceae) }\end{array}$ & Kallurki (Tm) & poultice & $\mathrm{T}$ & - & $13(427)$ \\
\hline 354 & $\begin{array}{l}\text { Premna herbacea Roxb. } \\
\text { (Verbenaceae) }\end{array}$ & $\begin{array}{l}\text { Bhumijambu } \\
\text { (S) }\end{array}$ & Poultice & - & Uttarakhand & $15(365)$ \\
\hline 355 & $\begin{array}{l}\text { Prosopis cineraria Linn. } \\
\text { (Mimosaceae) }\end{array}$ & Shami(S) & Fresh juice & - & - & $16(301)$ \\
\hline \multirow[t]{3}{*}{356} & $\begin{array}{l}\text { Psidium guajava Linn. } \\
\text { (Myrtaceae) }\end{array}$ & Beloti & Decoction & $\mathrm{O}$ & $\begin{array}{l}\text { Dantewada, } \\
\text { Chhattisgarh }\end{array}$ & 35 \\
\hline & & $\begin{array}{l}\text { Mausala (S) } \\
\text { Kayya (Tm \& } \\
\text { M1.) }\end{array}$ & $\begin{array}{l}\text { Wrapping the } \\
\text { leaves }\end{array}$ & $\mathrm{T}$ & $\begin{array}{l}\text { Khargone, M.P.; } \\
\text { Dharmapuri, Tamil } \\
\text { Nadu }\end{array}$ & $7(395), 30$ \\
\hline & & Amrud & - & - & $\begin{array}{l}\text { Bilaspur, } \\
\text { Chhattisgarh }\end{array}$ & 27 \\
\hline 357 & $\begin{array}{l}\text { Pterocarpus marsupium } \\
\text { Roxb. } \\
\text { (Fabaceae) }\end{array}$ & $\begin{array}{l}\text { Asan (S) } \\
\text { Murga (Snt.) }\end{array}$ & Juice & $\mathrm{T}$ & $\begin{array}{l}\text { Santhal Pargana, } \\
\text { Bihar }\end{array}$ & $\begin{array}{l}8(244), 13(434) \\
14(44)\end{array}$ \\
\hline 358 & $\begin{array}{l}\text { Pterospermum } \\
\text { acerifolium Willd. } \\
\text { (Sterculiaceae) }\end{array}$ & $\begin{array}{l}\text { Kanakchampa } \\
(\mathrm{H})\end{array}$ & - & - & - & $11(489)$ \\
\hline 359 & $\begin{array}{l}\text { Punica granatum L. } \\
\text { (Punicaceae) }\end{array}$ & - & Juice inhaling & $\mathrm{O}$ & Assam & $7(591)$ \\
\hline 360 & $\begin{array}{l}\text { Radermachera } \\
\text { xylocarpa (Roxb.) K. } \\
\text { Schum } \\
\text { (Bignoniaceae) }\end{array}$ & $\begin{array}{l}\text { Manjakadamb } \\
\text { e (Kur) }\end{array}$ & Paste & - & - & $8(272)$ \\
\hline
\end{tabular}




\begin{tabular}{|c|c|c|c|c|c|c|}
\hline S.No. & $\begin{array}{l}\text { Botanical Name } \\
\text { (Family) }\end{array}$ & Local name & $\begin{array}{l}\text { Mode of } \\
\text { administration }\end{array}$ & $\begin{array}{l}\text { Route of } \\
\text { administration }\end{array}$ & Tribal Area & References \\
\hline 361 & $\begin{array}{l}\text { Rhynchiglossum } \\
\text { obliquum } \mathrm{Bl} . \\
\text { (Gesneraceae) }\end{array}$ & Tipri-char & Paste & $\mathrm{T}$ & Nagaland & $20(175)$ \\
\hline \multirow[t]{3}{*}{362} & $\begin{array}{l}\text { Ricinus communis L. } \\
\text { (Euphorbiaceae) }\end{array}$ & Mnyonyo & $\begin{array}{l}\text { Crushed } \\
\text { and pounded }\end{array}$ & $\mathrm{T}$ & $\begin{array}{l}\text { Kimboza forest, } \\
\text { Tanzania }\end{array}$ & 32 \\
\hline & & $\begin{array}{l}\text { Eranda (S); } \\
\text { Mu-tih }\end{array}$ & Crushed & - & Uttarakhand & $\begin{array}{l}8(439), 11(225), 15(414), \\
16(306)\end{array}$ \\
\hline & & Ewé ogohoun & Paste & $\mathrm{T}$ & South-west Nigeria & 23 \\
\hline 363 & $\begin{array}{l}\text { Rosa brunonii Lindley } \\
\text { (Rosaceae) }\end{array}$ & Kubjak (S) & Juice & - & Uttarakhand & $15(203)$ \\
\hline 364 & $\begin{array}{l}\text { Rosa damascena } \mathrm{P} \text {. } \\
\text { Miller } \\
\text { (Rosaceae) }\end{array}$ & Rose & - & $\mathrm{T}$ & $\begin{array}{l}\text { Dantewada, } \\
\text { Chhattisgarh }\end{array}$ & 35 \\
\hline 365 & $\begin{array}{l}\text { Rosa indica L. } \\
\text { (Rosaceae) }\end{array}$ & Rose & - & - & $\begin{array}{l}\text { Bilaspur, } \\
\text { Chhattisgarh }\end{array}$ & 27 \\
\hline 366 & $\begin{array}{l}\text { Roscoea alpina Royle } \\
\text { (Zingiberaceae) }\end{array}$ & Kakoli (S) & Powder & - & Uttarakhand & $15(443)$ \\
\hline 367 & $\begin{array}{l}\text { Rubus fruticosus L. } \\
\text { (Rosaceae) }\end{array}$ & Alish & Infusion & - & - & $8(56)$ \\
\hline 368 & $\begin{array}{l}\text { Rumex nepalensis } \\
\text { Spreng. } \\
\text { (Polygonaceae) }\end{array}$ & Ghandruk & Paste & $\mathrm{T}$ & - & $8(408)$ \\
\hline 369 & $\begin{array}{l}\text { Sagitteria sagittifolia L. } \\
\text { (Alismataceae) }\end{array}$ & $\begin{array}{l}\text { Choto-kut, } \\
\text { Muya muya } \\
\text { (Bn) }\end{array}$ & - & - & - & $13(450)$ \\
\hline 370 & $\begin{array}{l}\text { Salvia glutinosa Linn. } \\
\text { (Lamiaceae) }\end{array}$ & $\begin{array}{l}\text { Cetrode } \\
\text { Jupiter } \\
\text { (Spanish) }\end{array}$ & Lotion & $\mathrm{T}$ & - & $511(416)$ \\
\hline 371 & $\begin{array}{l}\text { Salvia moorcroftiana } \\
\text { Wall. } \\
\text { (Lamiaceae) }\end{array}$ & $\begin{array}{l}\text { Kali jarri }(\mathrm{H}) \text {, } \\
\text { Gurgumma } \\
\text { (Pun) }\end{array}$ & Poultice & $\mathrm{T}$ & Uttarakhand & 11(416), 15(379) \\
\hline 372 & $\begin{array}{l}\text { Salvia nubiloca Wall. ex } \\
\text { Sweet (Lamiaceae) }\end{array}$ & Ganya (Lut) & Paste & - & Uttarakhand & $15(379)$ \\
\hline 373 & $\begin{array}{l}\text { Sauropus androgynus } \\
\text { Merr. } \\
\text { (Euphorbiaceae) }\end{array}$ & $\begin{array}{l}\text { Thavasai } \\
\text { murungai } \\
(\mathrm{Tm})\end{array}$ & Poultice & - & - & $13(460)$ \\
\hline 374 & $\begin{array}{l}\text { Schima wallichii (DC.) } \\
\text { Korth. } \\
\text { (Theaceae) }\end{array}$ & Khiang & Juice & - & - & $8(439)$ \\
\hline 375 & $\begin{array}{l}\text { Scoparia dulcis L. } \\
\text { (Scrophulariaceae) }\end{array}$ & Sarak-kotthini & Paste & $\mathrm{T}$ & $\begin{array}{l}\text { Tirunelveli hills, } \\
\text { southern India }\end{array}$ & 22 \\
\hline 376 & $\begin{array}{l}\text { Securinega leucopyrus } \\
\text { (Willd.) Muell } \\
\text { (Phyllanthaceae) }\end{array}$ & $\begin{array}{l}\text { Thumari, } \\
\text { Humari }\end{array}$ & Gel & $\mathrm{T}$ & Jamnagar & 48,49 \\
\hline 377 & $\begin{array}{l}\text { Selinum vaginatum } \\
\text { Clarke } \\
\text { (Apiaceae) }\end{array}$ & - & $\begin{array}{l}\text { Crushed and } \\
\text { paste }\end{array}$ & - & Kullu, H.P. & $7(185)$ \\
\hline 378 & $\begin{array}{l}\text { Senecio nudicaulis } \\
\text { D.Don. } \\
\text { (Asteraceae) }\end{array}$ & Ratpatia (H) & Paste & - & - & $16(307)$ \\
\hline
\end{tabular}




\begin{tabular}{|c|c|c|c|c|c|c|}
\hline S.No. & $\begin{array}{l}\text { Botanical Name } \\
\text { (Family) }\end{array}$ & Local name & $\begin{array}{l}\text { Mode of } \\
\text { administration }\end{array}$ & $\begin{array}{l}\text { Route of } \\
\text { administration }\end{array}$ & Tribal Area & References \\
\hline 379 & $\begin{array}{l}\text { Senna occidentalis (L.) } \\
\text { Link } \\
\text { (Fabaceae) }\end{array}$ & Guinjimognu & Powder of leaves & $\mathrm{T}$ & $\begin{array}{l}\text { Dogonland, Mali, } \\
\text { West Africa }\end{array}$ & 34 \\
\hline \multirow[t]{2}{*}{380} & $\begin{array}{l}\text { Sida acuta } \text { Burm. f } \\
\text { (Malvaceae) }\end{array}$ & Isekete & Decoction & $\mathrm{T}$ & South-west Nigeria & 23 \\
\hline & & $\begin{array}{l}\text { Arival manai } \\
\text { poondu }\end{array}$ & Paste & $\mathrm{T}$ & $\begin{array}{l}\text { Kancheepuram, } \\
\text { Tirunelveli and } \\
\text { Dharmapuri, Tamil } \\
\text { Nadu }\end{array}$ & $7(395), 7(363), 8(228), 25$ \\
\hline 381 & $\begin{array}{l}\text { Sida cordata (Burm. f.) } \\
\text { Barssum } \\
\text { (Malvaceae) }\end{array}$ & $\begin{array}{l}\text { Bhumibala, } \\
\text { Rajabala (S), } \\
\text { Daravan talai } \\
(\mathrm{Kd})\end{array}$ & Ground to paste & $\mathrm{T}$ & $\begin{array}{l}\text { Uttarakhand; } \\
\text { Phulbani, Odisha }\end{array}$ & $\begin{array}{l}8(260), 15(108), 16(312), \\
18(138)\end{array}$ \\
\hline 382 & $\begin{array}{l}\text { Sida orientalis } \\
\text { (Malvaceae) }\end{array}$ & - & Paste & $\mathrm{T}$ & - & $9(387)$ \\
\hline 383 & $\begin{array}{l}\text { Sida schimperiana } \\
\text { Hochst. } \\
\text { (Malvaceae) }\end{array}$ & - & Paste & - & - & $8(260)$ \\
\hline 384 & $\begin{array}{l}\text { Sida veronicaefolia } \\
\text { Lam. } \\
\text { (Malvaceae) }\end{array}$ & Rajabala(S) & Pounded & - & - & 11(469), 16(301) \\
\hline 385 & $\begin{array}{l}\text { Sida rhombifolia Linn. } \\
\text { (Malvaceae) }\end{array}$ & Arrow leaf & Paste & - & $\begin{array}{l}\text { Bilaspur, } \\
\text { Chhattisgarh }\end{array}$ & $9(387), 27$ \\
\hline 386 & $\begin{array}{l}\text { Skimmia anquetilia } \\
\text { Taylor \& Airy Shaw } \\
\text { (Rutaceae) }\end{array}$ & Patranga $(\mathrm{H})$ & - & - & Uttarakhand & $15(130)$ \\
\hline 387 & $\begin{array}{l}\text { Skimmia laureola (DC.) } \\
\text { Zucc. } \\
\text { (Rutaceae) }\end{array}$ & Masturipath & Juice & - & Kangra, H.P. & $20(178)$ \\
\hline 388 & $\begin{array}{l}\text { Solanum nigrum L. } \\
\text { (Solanaceae) }\end{array}$ & $\begin{array}{l}\text { Kakamachi } \\
\text { (S) }\end{array}$ & Infusion & - & $\begin{array}{l}\text { Dharmapuri dist., } \\
\text { Tamil Nadu; } \\
\text { Uttarakhand }\end{array}$ & $7(395), 13(473), 15(337)$ \\
\hline 389 & $\begin{array}{l}\text { Solanum incanum Linn. } \\
\text { (Solanaceae) }\end{array}$ & Inrimbudu & Decoction & $\mathrm{T}$ & $\begin{array}{l}\text { Dogonland, Mali, } \\
\text { West Africa }\end{array}$ & 34 \\
\hline 390 & $\begin{array}{l}\text { Solanum surratense } \\
\text { Burm. f. } \\
\text { (Solanaceae) }\end{array}$ & Kateri vangi & - & - & $\begin{array}{l}\text { Thane, } \\
\text { Maharashtra }\end{array}$ & $7(265), 16(315)$ \\
\hline 391 & $\begin{array}{l}\text { Sonchus asper (L.) Hill } \\
\text { (Asteraceae) }\end{array}$ & $\begin{array}{l}\text { Garwa, } \\
\text { Machal; } \\
\text { Jalymniar }\end{array}$ & Pounded & - & Uttarakhand & $\begin{array}{l}8(175), 11(364), 15(270), \\
15(279)\end{array}$ \\
\hline 392 & $\begin{array}{l}\text { Sorindeia } \\
\text { madagascariensis DC. } \\
\text { (Anacardiaceae) }\end{array}$ & Mpilipili & $\begin{array}{l}\text { Crushed or } \\
\text { pounded }\end{array}$ & $\mathrm{T}$ & $\begin{array}{l}\text { Kimboza forest, } \\
\text { Tanzania }\end{array}$ & 32 \\
\hline 393 & $\begin{array}{l}\text { Spermacoce articularis } \\
\text { L. f. } \\
\text { (Rubiaceae) }\end{array}$ & Kudalurukki & Paste & $\mathrm{T}$ & Attappady, Kerala & 21 \\
\hline 394 & $\begin{array}{l}\text { Spermacoce ocymoides } \\
\text { Burm.f. } \\
\text { (Rubiaceae) }\end{array}$ & Sirupeelai & Paste & $\mathrm{T}$ & $\begin{array}{l}\text { Tirunelveli hills, } \\
\text { southern India }\end{array}$ & 22 \\
\hline 395 & $\begin{array}{l}\text { Stachys palustris Linn. } \\
\text { (Lamiaceae) }\end{array}$ & $\begin{array}{l}\text { All heal, } \\
\text { clown's } \\
\text { woundwort } \\
\text { (E) }\end{array}$ & Pounded & - & - & $11(418)$ \\
\hline
\end{tabular}




\begin{tabular}{|c|c|c|c|c|c|c|}
\hline S.No. & $\begin{array}{l}\text { Botanical Name } \\
\text { (Family) }\end{array}$ & Local name & $\begin{array}{l}\text { Mode of } \\
\text { administration }\end{array}$ & $\begin{array}{l}\text { Route of } \\
\text { administration }\end{array}$ & Tribal Area & References \\
\hline 396 & $\begin{array}{l}\text { Stephaniajaponica } \\
\text { (Thunb.) Miers } \\
\text { (Menispermaceae) }\end{array}$ & - & Crushed & $\mathrm{O}$ & $\begin{array}{l}\text { Darjeeling, W.B.; } \\
\text { Khargone, M.P.; } \\
\text { Bhadrak, Odisha }\end{array}$ & $7(499), 30,50$ \\
\hline 397 & $\begin{array}{l}\text { Strychnos nux-vomica L. } \\
\text { (Loganiaceae) }\end{array}$ & $\begin{array}{l}\text { Etti (Trib) } \\
\text { Kuchla (H) }\end{array}$ & Poultice & $\mathrm{T}$ & - & $8(268)$ \\
\hline 398 & $\begin{array}{l}\text { Suaeda fruticosa (L.) } \\
\text { Forsk. } \\
\text { (Chenopodiaceae) }\end{array}$ & Lana, lani & - & - & - & $9(147)$ \\
\hline 399 & $\begin{array}{l}\text { Syzygium cumini (L.) } \\
\text { Skeels (Jam) } \\
\text { (Myrtaceae) }\end{array}$ & Jambu (S) & Juice & - & - & $8(329)$ \\
\hline 400 & $\begin{array}{l}\text { Tabernaemontana } \\
\text { crispa } \text { Roxb. } \\
\text { (Apocynaceae) }\end{array}$ & $\begin{array}{l}\text { Thikarothung } \\
\text { (Ncb) }\end{array}$ & Decoction & - & Wounds, ulcers & $8(375)$ \\
\hline 401 & $\begin{array}{l}\text { Tagetes erecta Linn. } \\
\text { (Asteraceae) }\end{array}$ & Genda & $\begin{array}{l}\text { Pounded and } \\
\text { tied }\end{array}$ & $\mathrm{T}$ & $\begin{array}{l}\text { Dantewada, } \\
\text { Chhattisgarh; } \\
\text { Bastar, M.P. }\end{array}$ & $\begin{array}{l}35 \\
17(119)\end{array}$ \\
\hline 402 & $\begin{array}{l}\text { Tagetes patula L. } \\
\text { (Asteraceae) }\end{array}$ & $\begin{array}{l}\text { Chandani } \\
\text { genda }\end{array}$ & Crushed, Juice & - & $\begin{array}{l}\text { Bilaspur, } \\
\text { Chhattisgarh; } \\
\text { Bhadrak, Odisha }\end{array}$ & 7(499), 8(219), 27 \\
\hline 403 & $\begin{array}{l}\text { Tamarindus indica Linn. } \\
\text { (Fabaceae) }\end{array}$ & Omolo & Decoction & $\mathrm{T}$ & $\begin{array}{l}\text { Dogonland, Mali, } \\
\text { West Africa }\end{array}$ & 34 \\
\hline 404 & $\begin{array}{l}\text { Tephrosia purpurea (L.) } \\
\text { Pers. } \\
\text { (Fabaceae) }\end{array}$ & Wild indigo & Powder & - & $\begin{array}{l}\text { Bilaspur, } \\
\text { Chhattisgarh; } \\
\text { Dharmapuri, Tamil } \\
\text { Nadu }\end{array}$ & $7(395), 16(301), 27$ \\
\hline \multirow[t]{2}{*}{405} & $\begin{array}{l}\text { Terminalia arjuna } \\
\text { (Roxb. ex DC.) Wight } \\
\text { and Arn. } \\
\text { (Combretaceae) }\end{array}$ & Kahua & - & $\mathrm{O}$ & $\begin{array}{l}\text { Dantewada, } \\
\text { Chhattisgarh }\end{array}$ & 35 \\
\hline & & Arjuna (S) & Paste & $\mathrm{T}$ & Uttarakhand & $\begin{array}{l}8(439), 9(147), 13(499), \\
15(213)\end{array}$ \\
\hline 406 & $\begin{array}{l}\text { Terminalia tomentosa } \\
\text { W. \& A. } \\
\text { (Combretaceae) }\end{array}$ & $\operatorname{Sal}(\mathrm{S})$ & Juice & - & - & $16(310)$ \\
\hline 407 & $\begin{array}{l}\text { Thevetia peruviana } \\
\text { (Pers.) Schum. } \\
\text { (Apocynaceae) }\end{array}$ & $\begin{array}{l}\text { Peeta karavira } \\
(\mathrm{S}) \\
\text { Konyaari }(\mathrm{O})\end{array}$ & $\begin{array}{l}\text { Boiled in } \\
\text { mustard oil; tied } \\
\text { over wounds }\end{array}$ & $\mathrm{T}$ & Phulbani, Odisha & $\begin{array}{l}16(306) \\
18(143)\end{array}$ \\
\hline 408 & $\begin{array}{l}\text { Thunbergia fragrans } \\
\text { Roxb. } \\
\text { (Acanthaceae) }\end{array}$ & $\begin{array}{l}\text { Kolikka (Kur) } \\
\text { Koligokke } \\
\text { (Irular) }\end{array}$ & Paste & - & - & $8(228), 8(272)$ \\
\hline 409 & $\begin{array}{l}\text { Tinospora cordifolia } \\
\text { Miers. } \\
\text { (Menispermaceae) }\end{array}$ & Seendil & Paste & $\mathrm{T}$ & $\begin{array}{l}\text { Kancheepuram, } \\
\text { Tamil Nadu }\end{array}$ & 25 \\
\hline 410 & $\begin{array}{l}\text { Trichodesma zeylanicum } \\
\text { (Burm. f.) R. Br. } \\
\text { (Boraginaceae) }\end{array}$ & $\begin{array}{l}\text { Mulluthumbai } \\
\text { chedi }\end{array}$ & Paste & $\mathrm{T}$ & $\begin{array}{l}\text { Tirunelveli hills, } \\
\text { southern India }\end{array}$ & 22 \\
\hline \multirow[t]{2}{*}{411} & $\begin{array}{l}\text { Tridax procumbens } \mathrm{L} . \\
\text { (Asteraceae) }\end{array}$ & Tongal modi & - & - & $\begin{array}{l}\text { Washim, } \\
\text { Maharashtra }\end{array}$ & 24 \\
\hline & & Kodele yiri & Paste & $\mathrm{T}$ & South-west Nigeria & 23 \\
\hline
\end{tabular}




\begin{tabular}{|c|c|c|c|c|c|c|}
\hline S.No. & $\begin{array}{l}\text { Botanical Name } \\
\text { (Family) }\end{array}$ & Local name & $\begin{array}{l}\text { Mode of } \\
\text { administration }\end{array}$ & $\begin{array}{l}\text { Route of } \\
\text { administration }\end{array}$ & Tribal Area & References \\
\hline \multirow[t]{4}{*}{411} & $\begin{array}{l}\text { Tridax procumbens L. } \\
\text { (Asteraceae) }\end{array}$ & $\begin{array}{l}\text { Vettukayapun } \\
\text { du }\end{array}$ & Paste & $\mathrm{T}$ & $\begin{array}{l}\text { Kancheepuram, } \\
\text { Tamil Nadu }\end{array}$ & 25 \\
\hline & & Pukavetti & Paste & $\mathrm{T}$ & $\begin{array}{l}\text { Attappady, Kerala; } \\
\text { Amravati and } \\
\text { Dharmapuri, } \\
\text { Maharashtra; } \\
\text { Tirunelveli and } \\
\text { Kanyakumari; } \\
\text { North East India; } \\
\text { Phulbani, Odisha; } \\
\text { Uttarakhand }\end{array}$ & $\begin{array}{l}7(273), 7(363), 7(369), 7 \\
(583), 7(395), 7(515), 8 \\
(89), 8(166), 8(175), 8 \\
(206), 8(192), 8(292), 9 \\
(387), 13(517), 915(275), \\
16(301), 21\end{array}$ \\
\hline & & - & Paste & $\mathrm{T}$ & $\begin{array}{l}\text { Erode District, } \\
\text { Tamil Nadu; } \\
\text { Khargone, M.P. }\end{array}$ & 30,51 \\
\hline & & Coat button & - & - & $\begin{array}{l}\text { Bilaspur, } \\
\text { Chhattisgarh }\end{array}$ & 27 \\
\hline 412 & $\begin{array}{l}\text { Trigonella foenum Linn. } \\
\text { (Fabaceae) }\end{array}$ & Methika (S) & Infusion & $\mathrm{T}$ & Uttarakhand & $9(259), 13(517), 15(191)$ \\
\hline 413 & $\begin{array}{l}\text { Triumfetta pilosa Roth. } \\
\text { (Tiliaceae) }\end{array}$ & Vattai gida & Paste & - & - & $8(272)$ \\
\hline 414 & $\begin{array}{l}\text { Tylophora indica (Burm. } \\
\text { f.) Merr. } \\
\text { (Asclepiadaceae) }\end{array}$ & Arkapatri (S) & $\begin{array}{l}\text { Paste with } \\
\text { turmeric }\end{array}$ & - & $\begin{array}{l}\text { Dharmapuri, Tamil } \\
\text { Nadu }\end{array}$ & $7(395), 16(303)$ \\
\hline 415 & $\begin{array}{l}\text { Urena labata L. } \\
\text { (Malvaceae) }\end{array}$ & $\begin{array}{l}\text { Katshinin } \\
\text { (Andm) } \\
\text { Kasinrih } \\
\text { (Ncb) }\end{array}$ & $\begin{array}{l}\text { Pounded, boiled } \\
\text { in coconut oil }\end{array}$ & - & - & $8(375), 16(323)$ \\
\hline 416 & $\begin{array}{l}\text { Urtica dioica L. } \\
\text { (Urticaceae) }\end{array}$ & - & $\begin{array}{l}\text { Crushed leaves } \\
\text { and warmed }\end{array}$ & $\mathrm{T}$ & - & 7 \\
\hline 417 & $\begin{array}{l}\text { Vanda teastacea } \\
\text { (Orchidaceae) }\end{array}$ & Godorli & Juice & $\mathrm{T}$ & Bastar, M.P. & $17(121)$ \\
\hline 418 & $\begin{array}{l}\text { Verbascum chinense } \\
\text { (Linn.) Santapau } \\
\text { (Scrophulariaceae) }\end{array}$ & - & Juice & - & Uttarakhand & $15(346)$ \\
\hline 419 & $\begin{array}{l}\text { Verbena officinalis L. } \\
\text { (Verbenaceae) }\end{array}$ & Pamukh & - & - & - & $13(526)$ \\
\hline 420 & $\begin{array}{l}\text { Vernonia amygdalina L. } \\
\text { (Asteraceae) }\end{array}$ & Ewuro & Decoction & $\mathrm{T}$ & South-west Nigeria & 23 \\
\hline 421 & $\begin{array}{l}\text { Vernonia cineria L. } \\
\text { (Asteraceae) }\end{array}$ & $\begin{array}{l}\text { Sahadevi (S); } \\
\text { Pokosungha } \\
\text { (O) }\end{array}$ & $\begin{array}{l}\text { Decoction of } \\
\text { leaves with } \\
\text { Ocimum } \\
\text { sanctum leaves }\end{array}$ & - & Koraput, Odisha & $7(473), 9(259), 13(527)$ \\
\hline 422 & $\begin{array}{l}\text { Vernonia conyzoides Wt. } \\
\text { (Asteraceae) }\end{array}$ & Communist & Crushed leaf & $\mathrm{T}$ & $\begin{array}{l}\text { Paniya tribes, } \\
\text { Nilgiri, Tamil } \\
\text { Nadu }\end{array}$ & 45 \\
\hline
\end{tabular}




\begin{tabular}{|c|c|c|c|c|c|c|}
\hline S.No. & $\begin{array}{l}\text { Botanical Name } \\
\text { (Family) }\end{array}$ & Local name & $\begin{array}{l}\text { Mode of } \\
\text { administration }\end{array}$ & $\begin{array}{l}\text { Route of } \\
\text { administration }\end{array}$ & Tribal Area & References \\
\hline 423 & $\begin{array}{l}\text { Vernonia divergens } \\
\text { (Roxb.) Edgew. } \\
\text { (Asteraceae) }\end{array}$ & Appale (Kur) & Paste & - & - & $8(272)$ \\
\hline 424 & $\begin{array}{l}\text { Viola sylvestris Lam. } \\
\text { (Violaceae) }\end{array}$ & - & Crushed & $\mathrm{T}$ & - & $11(284)$ \\
\hline 425 & $\begin{array}{l}\text { Vitex altissima L. } \\
\text { (Verbenaceae) }\end{array}$ & $\begin{array}{l}\text { Mayilai } \\
\text { maram }\end{array}$ & Decoction & $\mathrm{O}$ & $\begin{array}{l}\text { Tirunelveli hills, } \\
\text { southern India }\end{array}$ & 22 \\
\hline 426 & $\begin{array}{l}\text { Vitex negundo Linn. } \\
\text { (Verbenaceae) }\end{array}$ & Negur & - & - & $\begin{array}{l}\text { Bilaspur, } \\
\text { Chhattisgarh; } \\
\text { Amravati, } \\
\text { Maharashtra; } \\
\text { Bihar }\end{array}$ & $\begin{array}{l}7(645), 7(273), 8(206), 9 \\
(147), 9(219), 16(307), 27\end{array}$ \\
\hline 427 & $\begin{array}{l}\text { Vitex peduncularis Wall. } \\
\text { ex Schauer } \\
\text { (Lamiaceae) }\end{array}$ & Oreij ata daru & Paste & $\mathrm{T}$ & $\begin{array}{l}\text { Purulia district, } \\
\text { West Bengal }\end{array}$ & 38 \\
\hline 428 & $\begin{array}{l}\text { Wedelia biflora (L.) DC. } \\
\text { (Asteraceae) }\end{array}$ & Kotan (Ncb) & - & - & - & $8(375)$ \\
\hline 429 & $\begin{array}{l}\text { Withania somnifera (L.) } \\
\text { Dunal (Solanaceae) }\end{array}$ & $\begin{array}{l}\text { Ashvagandha } \\
\text { (S); Asgandh }\end{array}$ & - & - & Uttarakhand & $9(147), 15(338)$ \\
\hline 430 & $\begin{array}{l}\text { Wrightia tinctoria } \\
\text { (Roxb.)R. Br. } \\
\text { (Apocynaceae) }\end{array}$ & Pala kodisha & - & - & $\begin{array}{l}\text { Nalgonda } \\
\text { \&Warangal, A. P. }\end{array}$ & 43 \\
\hline 431 & $\begin{array}{l}\text { Xanthium strumarium L. } \\
\text { (Asteraceae) }\end{array}$ & Godhara & Crushed & - & Bhadrak, Odisha & 7(499), 11(375), 16(318) \\
\hline 432 & $\begin{array}{l}\text { Xylopia aethiopica } \\
\text { (Dunal) A. Rich. } \\
\text { (Annonaceae) }\end{array}$ & Eeru & Fresh leaves & $\mathrm{T}$ & South-west Nigeria & 23 \\
\hline 433 & $\begin{array}{l}\text { Ziziphus mauritiana } \\
\text { Lam. } \\
\text { (Rhamnaceae) }\end{array}$ & Oruwo & Fresh leaves & $\mathrm{T}$ & $\begin{array}{l}\text { Dogonland, Mali, } \\
\text { West Africa }\end{array}$ & 34 \\
\hline 434 & $\begin{array}{l}\text { Zizyphus xylopyrus } \\
\text { (Retz.) Willd. } \\
\text { (Rhamnaceae) }\end{array}$ & $\begin{array}{l}\text { Ghonta (S) } \\
\text { Karkat (Snt.) }\end{array}$ & Juice & - & $\begin{array}{l}\text { Santhal Pargana, } \\
\text { Bihar }\end{array}$ & $\begin{array}{l}16(320) \\
14(51)\end{array}$ \\
\hline
\end{tabular}

Table 2: Classification of wound healing leaf drugs reported according to route of administration

\begin{tabular}{lll}
\hline S. No. & Route of administration & Number of plants \\
\hline 1. & Topical & 202 \\
2. & Oral & 11 \\
3. & Both (Topical and Oral) & 9 \\
\hline
\end{tabular}

Table 3: Family wise classification of wound healing leaf drugs

\begin{tabular}{lll}
\hline $\begin{array}{l}\text { S. No. } \\
\text { Nome of families }\end{array}$ & $\begin{array}{c}\text { Total number of } \\
\text { enlisted families }\end{array}$ & $\begin{array}{c}\text { Plants } \\
\text { found } \\
\text { each }\end{array}$ \\
\hline $1 \quad$ & Alismataceae, Arecaceae, Basellaceae, Biebersteinaceae, Bignoniaceae, \\
in & 43 & 1 \\
& Burseraceae, Caesalpiniaceae, Cannabaceae, Capparidaceae, Caricaceae, & \\
& Caryophyllaceae, Clusiaceae, Commelinaceae, Costaceae, Cyperaceae, \\
& Dioscoreaceae, Elaeaghaceae, Elatinaceae, Ericaceae, Gentianaceae, \\
& Gesneraceae, Hernandiaceae, Loranthaceae, Lythraceae, Malpighiaceae, \\
& Moringaceae, Nymphaeaceae, Olacaceae, Papaveraceae, Passifloraceae, \\
& Pedaliaceae, Piperaceae, Pinaceae, Polypodiaceae, Polygonaceae, Portu- \\
& lacaceae, Punicaceae, Resedaceae, Saxifragaceae, Simaroubaceae, \\
& Theaceae, Violaceae and Zingiberaceae \\
\hline
\end{tabular}




\begin{tabular}{|c|c|c|c|}
\hline $\begin{array}{l}\text { S. } \\
\text { No. }\end{array}$ & Name of families & $\begin{array}{l}\text { Total number of } \\
\text { enlisted families }\end{array}$ & $\begin{array}{l}\text { Plants found } \\
\text { in each }\end{array}$ \\
\hline 2 & $\begin{array}{l}\text { Araceae, Aristolochiaceae, Begoniaceae, Ebenaceae, Capparaceae, Celas- } \\
\text { traceae, Cleomaceae, Cucurbitaceae, Cyatheaceae, Flacourtiaceae, Logani- } \\
\text { aceae, Lauraceae, Melastomataceae, Meliaceae, Mimosaceae, Myrtaceae, } \\
\text { Nyctaginaceae, Orchidaceae, Phyllanthaceae, Ranunculaceae, Rhamnaceae, } \\
\text { Sterculiaceae and Urticaceae }\end{array}$ & 23 & 2 \\
\hline 3 & $\begin{array}{l}\text { Agavaceae, Anacardiaceae, Apiaceae, Brassicaceae, Chenopodiaceae and } \\
\text { Oxalidaceae }\end{array}$ & 6 & 3 \\
\hline 4 & Annonaceae, Crassulaceae, Poaceae, Scrophulariaceae, Tiliaceae & 5 & 4 \\
\hline 5 & $\begin{array}{l}\text { Boraginaceae, Liliaceae, Menispermaceae, Oleaceae, Plantaginaceae and } \\
\text { Rosaceae }\end{array}$ & 6 & 5 \\
\hline 6 & Amaranthaceae, Apocynaceae, Convolvulaceae and Vitaceae & 4 & 6 \\
\hline 7 & Rutaceae & 1 & 8 \\
\hline 8 & Asclepiadaceae, Combretaceae and Moraceae & 3 & 9 \\
\hline 9 & Solanaceae & 1 & 11 \\
\hline 10 & Verbenaceae & 1 & 15 \\
\hline 11 & Acanthaceae and Malvaceae & 2 & 16 \\
\hline 12 & Rubiaceae & 1 & 17 \\
\hline 13 & Lamiaceae & 1 & 19 \\
\hline 14 & Euphorbiaceae & 1 & 34 \\
\hline 15 & Fabaceae & 1 & 38 \\
\hline 16 & Asteraceae & 1 & 51 \\
\hline
\end{tabular}

Table 4: Categorization of wound healing leaf drugs in Ayurvedic Classical texts

\begin{tabular}{|c|c|c|c|c|c|}
\hline $\begin{array}{l}\text { S. } \\
\text { No. }\end{array}$ & Name of Samhita & Gana name & $\begin{array}{l}\text { Classical name of drugs } \\
\text { mentioned }\end{array}$ & $\begin{array}{l}\text { Total } \\
\text { No. of } \\
\text { drugs }\end{array}$ & Karma \\
\hline 1. & Charaka Samhita & $\begin{array}{l}\text { Sandhaniya } \\
\text { mahakashaya }(52)\end{array}$ & $\begin{array}{l}\text { Madhuparni (Guduchi), Ambasthaki } \\
\text { (Patha) and Samanga (Lajjalu) }\end{array}$ & 3 & Sandhan karma \\
\hline \multirow[t]{8}{*}{2.} & \multirow[t]{8}{*}{ Sushruta Samhita } & $\begin{array}{l}\text { Aaragvadhadi gana } \\
\text { (53) }\end{array}$ & $\begin{array}{l}\text { Aaragvadha, Kantaki (Vikankata), } \\
\text { Kutaja \& Indrayava, Patha, Nimba, } \\
\text { Saireyaka and Guduchi }\end{array}$ & 7 & $\begin{array}{l}\text { Vrana shodhana } \\
(54)\end{array}$ \\
\hline & & Arkadi gana (55) & $\begin{array}{l}\text { Arka, Alarka, Mayuraka (Apamarga), } \\
\text { Bharangi, Indrapushpi (Langali), } \\
\text { Vrishikali (Uttmaarni) and Alavana } \\
\text { (Jyotishmati) }\end{array}$ & 7 & $\begin{array}{l}\text { Visheshad vrana } \\
\text { shodhana }(56)\end{array}$ \\
\hline & & Sursadi gana(57) & $\begin{array}{l}\text { Sursa (Tulasi), Bhustrana (Van Tulasi), } \\
\text { Nirgundi, Prachibala (Kakajangha), } \\
\text { Kakamachi and Vishamustika } \\
\text { (Mahanimba) }\end{array}$ & 6 & $\begin{array}{l}\text { Vrana shodhana } \\
(58)\end{array}$ \\
\hline & & Patoladi gana(59) & Guduchi and Patha & 2 & Vranya $(60)$ \\
\hline & & $\begin{array}{l}\text { Priyangvadi gana } \\
\text { (61) }\end{array}$ & Samanga (Lajjalu) & 1 & $\begin{array}{l}\text { Vrana ropana } \\
(62)\end{array}$ \\
\hline & & $\begin{array}{l}\text { Ambasthadi gana } \\
(63)\end{array}$ & $\begin{array}{l}\text { Ambastha (Patha), Samanga (Lajjalu), } \\
\text { Katvanga (Aralu) and Bilva }\end{array}$ & 4 & $\begin{array}{l}\text { Vrana ropana } \\
(62)\end{array}$ \\
\hline & & $\begin{array}{l}\text { Nygrodhadi gana } \\
\text { (64) }\end{array}$ & $\begin{array}{l}\text { Nygrodha (Vata), Kakubha (Arjuna), } \\
\text { Amra and Priyala }\end{array}$ & 4 & Vranya $(65)$ \\
\hline & & Lakshadi gana(66) & $\begin{array}{l}\text { Aarevat (Aaragvadha), Kutaja, } \\
\text { Ashwamara (Karvira) and Nimba }\end{array}$ & 4 & $\begin{array}{l}\text { Dusta vrana } \\
\text { vishodhana (67) }\end{array}$ \\
\hline \multirow[t]{3}{*}{3.} & \multirow[t]{3}{*}{$\begin{array}{l}\text { Ashtanga } \\
\text { Samhita }\end{array}$} & $\begin{array}{l}\text { Aaragvadhadi gana } \\
\text { (68) }\end{array}$ & $\begin{array}{l}\text { Aaragvadha, Indrayava, Nimba, Amrita } \\
\text { (Guduchi), Struv vriksha (Vikankata), } \\
\text { Patha, Bhunimba and Saireyaka }\end{array}$ & 8 & $\begin{array}{l}\text { Dustar vrana } \\
\text { vishodhana (69) }\end{array}$ \\
\hline & & Arkadi gana (70) & $\begin{array}{l}\text { Arka, Alarka, Pratayakpushpi } \\
\text { (Apamarga), Bharangi, Vishalaya } \\
\text { (Langali), Vrishikali (Uttmaarni) and } \\
\text { Peet taila (Jyotishmati) }\end{array}$ & 7 & $\begin{array}{l}\text { Visheshad vrana } \\
\text { shodhana }(71)\end{array}$ \\
\hline & & Sursadi gana (72) & $\begin{array}{l}\text { Sursa (Tulasi), Bhustrana (Van Tulasi), } \\
\text { Bhootkeshi (Nirgundi), Bharangi, } \\
\text { Kakamachi and Vishamustika } \\
\text { (Mahanimba) }\end{array}$ & 6 & $\begin{array}{l}\text { Vrana shodhana } \\
\text { (73) }\end{array}$ \\
\hline
\end{tabular}




\begin{tabular}{|c|c|c|c|c|c|}
\hline $\begin{array}{l}\text { S. } \\
\text { No. }\end{array}$ & $\begin{array}{l}\text { Name of } \\
\text { Samhita }\end{array}$ & Gana name & $\begin{array}{l}\text { Classical name of drugs } \\
\text { mentioned }\end{array}$ & $\begin{array}{l}\text { Total } \\
\text { No. of } \\
\text { drugs }\end{array}$ & Karma \\
\hline \multirow[t]{3}{*}{3.} & $\begin{array}{l}\text { Ashtanga Hridaya } \\
\text { Samhita }\end{array}$ & $\begin{array}{l}\text { Priyangvadi gana } \\
\text { (74) }\end{array}$ & Samanga (Lajjalu) and Bharangi & 2 & $\begin{array}{l}\text { Vrana ropana } \\
\text { (75) }\end{array}$ \\
\hline & & $\begin{array}{l}\text { Ambasthadi gana } \\
\text { (76) }\end{array}$ & 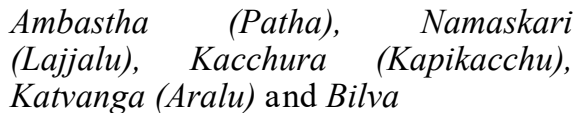 & 5 & $\begin{array}{l}\text { Vrana ropana } \\
(75)\end{array}$ \\
\hline & & $\begin{array}{l}\text { Nygrodhadi } \\
\text { (77) }\end{array}$ & $\begin{array}{l}\text { Nygrodha (Vata), Arjuna, Amra and } \\
\text { Priyala }\end{array}$ & 4 & Vranya $(78)$ \\
\hline
\end{tabular}

\section{Tribal areas}

Use of leaf drug by different tribal population in different tribal parts of the world are reported in table-1. Among these plants, many plants were reported for same activity from different tribal areas of the world indicating their ample uses. Tridax procumbens L. (Asteraceae) was reported from maximum 14 tribal areas while Cleome viscosa L. (Cleomaceae) and Chromolaena odorata (L.) R. M. King \& H. Robins. (Asteraceae) were from 8 tribal areas; Mimosa pudica Linn. (Fabaceae), Azadirachta indica A. Juss (Meliaceae) and Annona squamosa Linn. (Annonaceae) were from 7 tribal areas. Tridax procumbens L. was reported from Maharashtra, Tamil Nadu, Kerala, Odisha, Chhattisgarh, Uttarakhand, North East India and South-west Nigeria; Cleome viscosa L. from Tamil Nadu, Andhra Pradesha, Kerela, Maharashtra, Odisha, Chhattisgarh and Uttarakhand; Chromolaena odorata (L.) R. M. King \& H. Robins from Kerala, Odisha, Bihar, Andaman \& Nicobar, North East India and South -west Nigeria; Mimosa pudica Linn. from Chhattisgarh, Maharashtra, Kerela, Assam and Tamil Nadu; Azadirachta indica A. Juss from Assam, Maharashtra, Chhattisgarh, South-west Nigeria and West Africa; Annona squamosa Linn. from Chhattisgarh, Maharashtra, Odisha, Bihar and Uttarakhand.

\section{Route of administration}

Among these ethno medicinal plants, 202 plants reported for topical application, 11 for oral administration and 9 for both oral and topical (table 2). Remaining 211 plants were not mentioned for any particular route of administration in the reffered sources.

\section{Family wise classifications}

Family wise classifications of plants are noted in table 3. It was found that plants belonging to Asteraceae -51, Fabaceae-38 and Euphorbiaceae-34 drugs were maximum. Recent review study (79) indicates that Asteraceae is an important plant family for being a valuable and potential source for the natural products possessing wound healing activity. Most of plants of Asteraceae family possess wound healing activity. The plants of Fabaceae and Euphorbiaceae families are mostly of sweet taste (madhura rasa) and astringent taste (kashaya rasa). In Ayurveda, madhura rasa and kashaya rasa have been highlighted for their vranaropana and vrana-sandhana (wound healing) properties (80). Hence may be used as wound healing agents in many disease conditions.

\section{Ayurveda on Wound healing}

In Ayurvedic classics, many drugs have been described for their vranya, vrana-sodhana and vranaropana actions (Table-4). Plants having these properties are classified under Sandhaniya Mahakashaya in Charaka Samhita and Aaragvadhadi gana, Arkadi gana, Sursadi gana, Patoladi gana, Priyangvadi gana, Ambasthadi gana, Lakshadi gana in Sushruta Samhita and Aaragvadhadi gana, Arkadi gana, Sursadi gana, Priyangvadi gana, Ambasthadi gana in Ashtanga Hridaya Samhita. Patha (Cissampelos pareira L.), Guduchi (Tinospora cordifolia Miers.) and Lajjalu (Mimosa pudica Linn.) have been mentioned in Sandhaniya Mahakashaya in Charaka Samhita.

Aaragvadha (Cassia fistula Linn.), Vikankata (Flacourtia indica (Burm.f.) Merill), Kutaja (Holarrhena antidysenterica (Linn.)Wall.), Indrayava (Holarrhena antidysenterica (Linn.)Wall.), Patha (Cissampelos pareira L.), Nimba (Azadirachta indica A. Juss), Saireyaka (Barleria prionitis Linn.) and Guduchi (Tinospora cordifolia Miers.) have been mentioned in Aaragvadhadi gana; Arka (Calotropis procera (Ait.) R. Br., Alarka (Calotropis gigantia (Linn.) R. Br. ex Ait.), Apamarga (Achyranthes aspera L.), Bharangi (Clerodendrum serratum (L.) Moon.), Langali (Gloroisa superba L.), Uttmaarni (Pergularia daemia (Forssk.) Chiov.) and Jyotishmati (Celastrus paniculatus Willd.) in Arkadi gana; Tulasi (Ocimum sanctum L.), Van Tulasi (Hyptis suaveolens (L.) Poit.), Nirgundi (Vitex negundo Linn.), Kakajangha (Peristrophe bicalyculata (Retz.) Nees), Kakamachi (Solanum nigrum L.) and Mahanimba (Melia azedarach Linn.) in Sursadi gana; Guduchi (Tinospora cordifolia Miers.) and Patha (Cissampelos pareira L.) in Patoladi gana; Lajjalu (Mimosa pudica Linn.) in Priyangvadi gana; Patha (Cissampelos pareira L.), Lajjalu (Mimosa pudica Linn.), Aralu (Ailanthus excelsa Roxb.) and Bilva (Aegle marmelos L. Corr.) in Ambasthadi gana; Vata (Ficus benghalensis L.), Arjuna (Terminalia arjuna (Roxb. ex DC.) Wight and Arn.), Amra (Mangifera indica L.) and Priyala (Buchanania lanzan Spr.) in Nygrodhadi gana; Aargavadha (Cassia fistula Linn.), Kutaja (Holarrhena antidysenterica (Linn.) Wall.), Karvira (Nerium indicum Mill.) and Nimba (Azadirachta indica A. Juss) in Lakshadi gana in Sushruta Samhita.

Aaragvadha (Cassia fistula Linn.), Vikankata (Flacourtia indica (Burm.f.) Merill), Indrayava (Holarrhena antidysenterica (Linn.) Wall.), Patha (Cissampelos pareira L.), Nimba (Azadirachta indica A. Juss), Bhunimba (Andrographis paniculata (Burm. f.) 
Wall. ex Nees), Saireyaka (Barleria prionitis Linn.) and Guduchi (Tinospora cordifolia Miers.) have been mentioned in Aaragvadhadi gana; Arka (Calotropis procera (Ait.) R. Br., Alarka (Calotropis gigantia (Linn.) R. Br. ex Ait.), Apamarga (Achyranthes aspera L.), Bharangi (Clerodendrum serratum (L.) Moon.), Langali (Gloroisa superba L.), Uttmaarni (Pergularia daemia (Forssk.) Chiov.) and Jyotishmati (Celastrus paniculatus Willd.) in Arkadi gana; Tulasi (Ocimum sanctum L.), Van Tulasi (Hyptis suaveolens (L.) Poit.), Nirgundi (Vitex negundo Linn.), Bharangi (Clerodendrum serratum (L.) Moon.), Kakamachi (Solanum nigrum L.) and Mahanimba (Melia azedarach Linn.) in Sursadi gana; Lajjalu (Mimosa pudica Linn.) and Bharangi (Clerodendrum serratum (L.) Moon.) in Priyangvadi gana; Patha (Cissampelos pareira L.), Lajjalu (Mimosa pudica Linn.), Kapikacchu (Mucuna pruriens (L.) DC., Aralu (Ailanthus excelsa Roxb.) and Bilva (Aegle marmelos L. Corr.) in Ambasthadi gana; Vata (Ficus benghalensis L.), Arjuna (Terminalia arjuna (Roxb. ex DC.) Wight and Arn.), Amra (Mangifera indica L.) and Priyala (Buchanania lanzan Spr.) in Nygrodhadi gana, in Ashtanga Hridaya Samhita.

\section{Recent studies}

Many Indian medicinal plants are recommended for the treatment of wound. The wound healing activity of different medicinal plants has been evaluated. Apamarga (Achyranthes aspera L.), a Krimighna (antibacterial) plant mentioned in Ayurveda effectively shows wound healing activity on excision and incision wound of albino rats (81).

Vasa (Adhatoda vasica Nees.) shows significant wound healing activity. Wounds were created along the vertebral columns of buffalo calves, and alcoholic and chloroform extracts of Adhatoda in a powdered form were applied. As compared to control, the calves treated with Adhatoda vasica showed significantly improved healing. Improvement in breaking strength, tensile strength, absorption and extensibility in the wound repair tissue. In addition, the levels of elastin, collagen, hydroxyproline, hexosamine and zinc were greatly increased in the animals treated with $A$. vasica. The alcoholic extract of the herb was found to be the most effective (82).

In-vivo antioxidant activity of the methanolic leaf extracts of Bilva (Aegle marmelos L. Corr.) possesses good antioxidant power to heal the wounds in mice models equivalent to that of the Povidine Iodide used as a standard compound (83).

The topical application of Ghrita kumari (Aloe vera Burm. f.) gel significantly accelerated the wound contraction and marked wound closure. The effect produced by Aloe vera gel with reference to wound contraction, wound closure, decrease in surface area of wound, tissue regeneration at the wound site and histopathological characteristics were significant in treated rats (84). It also had a marked influence on the collagen level which is the precursor protein for wound healing mechanism.

Recent study (85) shows that the animals treated with methanol and aqueous extracts of Satyanashi
(Argemone maxicana L.) possess faster rate of wound healing compared to other extracts under study. The wound healing effects of the chloroform, methanol and aqueous extracts may be attributed to the presence of phytoconstituents like alkaloids, triterpenoids, tannins and flavonoids in the extracts which are known to promote the wound healing process mainly due to their astringent, antioxidant and antimicrobial properties.

Recent study (86) study indicates, that not only topical application of water extract of Pashanabheda (Bryophyllum pinnatum Lam.) hastened the healing process in excision wound model, but also all the three extracts (petroleum ether, alcohol and water) administered orally, promoted the healing of resutured incision and dead space wounds, as indicated by increased breaking strength and hydroxyproline content of the granulation tissue, thereby justifying its use in traditional medicine.

Shikari (Cordia macleodii hook.) is also a potent leaf drug for wound healing. Go-ghrita (cow's ghee) based formulation of $C$. macleodii leaf, was evaluated through exploratory, open and controlled clinical study on 20 patients, in two groups. One group was managed with Cordia macleodii ghrita and control group was treated with Povidone Iodine as local application, for duration of 21 days. The effect of drug based on sign and symptoms was assessed at 7th, 14th and 21st days. Significant changes was observed in discharge, tenderness, wound margin and wound size in $C$. macleodii ghrita treated group while in Povidone Iodine treated group showed highly significant result (87).

Effect of topical administration of methanolic extract in ointment form of Dodonea viscosa Linn was studied on the wounds in rats. In the excision model the extract treated wounds were found to epithelialise faster and the rate of wound contraction was higher, as compared to control wounds. The extract facilitates the healing process as evidenced by increase in the tensile strength in the incision model. The results were also comparable to those of standard drug Povidine Iodide (88).

Ethanolic extract of leaves of Hyptis suaveolens L. was evaluated for its wound healing activity in etheranaesthetized wistar rats at two different doses (400 and $800 \mathrm{mg} / \mathrm{kg}$ ) using incision, excision, and dead space wound model. Significant increase in skin breaking strength, granuloma breaking strength, wound contraction, hydroxyproline content and dry granuloma weight and decrease in epithelization period was observed (89).

Tulsi (Ocimum sanctum L.), a well known herb in Indian medicine, possesses various therapeutic properties including healing properties and cytokine induction. Wound healing activity of cold aqueous extract of $O$. sanctum leaves along with its effect on tumor necrosis factor-alpha (TNF-alpha) was assessed using excision model of wound repair in Wistar albino rats. After application of the $O$. sanctum extract, rate of epithelization with an increase in wound contraction was observed. In animals, treated with $10 \%$ O. sanctum extract in petroleum jelly, wound healing was faster as compared to control group which were treated with petroleum jelly alone but significant accelerated healing 
was noticed in animals which in addition to the topical application of $10 \%$ extract of $O$. sanctum, were prefed with $250 \mathrm{mg} / \mathrm{kg}$ body weight of aqueous $O$. sanctum extract daily for 20 consecutive days. During wound healing phase TNF-alpha level was found to be up regulated by $O$. sanctum treatment. Early wound healing may be pronounced due to $O$. sanctum extract, by elevating TNF-alpha production (90).

In excision wound model, $5 \%$ ointment of hydroalcoholic leaf extract of Shaka (Tectona grandis Linn.) showed a reduction in wound area $8^{\text {th }}$ day onwards. Reduction in wound area was very significant $(P<0.01)$ as compared to control. Whereas $10 \%$ ointment of hydro-alcoholic leaf extract of $T$. grandis and standard showed a reduction in wound area fourth day onwards, which was highly significant $(P<0.001)$ as compared to control. In incision wound model, animals treated with $5 \%$ ointment of Tectona grandis leaf extract showed significant $(P<0.05)$ increase in tensile strength as compare to control. However, animals treated with $10 \%$ ointment of Tectona grandis leaf extract showed very significant $(P<0.001)$ increase in tensile strength as compared with control. Animals treated with soframycin showed highly significant $(P<0.001)$ increase in tensile strength as compared with control (91).

Sarapunkha (Tephrosia purpurea (L.) Pers.) exhibited significant wound healing activity in diabetic rats. The hydro alcoholic extract of Tephrosia purpurea (L.) Pers. was evaluated for its wound healing activity in streptozotocin induced diabetic rats using excision and dead space wound models. Topical application, twice a day, of $5 \% \mathrm{w} / \mathrm{w}$ extract ointment shows more significant $(\mathrm{P}<0.001)$ wound contraction in normal and diabetic treatments when compare to control. The oral administration of $200 \mathrm{mg} / \mathrm{kg}$ bw/day also significantly increases the wet and dry granulation tissue weight when compare to the control (92).

Nirgundi (Vitex negundo Linn.) showed a definite, positive effect on wound healing, with a significant increase in the levels of hydroxyproline content, tensile strength and protein content of wounded skin in both incision and dead space wound model (93). The antioxidant enzymes level of superoxide dismutase and catalase increased in the granuloma tissue which support its wound healing property. The efficacy of this plant in wound healing may be due to its action on antioxidant enzymes, thereby justifying the traditional claim. So above description it can be said that many herbs which are mentioned in Ayurveda, claimed potent wound healing activity.

\section{Conclusion}

Present review reports, use of 434 leaf drugs for their wound healing activity. Leaf drugs of Asteraceae family have great potency for healing the wounds. Many of leaf drugs have been evaluated scientifically for their wound healing activity. Finding of the present review may give leads for new drug development for the management of wound. Now there is high demand of herbal drugs for the management of different disease conditions. If leaf drugs researched upon successfully, then rare plant population could be saved and society will get double benefit.

\section{References}

1. Baddui, Prakesh, Nagori et al. Role of medicinal plants in wound healing. Research Journal of medicinal plants. 2011; 5(4); 392-40.

2. Ramzi SC, Vinay K, Stanley R. Pathologic Basis of Diseases. 5th ed. Philadelphia; WB Saunders Company; 1994. 86p.

3. Menke NB, Ward KR, Witten TM, Bonchev DG, Diegelmann RF. Impaired wound healing. Clin Dermatol. 2007; 25; 19-25.

4. Alerico GC, Beckenkamp A, Vignoli-Silva M, Buffon A, Von Poser GL. Proliferati-ve effect of plants used for wound healing in Rio Grandedo Sul state, Brazil. J Ethnopharmacol. 2015; 176; 305310 .

5. Flanagan M. The physiology of wound hea-ling. J Wound Care. 2000; 9(6); 299-300.

6. Kadhirvel K. et al. Ethnomedicinal Survey on Plants used by Tribals in Chitteri Hills Environ. We Int. J. Sci. Tech. 2010; 5; 35-45.

7. Maheshwari J. K. Ethnobotany and Medicinal Plants of Indian Subcontinent. Jodhpur; Scientific Publishers; 2003. 391, 363, 499, 645, 331, 545, 583, 247, 341, 283, 369, 499, 363, 473, 395, 273, $599,283,569,515,331,185,609,381,223,265$, $651,265,591,604,467,253,451,265,369,583$, $395,473,645,273 p$.

8. Maheshwari J. K. Ethnobotany in South Asia. Jodhpur; Scientific Publishers; 1996. 292, 381, 37, $192,112,439,175,192,260,439,82,62,201,50$, $322,169,175,272,92,138,228,375,284,439$, $350,253,350,253,338,375,228,423,260,332$, $118,253,268,244,439,260,272,24,166,253,70$, 75, 56, 408, 228, 329, 219, 89, 206, 292p.

9. Trivedi P. C. Medicinal Plants: Ethnobotanical Approach. Jodhpur; AGROBIOS; 2006. 259, 147, 251, 387, 219, 52, 251p.

10. Guha Bakshi D. N., Sensharma P., Pal D. C. A Lexicon of Medicinal Plants in India. Vol.1. Calcutta; Naya Prokash; 1999. 23, 24, 26, 53, 66, $69,70,75,81,85,100,130,160,178,180,189$, $192,195,212,233,238,241,256,267,273,275$, $276,283,284,286,287,293,302,337,341,346$, 353, 356, 388, 394, 401, 413, 422, 428, 441, 478, 495p.

11. Caius J. F. The Medicinal and Poisonous Plants of India. $5^{\text {th }}$ reprint. Jodhpur; Scientific Publishers; 2003. 447, 186, 162, 161, 237, 317, 190, 444, 323, $190,324,388,126,475,171,339,344,202,206$, 208, 209, 210, 47, 481, 275, 458, 212, 399, 217, $462,464,20,277,223,414,489,225,416,469$, 364, 418, 284, 375p.

12. Pullaiah T. Medicinal Plants in India. Vol. I. New Delhi; Regency Publication; 2002. 18, 29, 33, 35, $51,65,67,75,80,96,108,113,115,132,135,146$, $154,166,178,184,200,216,223,233,241,253$, 256, 263, 270p.

13. Pullaiah T. Medicinal Plants in India. Vol. II. New Delhi; Regency Publication; 2002. 187, 279, 281, 282, 283, 289, 301, 303, 314, 315, 312, 322, 326, $340,345,346,350,358,361,361,363,366,380$, 
$386,387,391,398,402,406,427,434,450,460$, $467,473,490,517,526,527 \mathrm{p}$.

14. Varma S. K., Shriwastava D. K., Pandey A. K. Ethnobotany of Santhal Pargana. Delhi; Narendra Publishing House; 1999. 19, 20, 21, 22, 24, 25, 27, 29, 34, 37, 40, 41, 44, 45p.

15. Anil K. Dhiman. Medicinal Plants of Uttaranchal State. 1st ed. Varanasi; Chowkhamba Sanskrit Series Office; 2004. 103, 400, 386, 356, 438, 448, $449,258,132,160,387,279,71,260,400,464$, $354,128,207,309,418,86,176,67,88,89,380$, $324,331,282,265,94,362,253,321,332,290$, $363,218,371,412,103,106,188,332,334,374$, $357,413,50,384,376,365,414,203,443,379$, $108,130,337,270,279,213,191,346,338 p$.

16. Anonymus. An Appraisal of Tribal-Folk Medicines. 1st ed. New Delhi; CCRAS, Govt. of India; 1999. 301, 303, 304, 306, 307, 308, 309, 310, $311,312,314,316,315,317,318,319,320,321$, $323,324 \mathrm{p}$.

17. Anonymus. Glimpses of Medico-botany of Bastar district (M.P.). New Delhi; CCRAS, Govt. of India; 1990. 102, 108, 112, 114, 115, 119, 121p.

18. Anonymus. Medico-botanical exploration of Phulbani and Koraput district of Orissa. New Delhi; CCRAS, Govt. of India; 1996. 112, 119, 125, 129, $138,143 \mathrm{p}$.

19. Badhe P. K., Pande V. K. Medicinal plants of Nagpur and Wardha forest division, Maharashtra. New Delhi; CCRAS, Govt. of India; 1999. 4, 18, $20,28,32,33,38,54,56,57,61,63,66,67,68$, $147 \mathrm{p}$.

20. Jain S. K., Sinha B. K., Gupta R. C. Notable plants in Ethnomedicine of India. New Delhi; Deep publications; 1991. 40, 71, 104, 111, 124, 175, 178 p.

21. Abdul Latheef K, Smitha P Kumar, Remashree A B. Ethnomedicine used for treating cuts and wounds by the tribes of Attappady, Kerala. International Journal of Herbal Medicine 2014; 2 (2); 1-8.

22. Ayyanar M, Ignacimuthu S. Herbal medicines for wound healing among tribal people in Southern India: Ethnobotanical and Scientific evidences. International Journal of Applied Research in Natural Products. 2009; 2(3); 29-42.

23. Adewale Adetutu, Winston A. Morgan, Olivia Corcoran. Ethnopharmacological survey and in vitro evaluation of wound-healing plants used in South-western Nigeria. Journal of Ethnopharmacology. 2011; 137; 50-56.

24. Wadankar G. D., S. N. Malode, Sarambekar S. L. Traditionally Used Medicinal Plants for Wound Healing in the Washim District, Maharashtra (India). Int. J. Pharm Tech Res. 2011; 3(4); 20802084.

25. Chellaiah Muthu, Muniappan Ayyanar, Nagappan Raja and Savarimuthu Ignacimuthu. Medicinal plants used by traditional healers in Kancheepuram District of Tamil Nadu, India. Journal of Ethnobiology and Ethnomedicine. 2006; 2; 43.
26. Savithramma N., Yugandhar P., Linga Rao M. Ethnobotanical Studies on Japali Hanuman Theertham- A Sacred Grove of Tirumala hills, Andhra Pradesh, India. J. Pharm. Sci. \& Res. 2014; 6(2); 83-88.

27. Patel DK. Some Traditional Medicinal Plants Useful For Boil, Burn and for Wounds Healing. J Bio divers Endanger Species. 2014; 2(4); 133.

28. Sujata Bhardwaj and S. K. Gakhar. Ethnomedicinal plants used by the tribals of Mizoram to cure cuts \& wounds. Indian Journal of Traditional Knowledge. 2005; 4(1); 75-80.

29. Bikram K. Mallik, Tribhuban Panda, Rabindra N. Padhy. Traditional Herbal Practices by the Ethnic People of Kalahandi District of Odisha, India. Asian Pacific Journal of Tropical Biomedicine. 2012; 988-994.

30. Prabhat K. Das, Narendra S. Badore, Pankaj Patel, Nitin Deshmukh. Ethnomedicinal wound healing plant in Khargone district of Madhya Pradesh: a survey over Nimari communities. Pharmaceutical and Biological Evaluations. 2016; 3(4); 388-399.

31. Das Amar Jyoti et al. Ethno medicinal survey of medicinal plants used to cure wounds in Darikal Gaon of Tezpur in Assam, North East India. IRJP. 2012; 3(2); 193-95.

32. Ezekiel Amri and Daniel $P$ Kisangau. Ethnomedicinal study of plants used in villages around Kimboza forest reserve in Morogoro, Tanzania. Journal of Ethnobiology and Ethnomedicine. 2012; 8; 1 .

33. Binu Thomas, Rajendran Arumugam, Aravindhan Veerasamy, Sivalingam Ramamoorthy. Ethnomedicinal plants used for the treatment of cuts and wounds by Kuruma tribes, Wayanadu districts of Kerala, India. Asian Pacific Journal of Tropical Biomedicine. 2014; 4(1); 1-13.

34. Kari Inngjerdingen, Cecilie Sogn Nergård, Drissa Diallo, Pakuy Pierre Mounkoro, Berit Smestad Paulsen. An ethnopharmacological survey of plants used for wound healing in Dogonland, Mali, West Africa. Journal of Ethnopharmacology 2004; 92; 233-244.

35. Sahu P.K. et al. Ethnomedicinal Plants Used in the Healthcare Systems of Tribes of Dantewada, Chhattisgarh India. American Journal of Plant Sciences. 2014; 5; 1632-1643.

36. Sainkhediya Jeetendra, Pachaya Jeetendra. Studies of Ethnomedicinal Plants used by Tribals in Some Selected Villages of Nimar Region (M.P.). International Journal of Science and Research. 2015; 4(2); 1206-1210.

37. Sarita Das, Dash S. K. and Padhy S. N. Ethnomedicinal Informations from Orissa State, India, A Review. J. Hum. Ecol. 2003; 14(3); 165-227.

38. Abhijit Dey, Bhaskar Gupta and Jitendra Nath De. Traditional phytotherapy against skin diseases and in wound healing of the tribes of Purulia district, West Bengal, India. Journal of Medicinal Plants Research. 2012; 6(33); 4825-4831.

39. Chopda MZ, Mahajan RT. Wound Healing Plants of Jalgaon District of Maharashtra State, India. Ethnobot Leaflets. 2009; 13; 1- 32. 
40. Patil SB, Naikwade NS, Kondawar MS, Magdum CS, Awale VB. Traditional uses of plants for wound healing in the Sangli district, Maharashtra. Int J of Pharm Tech Res. 2009; 1(3); 876-878.

41. Senthil KM, Sripriya R, Vijaya RH, Sehgal PK. Wound healing potential of Cassia fistula on infected albino rat model. J Surgical Res. 2006; $131 ; 283-9$.

42. Silja VP, Samitha Varma K, Mohanan KV. Ethnomedicinal plant knowledge of the Mulla Kuruma tribe of Wayanad district, Kerela. Indian Journal of Traditional Knowledge. 2008; 7(4); 604612.

43. Nallella Sreeramulu, Sateesh Suthari, Ragan A, Vatsavaya S Raju. Ethno-botanico-medicine for common human ailments in Nalgonda and Warangal districts of Telangana, Andhra Pradesh, India. Annals of Plant Sciences. 2013; 02(07); 220229.

44. Alok Ranjan Sahu, Shashi Kanta Panigrahi, Anil kumar nayak. Survey of some important ethnomedicinal plants of Sohela block, Western Odisha, India. Life Sciences Leaflets. 2011; 11; 1-9.

45. Arul Manikandan P. N. Folk herbal medicine: a survey on the paniya Tribes of mundakunnu village of the nilgiri hills, South India. Ancient Science of Life. 2005; 25(1); 21-27.

46. Soma Manjula, Estari Mamidala. An ethnobotanical survey of medicinal plants used by traditional healers of Thadvai, Warangal district, Andhra Pradesh, India. Int J Med Res Health Sci. 2013; 2(1); 40-46.

47. Subramoniam A, Evans DA, Rajasekharan S, Nair GS. Effect of Hemigraphis colorata (Blume) H.G. Hallier leaf on wound healing and inflammation in mice. Ind J Pharmacol. 2001; 33; 283-85.

48. Santhapu H. Humari (Securinega leucopyrus). Plants of Saurashtra a Preliminary List. Rajkot; S.J.F.N.I. Saurashtra Research Society; 1953.

49. Naresh Kumar Ghodela, Dudhamal T. S. Clinical efficacy of Thumari gel (Securinega leucopyrus [Willd.] Muell) in the management of superficial non-healing leg ulcers- A rare case report. International Journal of AYUSH Case Reports 2017; 1(1); 1-5.

50. Srivastava SC, Mitra S, Bandopadhyay S. Some plants of ethnomedicinal importance from Darjeeling District, West Bengal. $\mathrm{J}$ of Econ and Taxon Bot. 2003; 27; 972-77.

51. Revathi P, Parimelazhagan T. Traditional Knowledge on Medicinal Plants Used by the Irula Tribe of Hasanur Hills, Erode District, Tamil Nadu, India. Ethnobot Leaflets. 2010; 14; 136-60.

52. Brahmanand Tripathi. Charaka Samhita, Sutra Sthana 4/9-5, Shadvirechanashatashritiye Adhyaya. Varanasi; Chaukhamba Surbharti Prakashan; reprint 2008. 78p.

53. Ambikadutta Shastri. Sushruta Samhita, Sutra Sthana 38/6, Dravyasangrahaniya Adhyaya. Varanasi; Chaukhamba Sanskrit Sansthan; reprint 2010. 183p.
54. Ambikadutta Shastri. Sushruta Samhita, Sutra Sthana 38/7, Dravyasangrahaniya Adhyaya. Varanasi; Chaukhamba Sanskrit Sansthan; reprint 2010. 183p.

55. Ambikadutta Shastri. Sushruta Samhita, Sutra Sthana 38/16, Dravyasangrahaniya Adhyaya. Varanasi; Chaukhamba Sanskrit Sansthan; reprint 2010. 184p.

56. Ambikadutta Shastri. Sushruta Samhita, Sutra Sthana 38/17, Dravyasangrahaniya Adhyaya. Varanasi; Chaukhamba Sanskrit Sansthan; reprint 2010. 184 p.

57. Ambikadutta Shastri. Sushruta Samhita, Sutra Sthana 38/18, Dravyasangrahaniya Adhyaya. Varanasi; Chaukhamba Sanskrit Sansthan; reprint 2010. 184 p.

58. Ambikadutta Shastri. Sushruta Samhita, Sutra Sthana 38/19, Dravyasangrahaniya Adhyaya. Varanasi; Chaukhamba Sanskrit Sansthan; reprint 2010. 184p.

59. Ambikadutta Shastri. Sushruta Samhita, Sutra Sthana 38/33, Dravyasangrahaniya Adhyaya. Varanasi; Chaukhamba Sanskrit Sansthan; reprint 2010. 185 p.

60. Ambikadutta Shastri. Sushruta Samhita, Sutra Sthana 38/34, Dravyasangrahaniya Adhyaya. Varanasi; Chaukhamba Sanskrit Sansthan; reprint 2010. 185p.

61. Ambikadutta Shastri. Sushruta Samhita, Sutra Sthana 38/45, Dravyasangrahaniya Adhyaya. Varanasi; Chaukhamba Sanskrit Sansthan; reprint 2010. 186p.

62. Ambikadutta Shastri. Sushruta Samhita, Sutra Sthana 38/47, Dravyasangrahaniya Adhyaya. Varanasi; Chaukhamba Sanskrit Sansthan; reprint 2010. 187p.

63. Ambikadutta Shastri. Sushruta Samhita, Sutra Sthana 38/46, Dravyasangrahaniya Adhyaya. Varanasi; Chaukhamba Sanskrit Sansthan; reprint 2010. 187p.

64. Ambikadutta Shastri. Sushruta Samhita, Sutra Sthana 38/48, Dravyasangrahaniya Adhyaya. Varanasi; Chaukhamba Sanskrit Sansthan; reprint 2010. 187p.

65. Ambikadutta Shastri. Sushruta Samhita, Sutra Sthana 38/49, Dravyasangrahaniya Adhyaya. Varanasi; Chaukhamba Sanskrit Sansthan; reprint 2010. 187p.

66. Ambikadutta Shastri. Sushruta Samhita, Sutra Sthana 38/64, Dravyasangrahaniya Adhyaya. Varanasi; Chaukhamba Sanskrit Sansthan; reprint 2010. 188p.

67. Ambikadutta Shastri. Sushruta Samhita, Sutra Sthana 38/65, Dravyasangrahaniya Adhyaya. Varanasi; Chaukhamba Sanskrit Sansthan; reprint 2010. 188p.

68. Atrideva Gupta. Ashtanga Hridaya, Sutra Sthana 15/17, Sodhanadiganasangraham Adhyaya. Varanasi; Chaukhambha Prakashan; reprint 2007. $105 \mathrm{p}$.

69. Atrideva Gupta. Ashtanga Hridaya, Sutra Sthana 15/18, Sodhanadiganasangraham Adhyaya. 
Varanasi; Chaukhambha Prakashan; reprint 2007. $105 p$.

70. Atrideva Gupta. Ashtanga Hridaya, Sutra Sthana 15/28, Sodhanadiganasangraham Adhyaya. Varanasi; Chaukhambha Prakashan; reprint 2007. 106p.

71. Atrideva Gupta. Ashtanga Hridaya, Sutra Sthana 15/29, Sodhanadiganasangraham Adhyaya. Varanasi; Chaukhambha Prakashan; reprint 2007. $106 \mathrm{p}$.

72. Atrideva Gupta. Ashtanga Hridaya, Sutra Sthana 15/30, Sodhanadiganasangraham Adhyaya. Varanasi; Chaukhambha Prakashan; reprint 2007. $106 \mathrm{p}$.

73. Atrideva Gupta. Ashtanga Hridaya, Sutra Sthana 15/31, Sodhanadiganasangraham Adhyaya. Varanasi; Chaukhambha Prakashan; reprint 2007. $106 \mathrm{p}$.

74. Atrideva Gupta. Ashtanga Hridaya, Sutra Sthana 15/37, Sodhanadiganasangraham Adhyaya. Varanasi; Chaukhambha Prakashan; reprint 2007. $107 p$.

75. Atrideva Gupta. Ashtanga Hridaya, Sutra Sthana 15/39, Sodhanadiganasangraham Adhyaya. Varanasi; Chaukhambha Prakashan; reprint 2007. $107 \mathrm{p}$.

76. Atrideva Gupta. Ashtanga Hridaya, Sutra Sthana 15/38, Sodhanadiganasangraham Adhyaya. Varanasi; Chaukhambha Prakashan; reprint 2007. $107 \mathrm{p}$.

77. Atrideva Gupta. Ashtanga Hridaya, Sutra Sthana 15/41, Sodhanadiganasangraham Adhyaya. Varanasi; Chaukhambha Prakashan; reprint 2007. $107 p$.

78. Atrideva Gupta. Ashtanga Hridaya, Sutra Sthana 15/42, Sodhanadiganasangraham Adhyaya. Varanasi; Chaukhambha Prakashan; reprint 2007. $107 p$.

79. SUNTAR Ipek. The Medicinal Value of Asteraceae Family Plants in Terms of Wound Healing Activity. FABAD J. Pharm. Sci. 2014; 39; 21-31.

80. Rajeswaradatta Shastri, Yadunandana Upadhaya, Ganga Sahaya Pandeya, Banarasidasa Gupta. Charaka Samhita, Sutra Sthana 26/42, Aateryabhadrakapiya Adhyaya. Varanasi; Chaukhamba Sanskrit Pratishthan; 2001. 506p.

81. Fikru A et al. Evaluation of in vivo wound healing activity of methanol extract of Achyranthes aspera L. J Ethnopharmacol. 2012; 143(2); 469-74.
82. Bhargava MK, Singh H, Kumar A. Evaluation of Adhatoda vasica as a wound healing agent in buffaloes. Clinical, mechanical and biochemical studies. Indian Veterinary Journal. 1988; 65(1); 33.

83. Kantha D. Arunachalam et al. Wound healing and Antigenotoxic activities of Aegle marmelos with relation to its antioxidant properties. Journal of Pharmacy Research 2012;5(3):1492-1502.

84. Haritha Yadav K. C. et al. Wound healing activity of topical application of Aloe vera gel in experimental animal models. International Journal of Pharma and Bio Sciences 2012; 3(2); 63-72.

85. Dash GK, Murthy PN. Evaluation of Argemone mexicana Linn. Leaves for wound healing activity. J Nat Prod Plant Resour. 2011; 1(1); 46-56.

86. Khan M, Patil PA, Shobha JC. Influence of Bryophyllum pinnatum (Lam.) leaf extract on wound healing in albino rats. J Natural Remedies. 2004; 4; 41-6.

87. Sharma A, Acharya RN, Gupta SK, Dudhamal TS, Mohanto VD. Clinical Evaluation of Shikari (Cordia macleodii) Ghrita on Vrana Ropana (Wound Healing) Property. Ayurpharm Int J Ayur Alli Sci. 2013; 2(4); $98-104$.

88. Ramya et al. Wound healing activity of Dodonea viscosa Linn. ointment in rats. International Journal of Research in Pharmacy and Chemistry. 2011; 1(3); 481-83.

89. Shirwaikar A, Shenoy R, Udupa AL, Udupa SL and Shetty S. Wound healing property of ethanolic extract of leaves of Hyptis suaveolens with supportive role of antioxidant enzymes. Indian $\mathrm{J}$ Exp Biol. 2003; 41(3); 238-41.

90. Goel A, Kumar S, Singh DK and Bhatia AK. Wound healing potential of Ocimum sanctum Linn. with induction of tumor necrosis factor-alpha. Indian J Exp Biol. 2010; 48(4); 402-6.

91. Sushilkumar B. Varma and Sapna P. Giri. Study of wound healing activity of Tectona grandis Linn. leaf extract on rats. Anc Sci Life. 2013; 32(4): 241244.

92. Sudhakar P., Sathish kumar A., Satheesh Kannan C. and Maheshwaran P. Wound Healing Potential oF Tephrosia purpurea (L.) Pers. in Streptozotocin Induced Diabetic Rats. IJAPR. 2013; 4(3); 15571562.

93. Roosewelt C., Vincent S., Sujith K., Ronald Darwin C. Wound healing activity of methanolic extract of Vitex negundo leaves in albino Wistar rats. Journal of Pharmacy Research. 2011; 4(8); 2553-2555. 